\title{
El aptaycachana de Juan de Castromonte - un manual sacramental quechua para la sierra central del Perú (ca. 1650)
}

Le aptaycachana de Juan de Castromonte - un manuel de sacrements quechua pour la sierra centrale du Pérou (ca. 1650)

Juan de Castromonte's aptaycachana - a Quechua sacramental manual for the central Peruvian highlands (ca. 1650)

\section{Alan Durston}

\section{CpenEdition}

\section{Journals}

Edición electrónica

URL: http://journals.openedition.org/bifea/6719

DOI: 10.4000/bifea.6719

ISSN: 2076-5827

Editor

Institut Français d'Études Andines

Edición impresa

Fecha de publicación: 1 agosto 2002

Paginación: 219-292

ISSN: 0303-7495

Referencia electrónica

Alan Durston, «El aptaycachana de Juan de Castromonte - un manual sacramental quechua para la sierra central del Perú (ca. 1650) », Bulletin de l'Institut français d'études andines [En línea], 31 (2) | 2002, Publicado el 08 agosto 2002, consultado el 08 diciembre 2020. URL : http://journals.openedition.org/ bifea/6719; DOl : https://doi.org/10.4000/bifea.6719

\section{(9) $(\mathcal{\Theta \Theta}$}

Les contenus du Bulletin de l'Institut français d'études andines sont mis à disposition selon les termes de la licence Creative Commons Attribution - Pas d'Utilisation Commerciale - Pas de Modification 4.0 International. 


\title{
EL APTAYCACHANA DE JUAN DE CASTROMONTE - UN MANUAL SACRAMENTAL QUECHUA PARA LA SIERRA CENTRAL DEL PERÚ (CA. 1650)
}

\author{
Alan DURSTON*
}

\begin{abstract}
Resumen
Este artículo presenta una edición crítica del Aptaycachana de Juan de Castromonte, un manual sacramental quechua escrito a mediados del siglo XVII para ser usado en las parroquias indígenas de la sierra central del Perú (actuales departamentos de Junín, Pasco, Huánuco, Ancash y Lima). A pesar de que la Iglesia peruana había impuesto una lingua franca pastoral de base cuzqueña desde el III Concilio Limense de 1583, hay abundantes elementos léxicos, morfológicos y fonológicos del quechua central en el Aptaycachana, más que en cualquier otro texto colonial. El manual de Castromonte es así una fuente importante para la lingüística histórica del quechua y para el estudio de las prácticas de traducción de la iglesia en los Andes coloniales. Esta edición, que consiste en una transcripción paleográfica y traducción castellana anotadas, es precedida por un estudio preliminar que explica los contextos históricos inmediatos del Aptaycachana y discute algunos de sus rasgos más destacables.
\end{abstract}

Palabras claves: Quechua, traducción misionera, manuales sacramentales.

\section{LE APTAYCACHANA DE JUAN DE CASTROMONTE - UN MANUEL DE SACREMENTS QUECHUA POUR LA SIERRA CENTRALE DU PÉROU (CA. 1650)}

Résumé

Cet article présente une édition critique du Aptaycachana de Juan de Castromonte, un manuel de sacrements quechua écrit au milieu du XVII ${ }^{\mathrm{eme}}$ siècle pour être utilisé dans les paroisses indiennes de la Sierra centrale du Pérou (actuels départements de Junín, Pasco, Huánuco, Ancash et Lima). Bien que l'Église péruvienne ait imposé une langue franche sur une base cuzquénienne dès le III ${ }^{\text {me }}$ Concile de Lima de 1583, il existe de nombreux éléments lexicaux, morphologiques et phonétiques du quechua central dans le Aptaycachana plus que dans n'importe quel texte colonial. Le manuel de Castromonte représente donc une source importante pour la linguistique historique du quechua et pour l'étude des pratiques de traduction de l'Église dans les Andes coloniales. Cette édition, qui consiste en une transcription paléographique et une traduction espagnole anotées, est précédée d'une étude préliminaire qui explique le contexte historique immédiat du Aptaycachana et propose une discussion des traits les plus marquants.

Mots clés : Quechua, traduction missionaire, manuels de sacrements.

* Departamento de Antropología, Universidad de Chicago. 1126 East 59th Street, Chicago, IL 60637 EE.UU. E-mail: atdursto@midway.uchicago.edu 


\section{JUAN DE CASTROMONTE'S APTAYCACHANA - A QUECHUA SACRAMENTAL MANUAL FOR THE CENTRAL PERUVIAN HIGHLANDS (CA. 1650)}

\section{Abstract}

This article presents a critical edition of Juan de Castromonte's Aptaycachana, a Quechua sacramental manual written in the mid $17^{\text {th }}$ century to be used in the Indian parishes of the central Peruvian highlands (present-day departments of Junín, Pasco, Huánuco, Ancash and Lima). Even though the Peruvian Church had imposed a pastoral lingua franca based on Cuzco Quechua since the Third Lima Council of 1583, there are abundant Central Quechua lexical, morphological and phonological elements in the Aptaycachana - more so than in any other colonial text. Castromonte's manual is thus an important source for Quechua historical linguistics and for the study of the translation practices of the Church in the colonial Andes. This edition, which consists of an annotated paleographic transcription and Spanish translation, is preceeded by a preliminary study which explains the immediate historical contexts of the Aptaycachana and discusses some of its main features.

Key words: Quechua, missionary translation, sacramental manuals.

El Aptaycachana es uno de los más atípicos y menos conocidos de los textos pastorales en quechua escritos por sacerdotes criollos durante los siglos XVI y XVII (1). Se trata de un breve manual sacramental manuscrito redactado entre 1650 y 1653 en un tipo de quechua que el autor denomina "lengua general Çhinçhaysuyo". En realidad, el quechua empleado en el Aptaycachana es más cercano a la lingua franca pastoral de base cuzqueña conocida como "la lengua general" a secas, que a las lenguas quechuas de la sierra central del Perú ("quechua I" en la clasificación de Alfredo Torero), que entonces eran denominadas "quechua chinchaysuyo" (2). Sin embargo, de todos los textos coloniales conocidos este es el que más se les aproxima.

Su autor, el clérigo Juan de Castromonte (1625-¿1699?), era huanuqueño y redactó el texto cuando estaba recién ordenado y ocupaba el cargo de párroco interino de la doctrina de Huancabamba (actual departamento de Pasco), en la provincia eclesiástica de Tarma y Chinchaycocha. Mientras que los demás sacerdotes de la época que escribían para los "indios chinchaysuyos" se contentaban con introducir algunas raíces centrales en textos en lengua general (ver sección 5), Castromonte también utiliza

(1) El título completo es: Aptaycaçhana o Manual en que se contiene todo lo q[ue] los curas an de deçir y enseñar a los yndios en su lengua quando les administran los santos sacramentos de la yglesia. Sacado fielmente del Ritual Romano de la santidad de Paulo Quinto, y traducido en la lengua general Chinçhaysuyo, del Peru por el B [achille] ${ }^{r}$ Juan de castromonte cura ynterim del Beneficio de Guancabamba. Consta de 16 folios encuadernados al final de un volumen perteneciente a la Biblioteca Nacional del Perú (manuscrito F933). Esta edición se realiza con la autorización de la Biblioteca Nacional del Perú.

(2) La rama I de la familia lingüística quechua, o "quechua central", arraigada en los departamentos de Junín, Pasco, Huánuco, Ancash y partes del departamento de Lima se diferencia considerablemente tanto de las lenguas quechuas habladas hacia el norte (sierra norperuana y Ecuador) como de las que se extienden hacia el sur (sierra sudperuana y Bolivia), todas agrupadas en la rama II (Torero, 1964; Cerrón-Palomino, 1987). La aplicación del término "chinchaysuyo" al quechua I se discute en la sección 4. 
varios morfemas gramaticales característicos del quechua I, si bien de forma esporádica y por aparentes lapsus. Aunque el Aptaycachana no puede considerarse el primer texto quechua I (3), no deja de ser un testimonio valioso para la lingüística histórica del quechua. Sobre todo, dice mucho sobre cómo el régimen colonial enfrentó la diversidad lingüística al interior del quechua, y sobre las relaciones que se entablaron entre la lengua general y las variedades centrales. Fuera de sus rasgos dialectales, el Aptaycachana destaca dentro de la literatura pastoral quechua de los siglos XVI y XVII por ser uno de sólo dos manuscritos conocidos (4), lo que significa que no fue sometido al coladero de controles institucionales a la imprenta. Es también el único texto de su tipo que no contiene versiones castellanas de los textos quechuas, y el único que lleva un título quechua (5).

Existe una edición anterior del Aptaycachana, realizada por el historiador Raúl Rivera Serna en 1965 (6). Me enteré de la existencia del texto por un estudio de Torero, quien cita la edición de Rivera Serna y destaca la importancia del Aptaycachana como testimonio temprano sobre el quechua I (Torero, 1995: 17). Al leer esta edición me di cuenta de que estaba plagada de errores de transcripción, lo que me llevó a hacer una nueva transcripción a partir del original, que se encuentra en la Biblioteca Nacional del Perú. Posteriormente, encontré varios documentos relacionados con Juan de Castromonte en el Archivo Arzobispal de Lima, entre ellos su expediente de ordenación. Estos documentos permiten fechar el Aptaycachana con bastante precisión y, lo que era de vital importancia para el análisis del texto, comprobar que es un manuscrito autógrafo.

Esta edición tiene por objetivo proporcionar:

1) una transcripción paleográfica fidedigna;

2) versiones castellanas de los textos quechuas, ya que no los hay en el original;

3) una contextualización histórica del Aptaycachana, especialmente en cuanto a lo que significaba escribir en "quechua chinchaysuyo" a mediados del siglo XVII.

(3) Este honor podría corresponder a dos volantes emitidos en 1822 por el general realista José Canterac desde su cuartel general en Jauja. En ellos Canterac ofreció una amnistía a los habitantes de la sierra central que estaban apoyando las fuerzas independentistas (Rivet \& Créqui-Montfort, 1951: 282-284). Uno de los volantes está dirigido a los habitantes de los actuales departamentos de Ancash y Huánuco, y el otro a los de Pasco y Junín. La redacción de dos versiones de la proclama parece reflejar un reconocimiento de las diferencias internas del quechua I.

(4) El otro manuscrito es el sermonario del franciscano Diego de Molina (1649), también asociado a la zona de Huánuco (ver sección 4).

(5) La palabra aptaycachana (/apta-ykacha-na/, "algo que debe tomarse frecuentemente en la mano") traduce literalmente el concepto bibliográfico de "manual”. La forma cuzqueña de la raíz es /hapt'a-/, de manera que el título del Aptaycachana ya es un "chinchaysuyismo".

(6) La edición consiste en un breve prólogo y una malograda transcripción, y carece de traducciones de los textos quechuas. 


\section{JUAN DE CASTROMONTE Y EL APTAYCACHANA}

\section{1. Esbozo biográfico}

Juan de Castromonte nació en la ciudad de León de Huánuco en 1625 y según declaró en su expediente de ordenación, sus padres (Francisco Gómez Castromonte e Isabel de Rivera) eran vecinos de la ciudad y "cristianos viejos" (7). Alrededor de 1643 se trasladó a Lima para iniciar sus estudios para el sacerdocio y en 1647 realizaba los trámites de ordenación (A.A.L., serie “Ordenaciones”, legajo 10, expediente 25). En 1650 se "opuso" (o presentó como candidato para párroco) a la parroquia urbana de Santa Ana en Lima (A.A.L., serie "Concursos", legajo4, expediente 5).Esta "oposición" fue probablemente una forma de darse a conocer ante las autoridades arzobispales, ya que dada su juventud no tenía mayores posibilidades de obtener una parroquia tan importante. En ese momento estaba recién ordenado y graduado de bachiller, y no ocupaba ningún cargo. En 1653 se opuso a la doctrina de Pararín(Huaylas), presentándose ahora como "cura en interin que e sido de la doctrina de indios de Guancabamba" [A.A.L., serie "Concursos", legajo 4, expediente 9, folio 7 (énfasis mío)]. Ya que Castromonte se identifica como "cura ynterim del Beneficio de Guancabamba" en el título del Aptaycachana, estas dos oposiciones permiten fechar su redacción entre 1650 y 1653, cuando Castromonte tenía entre 25 y 28 años.

Durante 1656 y 1657 se opuso a varias doctrinas más, la mayoría de ellas en las zonas de Cajatambo, Huaylas y Conchucos, aunque no se sabe si con éxito o no (A.A.L., serie "Concursos", legajo 4, expedientes 53, 54, 55, 56, 57, 58 y 59). Castromonte reaparece en la documentación arzobispal en 1666 como cura de Huaraz y vicario de la provincia eclesiástica de Huaylas (A.A.L., serie "Capítulos", legajo 6, expediente 19). Debido a su tamaño, Huaraz tenía dos doctrineros, y en 1685 Castromonte y su co-párroco, Agustín de Pedrejón y Zambrano, fueron objeto de una visita eclesiástica que comprobó que ambos sacerdotes eran "sobremanera vigilantes... en ynstruirlos [a los indios] en las cosas de n[uest] $\mathrm{ra}$ s[an]ta fee", y que "en las festiuidades del año les predican en la lengua yndica"(A.A.L., serie "Visitas de Ancash", legajo 3, expediente 22, folios 4 y 7). En su fallo, el visitador Pedro González de Cisneros y Mendoza dictaminó que merecían ascender a prebendas catedralicias (A.A.L., serie "Visitas de Ancash", legajo 3, expediente 22, folio 9v). Sin embargo, Castromonte permaneció en el cargo de doctrinero de Huaraz hasta su muerte en los últimos años del siglo XVII. En 1700 la orden hospitalaria de los betlemitas pedía autorización al arzobispado para fundar un hospital de indios en Huaraz con bienes legados por Castromonte (A.A.L., serie "Orden Betlemita”, legajo 1, expediente 9).

La carrera eclesiástica de Castromonte fue bastante típica para la época, asemejándose a la de clérigos quechuistas más famosos como Francisco de Ávila y Fernando de Avendaño. Como español criollo y quechuahablante nativo era candidato ideal para "doctrinero" o párroco de indios, e inició su carrera alrededor de los 25 años con un puesto de importancia menor - la de párroco interino de la aislada doctrina de

(7) El que sus padres lo hicieran bautizar recién a los siete meses sugiere que éstos residían fuera de la ciudad, probablemente en una hacienda, lo que habría aumentado sus contactos tempranos con quechuahablantes. 
Huancabamba- (8). Después regresó a Lima en busca de un mejor cargo, lo que logró algunos años más tarde al ser nombrado párroco de Huaraz, uno de los pueblos de indios más grandes de la arquidiócesis. Castromonte nunca dio el siguiente paso en la carrera eclesiástica, que era obtener una parroquia de españoles para después ganar una prebenda o canonjía en una catedral, como lo hicieron Ávila y Avendaño. Donde sí tuvo éxito fue en reunir una fortuna considerable que le permitió legar alrededor de 50000 pesos a los betlemitas para que cuidaran de los indios enfermos de Huaraz (9).

Puede especularse que la decaída en el interés por el cultivo del quechua a partir de mediados del siglo XVII haya impedido que Castromonte ascendiera a cargos mayores. Los años 1648 y 1649 marcaron el zenit (por lo menos en términos cuantitativos) de la producción de textos pastorales en quechua (ver sección 4). A fines de la década de 1640 había por lo menos cuatro quechuistas en la catedral de Lima: el arcediano Fernando de Avendaño, los canónigos Francisco de Ávila y Diego de Encinas, y el cura rector Alonso Osorio (10). Este auge fue propiciado por el arzobispo Pedro de Villagómez (1641-1671) y probablemente estuvo relacionado con la campaña de extirpación de idolatrías iniciada en 1649, que incluyó entre sus visitadores a los quechuistas Fernando de Avendaño, Alonso Osorio y Bartolomé Jurado Palomino (Duviols, 1977: 197-199). Tal auge parece haber producido un efecto de saturación - a partir de 1650 la producción de textos pastorales en quechua decayó notoriamente y no volvió a recuperarse por el resto del período colonial- (11). La generación de "lenguas" criollas nacidas hacia comienzos del siglo XVII parece haber sido la última que pudo utilizar el conocimiento del quechua para hacerse de carreras eclesiásticas de nivel medio o alto. Castromonte recién tenía 25 años en 1650 y para cuando estaba en edad como para obtener cargos de importancia su condición de quechuista ya no le habría servido de mucho.

(8) Huancabamba era el pueblo más oriental y más "yunga" de la provincia eclesiástica de Tarma y Chinchaycocha. Es probable que Castromonte haya aceptado hacerse cargo de esta doctrina por su proximidad a su ciudad natal.

(9) Esta herencia fue objeto de un pleito entre los betlemitas y los herederos de Castromonte fallado en 1708 (A. A. L., serie "Orden Betlemita", legajo 1, expediente 31).

(10) En 1648 Diego de Encina y Alonso Osorio examinaron al propio Castromonte en su capacidad para catequizar, predicar y administrar los sacramentos en quechua, como consta en su expediente de ordenación (A. A. L., serie "Ordenaciones", legajo 10, expediente 25).

(11) La producción quechuística de las imprentas limeñas entre 1650 y la época republicana puede resumirse en pocas líneas. El Directorio espiritual del jesuita Pablo de Prado fue reeditado en 1705, y el Arte del también jesuita Diego de Torres Rubio fue reeditado en 1700 y 1754 con secciones nuevas dedicadas al quechua I. Hubo también reediciones de algunos textos del III Concilio en 1773 (Rivet \& Créqui-Montfort, 1951: 170-172). En cuanto a obras nuevas, en 1691 Esteban Sancho de Melgar, catedrático de quechua en San Marcos, imprimió una gramática quechua, pero este libro sugiere una decadencia en la tradición quechuística más que su continuación. En 1730 un clérigo de La Plata publicó un catecismo cuyo lenguaje difiere de la lengua general y que parece estar adaptado al quechua local (Dávila Morales, 1730), mientras que en 1725 y 1753 se imprimieron obras en quechua ecuatoriano (Rivet \& Créqui-Montfort, 1951: 141-147 y 156-158). Al igual que las reediciones del Arte de Torres Rubio estas publicaciones demuestran un nuevo interés por las variedades antes despreciadas del quechua, pero en general la producción de textos pastorales nuevos en este período es mínima en comparación con la de los años entre el III Concilio Limense y la redacción del Aptaycachana. 


\section{2. El códice Castromonte}

Los 16 folios del Aptaycachana están encuadernados con 234 folios de comentarios de teología escolástica y moral en latín, algunos de ellos tomados en cursos dictados en la Universidad de San Marcos. El volumen es de tamaño in quarto y está encuadernado en pergamino, con una anotación en letra gótica de difícil lectura en el dorso, "Aliqu.t Theologic. Certam[ina]", que parece referirse a los textos latinos. Estos se encuentran divididos en secciones cuyos títulos a veces contienen los nombres de los catedráticos y las fechas de los cursos, que corresponden a los años 1649, 1650 y 1656 . Fuera del título del Aptaycachana, los textos reunidos en este códice no contienen referencias a su autor, ni prólogos o notas explicativas de ningún tipo. Sin embargo, los textos latinos son de la misma mano que el Aptaycachana, y al comparar estos manuscritos con documentos firmados por Castromonte que se encuentran en el Archivo Arzobispal de Lima, es fácil comprobar que el códice de la Biblioteca Nacional es autógrafo (12).

Es probable que Castromonte haya tomado estos apuntes como preparación para las "oposiciones" o concursos para curatos. En estos concursos los candidatos eran examinados en su "suficiencia de letras" — es decir, en su capacidad para resolver "casos" o dudas que podían surgir en el cumplimiento de sus deberes pastorales (sobre todo en la administración de los sacramentos) - a partir de sus conocimientos de teología moral y derechocanónico. El hecho de que el Aptaycachana se haya encuadernado junto con estos apuntes sugiere que fue redactado con un propósito similar. En él, Castromonte hacía gala no sólo de sus conocimientos del quechua en su variante chinchaysuyo, sino también de su preparación como pastor. La pulcritud de la escritura tanto en el Aptaycachana como en los apuntes latinos, y la abundancia de elementos decorativos, sugieren que estos textos no eran simples borradores. Es probable que este códice fuera diseñado en su conjunto para ser exhibido ante los superiores de Castromonte como parte de sus campañas para obtener mejores puestos.

\section{LOS MANUALES PERUANOS}

Un manual o ritual católico es una guía para la administración de los sacramentos del bautismo, confesión, comunión, extrema unción y matrimonio - contiene los "oficios" o textos sacramentales, junto a instrucciones para la administración o "rúbricas"- Los sacramentos restantes (confirmación y ordenación) son de administración exclusiva de los obispos y por lo tanto no figuran en los manuales, que están destinados al uso de los párrocos. Antes del Concilio de Trento, se había consolidado el uso de ritos sacramentales diferentes y muchos territorios eclesiásticos tenían sus propios manuales. Mientras que las fórmulas sacramentales básicas en latín (las "formas") no variaban, los manuales se diferenciaban considerablemente en el ceremonial secundario. El Concilio de Trento propició un esfuerzo de uniformización

(12) El carácter autógrafo del Aptaycachana se deduce sobre todo al compararlo con dos peticiones firmadas por Castromonte que se encuentran en su expediente de ordenación, y que datan de 1647 (A. A. L., serie "Ordenaciones", legajo 10, expediente 25). Hay varios otros documentos firmados por Castromonte en el Archivo Arzobispal que datan de años posteriores y cuya escritura es idéntica a la del códice de la Biblioteca Nacional. 
en ésta como en otras áreas del ceremonial católico, pero fue recién en 1614 que se publicó el Rituale romanum de Pablo V, cuyo uso era recomendado (aunque no obligatorio) para toda la Iglesia.

A diferencia de México, donde en 1556 se imprimió un manual elaborado por el I Concilio Mexicano (el "manual mexicano"), Perú nunca tuvo un manual oficial propio. Los Concilios Limenses I y II (1551-1552 y 1567-1568) dispusieron el uso del manual sevillano en los bautismos, añadiendo que los indios podían ser bautizados con el manual romano de aquel entonces porque su oficio bautismal era más breve (Vargas Ugarte ed., 1951: 12,245). En cambio, el sínodo limense de 1613 ordenó el uso del manual toledano, añadiendo que los curas de indios podían usar el mexicano "mientras por su Santidad no se mandare otra cosa" (Sínodos de Lima, 1987: 61). Fue recién en el sínodo limense de 1636 que se ordenó el uso del "Ritual Romano de la Santidad de Paulo V o de los manuales aprobados para este Arzobispado" (Sínodos de Lima, 1987: 279, 280). De esta manera, aún después de la publicación del Rituale romanum, se mantuvo el uso de los manuales toledano y mexicano, este último considerado especialmente apto para ser usado entre indios.

Fue quizá debido a la demora en la publicación del Rituale romanum, y a la incertidumbre anterior sobre cuál de los manuales existentes debía usarse como modelo, que la aparición de un manual con textos quechuas fue tardía. Los tres volúmenes pastorales del III Concilio Limense (1582-1583) (13), que contienen los únicos textos vernáculos oficiales que generó la Iglesia peruana, por lo general se limitan a la explicación de los sacramentos. El Confessionario (1585) incluye exhortaciones para la buena muerte, la letanía para rogar por los muertos, una plática sobre el matrimonio, y un texto para hacer las amonestaciones previas al matrimonio, pero no contiene oficios. Hay que hurgar en los catecismos de la Doctrina christiana (1584) para encontrar una versión quechua de la "forma" bautismal.

El primer manual peruano fue el Rituale seu manuale peruanum del célebre franciscano huamanguino Luis Jerónimo de Oré, publicado en Nápoles en 1607. Éste era un manual para todo el virreinato, ya que incluye textos en aimara, puquina, mochica y guaraní además de quechua. Oré lo define como un "Manual Catholico Romano Peruano y Cuzquense" y explica que lo redactó a partir del manual salamantino, del sevillano, y del "Mexicano antiguo y nuevo" (Oré, 1607: 11). El Rituale seu manuale peruanum es una compilación de oficios latinos de los cuales sólo una pequeña parte se traducen al quechua y las otras lenguas indígenas. También incluye pláticas y catecismos que fueron compuestos originalmente en lenguas indígenas, entre ellos varios textos del III Concilio Limense. El manual de Oré es lo más cercano a un manual peruano oficial, ya que su uso fue aprobado por el obispado de Huamanga en sus sínodos de 1629 y 1671 (el sínodo de 1671 recomienda en primer lugar el manual toledano y no menciona al Rituale romanum) (Sínodo de Huamanga de 1629, 1970: 34, 41; Sínodo de Huamanga de 1672, 1677: f. 61).

Al manual de Oré le siguió el Ritual formulario, e institucion de curas del clérigo cuzqueño Juan Pérez Bocanegra, impreso en Lima en 1631. A diferencia del manual de Oré, el de Bocanegra sólo reproduce aquellas partes de los oficios que debían decirse

(13) La Doctrina christiana y catecismo (1584), el Confessionario para los curas de indios (1585), y el sermonario o Tercero cathecismo (1585) (reproducidos facsimilarmente en Pereña, ed., $1985[1584 ; 1585 ; 1585])$. 
en quechua, de manera que el párroco también debía tener a mano el Rituale romanum para decir los oficios completos. Sin embargo, el manual de Bocanegra es mucho más extenso debido a sus abundantes rúbricas y a la inclusión de un confesionario extraordinariamente detallado y de varias oraciones e himnos. Los textos quechuas del Ritual formulario ocupan más de un tercio de sus 729 páginas, y son una fuente incomparable para la historia religiosa andina, tanto autóctona como cristiana. Bocanegra declara que su manual está conforme con el Rituale romanum de Pablo V y que este había reemplazado a "tantos cerimoniales, y Manuales, Breues, y mas ad longum, impressos, y de mano, como en estas Indias Occidentales corrían; sin mas autoridad que la que les querían dar los Autores dellos" (14). También se refiere despectivamente a los intentos anteriores por traducir los oficios sacramentales al quechua, incluyendo entre ellos al Rituale seu manuale peruanum. A pesar de las ambiciones de Bocanegra de que el Ritual formulario se convirtiera en el manual peruano, no hay evidencia alguna de que haya sido acogido por las autoridades eclesiásticas (15).

Hay otros libros de la época que sin ser rituales en sentido estricto servían como guías sacramentales y alcanzaron gran difusión. En 1619 el jesuita Diego de Torres Rubio publicó un Arte de la lengua quichua (reeditado en 1700 y 1754) que contiene un confesionario y los oficios del matrimonio y del viático, cosa que no se menciona en el título del libro ni en las aprobaciones preliminares. También debe mencionarse el Directorio espiritual del jesuita Pablo de Prado, impreso en Lima en 1641 y reeditado en 1650 y 1705 . Este libro es un manual devocional dirigido a indígenas, que si bien no incluye el ceremonial sacramental sí entrega abundantes instrucciones sobre cómo los indios debían prepararse para recibir los sacramentos, especialmente la comunión.

En resumen, el Aptaycachana es el último de los tres manuales peruanos coloniales. Con sus 16 folios parece un documento exiguo, pero hay que enfatizar que debía usarse conjuntamente con el Rituale romanum ya que sólo contiene aquellas partes de los oficios que debían decirse en quechua. El oficio que traduce para algunos sacramentos es más completo que el del Ritual formulario. No encuentro evidencia de que Castromonte haya utilizado o siquiera conocido los manuales de Oré y Bocanegra. Sus traducciones de los oficios sacramentales difieren de las de Oré y Bocanegra más allá de la utilización de algunas formas centrales, y parece que Castromonte redactó su manual trabajando directamente a partir del Rituale romanum, como él mismo lo dice (16). Como ya se mencionó, el Aptaycachana es el único documento pastoral de su época que no incluye versiones castellanas de los textos quechuas. Esa ausencia sugiere que el Aptaycachana, en esta versión, no estaba destinado a la difusión sino más bien a ser exhibido ante las autoridades eclesiásticas, posiblemente con miras a su impresión en una versión ampliada.

(14) "Epístola a los curas" en Pérez Bocanegra, 1631.

(15) El hecho de que Bocanegra no siguió las pautas establecidas por el III Concilio Limense en el tratamiento de varios términos teológicos y pastorales, e incluso utilizó algunos términos con un alto contenido religioso autóctono ( $c f$. Mannheim, 1999: 20-21), puede estar relacionado con esta falta de acogida oficial.

(16) Las similitudes [por ejemplo, el hecho de que tanto Bocanegra como Castromonte utilicen la raíz milla- ("tener asco de") para abrenuntiare en el oficio bautismal] no implican necesariamente una influencia del uno en el otro, ya que éstas pueden reflejar una tradición independiente. 


\section{CONTENIDOS PRINCIPALES DEL APTAYCACHANA}

\section{1. Bautismo}

La sección bautismal del Aptaycachana comienza con indicaciones para bautizar a recién nacidos en peligro de muerte, en cuyo caso se omitía el ceremonial completo y el bautizo podía ser realizado por cualquier persona si no había un sacerdote a la mano. Castromonte da la forma bautismal en "la lengua general quiçhua çhinçhaysuyu" como Ñôam Baptizayqui, Yayap, Churip, Spiritu Santop sutimpi (f. 2). Esta forma, sin embargo, es idéntica a la forma canónica que apareció por primera vez en la Doctrina christiana y catecismo del III Concilio y que fue repetida por Oré y Bocanegra, entre otros (Pereña, ed., 1985[1584; 1585; 1585]: 112; Oré, 1607: 37; Pérez Bocanegra, 1631: 45). Castromonte no realiza ninguna adaptación de tipo dialectal. A la forma común le siguen dos variantes sub conditione para bautizar a recién nacidos que podían estar muertos o que carecían de "forma humana", cosa que ni Oré ni Bocanegra consideraron necesario.

La siguiente sección, "Para Bautizar solemnemente", contiene las partes del oficio bautismal que debían decirse en quechua ya que requerían respuestas por parte de los padrinos o estaban dirigidas a ellos. Ya en el I Concilio Limense se había dispuesto que esta parte del oficio se hiciera "en lengua que lo entiendan, y ellos propios respondan a ello" (Vargas Ugarte, ed., 1951: 11). Una disposición del II Concilio Limense parece referirse a una versión quechua oficial de esta parte del oficio que debían tener los doctrineros (Vargas Ugarte, ed., 1951: 245), pero no se conoce ninguna versión anterior a la publicada por Oré (1607: 61-84). Las versiones de Castromonte son ligeramente distintas a las anteriores. También traduce partes del oficio que Oré y Bocanegra omitieron o reprodujeron en latín: la admonición inicial Si igitur vis ad vitam ingredi y la invitación a ingresar a la iglesia Ingredere in templum Dei.

\section{2. Confirmación}

A pesar de que el sacramento de la confirmación era administradoexclusivamente por los obispos, y de que era extremadamente raro que un arzobispo de Lima llegara a las doctrinas serranas de su arquidiócesis, Castromonte le dedica una larga plática que ocupa un tercio del manual (ff. 3-8). Oré simplemente no lo menciona, como era usual en un manual. El manual de Bocanegra tiene una breve plática de la confirmación para preparar a los feligreses en el caso de que un obispo llegara a la doctrina en el transcurso de una visita (Pérez Bocanegra, 1631:81-88). Es con este objeto que Castromonte trata el tema, pero su "plática" es un verdadero sermón con citas bíblicas y patrísticas en latín, e incluso un pequeño exemplum sobre Alejandro Magno. La plática de Bocanegra es una instrucción escueta que enumera los beneficios y requisitos del sacramento, mientras que la de Castromonte despliega una serie de recursos retóricos para inspirar la devoción necesaria en los confirmandos. Castromonte sigue a la letra las instrucciones de los autores del sermonario del III Concilio, quienes recomendaron el uso de símiles y de "cosas que prouoquen y despierten el affecto, como apostrophes, exclamaciones y otras figuras" (Pereña, ed., 1985[1584; 1585; 1585]: 356). Cada punto importante se ilustra con un símil o comparación, y la exposición está salpicada con exclamaciones y 
preguntas retóricas. La inserción de citas latinas va menos de acuerdo con las normas del III Concilio, que exigía la sencillez de los textos pastorales, pero era frecuente en los sermonarios quechuas de mediados del siglo XVII.

El que Castromonte se haya esmerado tanto en esta sección debe entenderse como una respuesta a una situación coyuntural: la preocupación que se ventilaba en torno a la confirmación de indígenas durante la década de 1650. Por estos años, el provincial dominico Francisco de la Cruz, el cabildo secular de Lima, y el alcalde del crimen de la audiencia, Juan de Padilla, escribieron sendas cartas al rey quejándose de que los indios no accedían a la confirmación porque sus obispos no los visitaban (17). La preocupación por la confirmación de indios forma parte de una exigencia más amplia de que el arzobispo actuara de forma directa en el mejoramiento del sistema pastoral. (Villagómez llevaba más de una década como arzobispo y apenas había realizado visitas personales de su arquidiócesis.) Ambas quejas estuvieron relacionadas directamente con la campaña de extirpación de idolatrías que Villagómez inauguró en 1649. Las idolatrías que descubrían los extirpadores eran atribuidas por sus opositores al hecho de que no hacia las visitas personalmente. Por otra parte, la eficacia de la confirmación como una especie de segundo bautismo que, según un autor de la época, daba "una sobrenatural fortaleza con que el Christiano con valencia defiende la Fé" (Peña Montenegro, 1678: 447), pudo adquirir nueva relevancia a medida que aumentaban los casos de idolatría. La plática de la confirmación le habría dado una contemporaneidad especial al Aptaycachana, y probablemente se redactó anticipando futuras visitas que realizaría Villagómez.

\section{3. Comunión y viático}

Las indicaciones que da Castromonte para la comunión, tanto en la misa como por viático, son bastante breves (éste era un tema que ya había sido tratado con abundancia por Oré, Bocanegra y Pablo de Prado). Lo más interesante de esta sección son sus dos versiones quechuas de la oración de contrición para comulgar Domine non sum dignus. La segunda versión se diferencia por un mayor uso de préstamos del castellano (18), y estaba destinada a "yndios o yndias ladinas, mestisas, o Zambas, en habito de Yndias porq[ue] les muebe a mayor devoçion su lenguaje" (f. 8). Este es el único caso en la literatura pastoral colonial de un texto adaptado para poblaciones cuyo quechua estaba altamente castellanizado por su permanente contacto con españoles pero que no tenían un manejo pleno del castellano. Las formas canónicas del quechua pastoral se caracterizaron, sin duda, por el recurso a préstamos del castellano para el léxico teológico y pastoral. Sin embargo, también evidencian un grado de purismo lingüístico en cuanto rechazaban el uso de cualquier forma ajena al quechua cuzqueño fuera de tales préstamos. La rara postura de Castromonte era que los comulgandos

(17) Carta de Francisco de la Cruz al Rey, 1657 (Vargas Ugarte, 1960: 476); Carta de Juan de Padilla al Rey, 15 de octubre 1654 (Cedulario del Archivo Arzobispal de Lima, volumen II, ff. 260260v). La carta del cabildo secular de Lima se menciona en una cédula real del 13 de diciembre 1671 que también se refiere a una réplica de Villagómez de 1654 (Cedulario del Archivo Arzobispal de Lima, volumen II, f. 305).

(18) mereci- por cama ca-, cuerpo por vcu, y perdona- por pampacha-. 
debían decir las oraciones en el "lenguaje” que les era más íntimo y familiar. También es única y muy sugerente la referencia a "zambas" (mujeres de origen africano) que comulgaban en quechua, lo que implica que para muchos africanos la cristianización pasaba por una quechuización intermedia (19). Castromonte excluye implícitamente de la comunión en quechua a los mestizos y a los zambos, quizá porque solían tener un mayor dominio del castellano que las mujeres de su mismo grupo racial.

\section{4. Extrema unción y oraciones para enfermos y moribundos}

Después de la sección sobre la extrema unción, que es bastante breve ya que no traduce el oficio (como sí lo hizo Bocanegra), Castromonte añade dos secciones de pequeñas pláticas y rezos para ayudar a la buena muerte, preocupación central de los discursos pastorales de la época. El párroco debía visitar varias veces a sus feligreses que estaban en peligro de muerte, y fuera de administrarles el viático y la extrema unción, se les debía acompañar en sus horas finales con una verdadera liturgia de la muerte, en la cual el sacerdote y los asistentes rezaban por el alma del moribundo y este se encomendaba a la misericordia divina.

En la primera de estas secciones pro morientes, "Para vissitar a los enfermos que estuvieren en peligro de muerte", Castromonte traduce seis protestaciones en las que el enfermo se afirma en su fe en la misericordia de Dios. Estas protestaciones no figuran en el Ritual formulario de Bocanegra, pero sí aparecen, en versión latina y castellana, en el Rituale seu manuale peruanum de Oré, en una sección titulada "Ordo iuuandi morientes ex Ioanne Gerson in Tripartito" (1607: 229-246). Según Oré, estas protestaciones fueron comunicadas por revelación divina a un fraile, y figuraban en los rituales de Torino y Venecia, "y en un manual pequeño de que usan los padres Capuchinos". Añade que "fue reuelado que ninguno que con verdadero coraçon protestare las tales cosas... se podra condenar" (Oré, 1607: 241). Sin embargo, estas protestaciones no formaban parte del Rituale romanum, lo que obliga a Castromonte a citar su fuente: el Ytinerario para la eternidad de Antonio de Molina, quien las recomienda justamente por su origen divino (f. 10v). El hecho de que Castromonte no cita a Oré en este punto, y de que hay importantes diferencias de contenido entre sus versiones quechuas y las castellanas de Oré, es otra evidencia de que Castromonte no utilizó el Rituale seu manuale peruanum para componer el Aptaycachana.

La siguiente sección, "Para ayudar a los q[ue] estan en el trançito de la muerte", contiene los 11 versos odeprecaciones para moribundos que figuran en el Rituale romanum. Bocanegra, quien también los traduce, sugiere que sus versiones quechuas fueran memorizadas como preparación para la buena muerte (Pérez Bocanegra, 1631: 550). Al contrastar las versiones de Bocanegra y Castromonte, comprobamos que las traducciones de Castromonte son a la vez menos literales y más sencillas. En la tercera deprecación, por ejemplo, Bocanegra traduce Deus veritatis “Dios de la verdad" como checan caipa Diosnin "Dios del ser verdadero" (Pérez Bocanegra, 1631: 550), abstracción probablemente

(19) La expresión "zambas en hábito de indias" no se refiere a zambas que vestían como indias, sino a zambas que habían asumido comportamientos culturales andinos, como el uso del quechua - de la misma manera, se hablaba también de "mestizas en hábito de indias". 
incomprensible en quechua sin el referente de la expresión latina o castellana, mientras que Castromonte dice mana pantaĉ Dios "Dios que no se equivoca" (f. 12).

\section{5. Matrimonio}

La sección matrimonial contiene modelos para las "amonestaciones" con que se anunciaban los matrimonios, además de los oficios del desposorio y de la bendición de las arras. Las amonestaciones, que debían leerse en tres días de fiesta anteriores al matrimonio, tenían especial importancia en los matrimonios de indios dado que se les atribuía una tendencia a violar las normas canónicas en cuanto a los grados de parentesco permitidos entre los contrayentes. Un texto quechua para las amonestaciones ya se había publicado en el Confessionario del III Concilio Limense (Pereña ed., 1985[1584; 1585; 1585]: 328-332), y el mismo texto aparece en el Rituale seu manuale peruanum de Oré (1607: 208-209), mientras que Bocanegra publicó su propia versión (Pérez Bocanegra, 1631: 619-620).

Castromonte presenta tres textos para las amonestaciones:

1) la amonestación estándar,

2) un texto más breve para la segunda o tercera vez que se hacia la amonestación, y

3) una amonestación para matrimonios entre viudos.

Las amonestaciones contienen nombres completos de contrayentes con los nombres de sus padres, pueblos y grupos segmentarios (ayllus y pachacas), como si se tratara de personas reales. Algo similar había hecho Bocanegra, ya que su amonestación menciona los nombres de los ayllus de los contrayentes ficticios, que son del mismo pueblo (20). Castromonte redactó sus amonestaciones a partir de su experiencia como párroco de Huancabamba, posiblemente utilizando casos reales. La mayoría de los pueblos nombrados -Huancabamba, Quiparacra, Ullucmayo (o Ullcumayo), Carhuamayo, y Paucartamboson de la provincia de Tarma y Chinchaycocha, y es probable que los nombres de ayllus y pachacas también sean verídicos. En cada una de las amonestaciones, los contrayentes son de pueblos y grupos segmentarios distintos y el matrimonio se ha de realizar en el pueblo del novio, lo que podría reflejar una práctica matrimonial generalizada en la zona.

\section{6. Apéndices (sección no sacramental)}

A la sección matrimonial le sigue una serie de breves textos para proclamar los ayunos y descansos de las fiestas cuya observancia era obligatoria para los indios. Se trata de un género nuevo en la literatura pastoral en quechua, pero de clara utilidad para los doctrineros, quienes tenían la obligación de imponer una observancia adecuada de las "fiestas de guarda", explicando el acontecimiento de la historia sagrada que se conmemoraba en cada fiesta, y las particulares abstinencias laborales y alimenticias que requería (21) (Sínodos de Lima, 1987: 185). Les sigue el Acto de Contrición, una oración

(20) Los ayllus son Salloc (del novio) y Antahuailla (de la novia) —al parecer se trata de nombres de ayllus del pueblo de Andahuaylillas, donde Bocanegra fue párroco (Pérez Bocanegra, 1631: 619)—.

(21) El sínodo limense de 1613 había indicado que los curas tenían la obligación de "avisar à sus Feligreses en el dia de Domingo, q[ue] dias de ayuno hay aquella semana, para que ninguno dexe de ayunarlos por ignorancia”. 
que en principio era una preparación para la confesión auricular, pero que también servía para aplazarla si no había un sacerdote a la mano. La plática de la confirmación indica que los confirmandos que no habían podido confesarse debían hacer un acto de contrición como preparación para recibir la confirmación en estado de gracia (f. 7).

El Aptaycachana concluye con el Cantarcillo, un himno eucarístico en 17 estrofas de cuatro versos en que se alternan versos de seis y cinco sílabas. Este himno no tiene una relación clara con el resto del manual, ya que las secciones sobre la comunión y el viático no hacen referencia a él. Al revisar el corpus del quechua pastoral encontramos varias oraciones cortas para adorar a la hostia y el cáliz, pero las canciones eucarísticas son bastante raras. El precedente más cercano del Cantarcillo de Castromonte son las últimas 15 estrofas del quinto cántico del Symbolo catholico indiano de Oré (1598), que alaban la hostia y el cáliz consagrados y afirman los dogmas principales de la eucaristía (Oré, 1992[1598]: 324-326). Mientras que estas estrofas forman parte del ciclo narrativo de los siete cánticos, también tuvieron amplia acogida como un himno independiente conocido hasta la actualidad con el título Cammi Dios canqui (22). El contenido del Cantarcillo es muy cercano al del Cammi Dios canqui. Ambos himnos enfatizan la presencia real de Jesucristo en la eucaristía, retratándolo como algo que está escondido (pacacusca) al interior de la hostia. La composición de Castromonte podría ser una adaptación abreviada de la de Oré en otro esquema métrico.

Los devocionarios en quechua ancashino publicados por el redentorista Juan Lobato a fines del siglo XIX contienen un himno eucarístico que recuerda mucho al Cantarcillo (e.g., Redentoristas, 1889[1888]: 29-30). Este himno —el Cahuac Jesusmi consta de nueve estrofas de cuatro líneas de cinco sílabas cada una, y al igual que el Cantarcillo es una declaración de la doctrina de la eucaristía, cosa bastante rara en los himnos de los siglos XIX y XX, que por lo general son de carácter más "rogativo" que "declarativo". La tercera estrofa del Cahuac Jesusmi parece tomada del Cantarcillo:

$$
\begin{gathered}
\text { Kei eiza nahui } \\
\text { tantami, ninmi; } \\
\text { shuncuica creinmi } \\
\text { Jesús cashcanta. }
\end{gathered}
$$

"Estos ojos de carne dicen que [la hostia] es pan, pero mi corazón cree que es Jesus" Compárense las estrofas 5 y 6 del Cantarcillo:

$$
\begin{gathered}
\text { Ñaui, maqui, callu } \\
\text { ançhuricullay } \\
\text { tantam vinum ñispa } \\
\text { pacta muspayman }
\end{gathered}
$$
y vino"

"Aléjense de mi, mis ojos, manos y lengua, para que yo no piense que esto es pan

(22) En la ciudad del Cuzco y alrededores, el Cammi Dios canqui suele cantarse en la misa inmediatamente después de la consagración. 


\section{Rinrillaytam cunam \\ yaçhaçhipuan \\ Jesuçhristom ñispa \\ Fee mana pantaĉ}

"La fe, que no se equivoca, enseña sólo a mis oidos, diciendo que es Jesucristo"

El Cahuac Jesusmi, registrado a fines del siglo XIX, pertenece a la misma tradición de himnos eucarísticos que probablemente eran cantados durante la comunión del pueblo al final de la misa. Dadas las semejanzas de contenido y formales, este himno pubo haber derivado directamente del Cantarcillo.

\section{EL “CHINCHAYSUYO” EN EL QUECHUA PASTORAL DEL SIGLO XVII}

La definición más sucinta de lo que los españoles entendían por "quechua chinchaysuyo" en el siglo XVII se encuentra en la gramática del clérigo huanuqueño Alonso de Huerta:

Aunque la lengua Quichua, y General de el Inga, es vna, se ha de aduertir primero, que esta diuidida en dos modos de vsar de ella, que son, el vno muy pulido y congruo, y este llaman de el Inga, que es la lengua que se habla en el Cuzco, Charcas, y demas partes de la Prouincia de arriua, que se dize Incasuyo. La otra lengua es corrupta, que llaman Chinchaysuyo, que no se habla con la pulicia y congruydad que los Ingas la hablan... [y] empieçan, la del Inga desde Guamanga arriua, y la de Chinchaysuyo desde alli abajo hasta Quito (Huerta, 1993[1616]: 18).

La escisión del quechua en dos bloques y la relegación del más amplio y diverso de ellos como "corrupto" fue un resultado de la política lingüística del III Concilio Limense, puntualmente de su consagración de una lengua general de base cuzqueña como medio pastoral.

El apéndice lingüístico de la Doctrina christiana de 1584(titulado “Annotaciones, o scolios, sobre la traduccion de la Doctrina christiana...") opone el cuzqueño a las variedades habladas "desde Guamanga hasta Quito" y en "los llanos [de la costa]", y al "vso que comunmente rescibieron todos los q[ue] se llaman Chinchaysuyos" (Pereña ed., 1985[1584; 1585; 1585]: 167). El chinchaysuyo se hablaba, entonces, al norte del territorio de la ciudad de Huamanga (poco más tarde convertido en diócesis), espacio que abarcaba los actuales departamentos de Ayacucho y Huancavelica (CerrónPalomino, 1995: nota 7). Esta línea divisoria corresponde justamente a la frontera moderna entre la sub-rama IIC (conformada por el quechua cuzqueño y ayacuchano y por las hablas bolivianas) y la rama I (hablada en los departamentos de Junín, Pasco, Huánuco, Ancash y partes del departamento de Lima). Sin embargo, la etiqueta "chinchaysuyo" también se aplicaba a hablas hoy consideradas quechua II, como el quechua ecuatoriano y el desaparecido quechua de la costa central del Perú, descrito por Domingo de Santo Tomás en su gramática y diccionario de 1560 y que habría funcionado como lengua general hasta la década de 1580 (Torero, 1995; Cerrón- 
Palomino, 1995). En su sentido más lato, el "quechua chinchaysuyo" era cualquier variedad del quechua que difiriera mucho del cuzqueño. Ya que estas hablas diferentes se extendían hacia el noroeste del área cuzqueña, el nombre de la división correspondiente del Tahuantinsuyo se ofrecía como etiqueta conveniente. Sin embargo, queda claro que el quechua I era el chinchaysuyo por excelencia. Si bien algunas de las formas léxicas y fonológicas registrados como chinchaysuyismos en las "Annotaciones" pudieron ser comunes con o incluso características del quechua costeño, en la mayoría de los casos los autores parecen estar pensando en las hablas de la sierra central. Esta identidad de lo que los quechuistas coloniales consideraban quechua chinchaysuyo con lo que hoy llamamos quechua I habría aumentado en las décadas posteriores al III Concilio, a medida que el quechua costeño perdió toda importancia con la veloz baja demográfica y castellanización de la población costeña.

A pesar de que las "Annotaciones" de la Doctrina christiana declaran que los traductores diputados por el III Concilio tomaron en cuenta las variaciones del quechua “desde Quito hasta los Charcas" (Pereña, ed., 1985[1584; 1585; 1585]: 167), no hay nada en sus textos que no sea identificable con el cuzqueño del siglo XVI. Si bien parecen haber privilegiado aquellos elementos del léxico cuzqueño que eran panquechuas y optaron por no representar las oclusivas laringalizadas características de la fonología cuzqueña, los quechuistas del concilio parecen haber desarrollado una fobia hacia las formas ajenas al cuzqueño. Tales formas (léxicas, morfológicas, y fonológicas) fueron identificadas con un "modo tosco, y corrupto de hablar" y con un "sonsonete de rusticos y agenos de policia" (Pereña, ed., 1985[1584; 1585; 1585]: 167, 168). A la larga, la Iglesia peruana parece haber generado un régimen diglósico en la sierra central ya que el quechua que debía utilizarse en la catequesis, la liturgia, y la sacramentación era sustancialmente diferente de las hablas locales. Esta situación no se corrigió durante la colonia, por lo menos en lo que se refiere a los textos escritos. El Aptaycachana forma parte de un movimiento de mediados del siglo XVII que propició el uso de formas centrales en los textos pastorales destinados a la arquidiócesis de Lima, pero al parecer nunca se llegó a escribir íntegramente en una lengua central. En el siglo XVIII, los jesuitas publicaron dos reediciones de la gramática-diccionario de Diego de Torres Rubio con apéndices gramaticales y lexicográficos sobre el chinchaysuyo (Torres Rubio \& Figueredo, s.f. (1700) y Torres Rubio, Figueredo et al., 1754.), lo que refleja una voluntad al interior de la orden jesuita, por lo menos, por evangelizar en las hablas centrales. Sin embargo, fue recién a fines del siglo XIX que el redentorista ecuatoriano Juan Lobato publicó los primeros catecismos en lenguas centrales (E.g.: Redentoristas, 1889[1888]; Redentoristas, 1891; Redentoristas, 1900) (23).

Entre el III Concilio Limense y mediados del siglo XVII, Luis Jerónimo de Oré fue el único autor que incorporó lexemas ajenos al quechua cuzqueño en sus textos pastorales. Por lo general, Oré se atuvo al estándar del concilio, pero también inauguró el uso de los llamados "pares lexémicos", en que se yuxtaponen lexemas sureños y

(23) Estas obras se publicaron de forma anónima, pero Paul Rivet las atribuye a Juan Lobato (Rivet \& Créqui-Montfort, 1951: 136-137, 157-158, 203, 290-291, 331-332). Lobato usaba el término "chinchaysuyo" específicamente con referencia al quechua ancashino (ancash-huaylas), en oposición al juninense (quechua huanca). 
centrales. En los cánticos del Symbolo catholico indiano Oré utiliza los chinchaysuyismos tamya y marca junto a sus equivalentes sureños para y llacta ("lluvia” y “pueblo") (Oré, 1992[1598]; cf. Cerrón-Palomino, 1992: 223). Más que un intento por aumentar la inteligibilidad de sus cánticos en la sierra central, éste es un caso de "licencia poética" — los lexemas centrales son reclutados para armar los pares semánticos tan importantes en el arte verbal quechua-. Otra cosa ocurre en el confesionario publicado por Oré en el Rituale seu manuale peruanum, donde aparecen los pares llamca-/vria- ("trabajar"), quericha-/chocri- ("herir"), ayque-/mitica- ("huir"), y ranti-/rana- ("comprar") (1607: $150,152)$. Mientras que en los cánticos los pares a menudo se dan en frases consecutivas, los pares del confesionario están yuxtapuestos de forma casi inmediata, de manera que el segundo término está destinado a remplazar al primero cuando fuera necesario para la inteligibilidad de la pregunta (24).

Quizá el primer quechuista en señalar la necesidad de estudiar las hablas centrales fue el ya mencionado Alonso de Huerta, paisano de Castromonte que regentó las cátedras de quechua de San Marcos y de la catedral de Lima durante las primeras décadas del siglo XVII. En el prólogo de su Arte de la lengua quechua Huerta declara que registrará variantes chinchaysuyo en su descripción de la lengua general, aunque en la práctica lo hace de una forma muy limitada (Huerta, 1993[1616]: 18; cf. CerrónPalomino, 1992: 222) (25). El hecho de que Huerta reconocía al chinchaysuyo como habla(s) sustancialmente distinta(s) se trasluce sobre todo en los certificados de conocimiento del quechua que, como catedrático de San Marcos, otorgaba a los sacerdotes que postulaban a parroquias de indios. Existen por lo menos tres certificados donde Huerta aprueba a postulantes que aprendieron el quechua "según el uso y ejercicio de hablar con los indios chinchaysuyos". En 1616, por ejemplo, Huerta hace el siguiente comentario sobre Luis Mejía, clérigo limeño que buscaba ordenarse "a título de indios": "demas de saber la lengua segun el vso de ablar con los yndios chinchaysuyos al presente la cursa y me oye con mucho cuydado y se va perfiçionando en ella para poder administrarles los s[an]tos sacramentos a los yndios" (A.A.L., serie "Ordenaciones", legajo 2, expediente 31) (26). El quechua que Huerta enseñaba como catedrático era la lengua general de base cuzqueña, pero estaba dispuesto a aprobar a ordenantes o postulantes a parroquias de indios que sólo manejaban el chinchaysuyo. En algunos, casos, como el de Luís Mejía, hablantes del chinchaysuyo posteriormente se "perfeccionaban" siguiendo sus cursos de lengua general, quedando así mejor calificados para utilizar los textos oficiales del quechua pastoral.

(24) Los pares del confesionario de Oré parecen estar destinados a los hablantes del quechua costeño. La forma vria- lleva la nota "en los llanos del arçobispado [de Lima]" (1607: 150). A juzgar por el Lexicon de Domingo de Santo Tomás, el quechua costeño tenía mucho léxico común con el quechua I.

(25) En cuanto a morfología, Huerta menciona el uso de -chau para el caso locativo, del alargamiento vocálico para la primera persona actora, de -ma para la primera persona objeto, y de -ica como sufijo durativo (Huerta, 1993[1616]: 22, 36, 41, 57).

(26) Otras aprobaciones para hablantes del quechua chinchaysuyo se encuentran en: Archivo de San Francisco de Lima, Registro 13 f. 501v (1628); y A. A. L., serie “Ordenaciones", legajo 4, expediente 17 (1628). 
La "chinchaysuyización" del quechua pastoral de mediados del siglo XVII fue limitada, pero no dejó de marcar un cambio importante en las políticas lingüísticas coloniales. Los apologistas más explícitos del quechua chinchaysuyo fueron Fernando de Avendaño en su obra Sermones de los misterios de nuestra Santa Fe Catolica (1649), y el franciscano Diego de Molina en sus Sermones de la quaresma, un sermonario manuscrito redactado entre 1645 y 1649, cuando Molina era doctrinero de Santa María del Valle, cerca de Huánuco. En los prólogos de sus sermonarios, ambos critican el uso indiscriminado de la lengua general entre poblaciones que no la comprendían, y proclaman la necesidad del uso del chinchaysuyo en la arquidiócesis de Lima, a la que Molina denomina "el obispado de Chinchaysuyu" (Avendaño, s.f. (1649) "Prologo al lector”; Molina, 1649: f. 11; Romero, 1928: 75) (27). En realidad, Avendaño no evidencia conocimiento alguno del quechua I más allá de unos pocos lexemas como marca y tamya utilizados de forma muy inconsistente en algunos de sus sermones, que por lo demás son 100\% lengua general. En cambio, Molina explica en su prólogo que los "chinchaysuyus" se distinguen por el uso de la sibilante $\{\mathrm{x}\}$, del sufijo -rcayqui en vez de -rcanqui como segunda persona del pasado, de -ma en vez de -hua como marcador de primera persona objeto, y del locativo - chau en vez de - pi (Molina, 1649: f. 11; Romero, 1928: 75). Sin embargo, estas formas no aparecen en sus sermones, cuya morfología no se desvía en absoluto de la lengua general. Hay una presencia importante de lexemas centrales en los sermones de Molina, pero ésta sigue siendo minoritaria.

Hay dos autores más, ambos cuzqueños que hicieron sus carreras en el arzobispado de Lima, que utilizan lexemas centrales sin pronunciarse explícitamente a favor del quechua chinchaysuyo. El Tratado de los evangelios (1648), el extenso sermonario de Francisco de Avila, contiene chinchaysuyismos como allauca "derecha" e ichoca "izquierda" (p. 29), huallca "poco" (p. 183) y marca "pueblo" (pp. 42, 178, 458), que por lo general aparecen junto a sus equivalentes sureños. La Declaracion copiosa... de la doctrina christiana de Bartolomé Jurado Palomino (1649), una traducción del catecismo del cardenal Roberto Bellarmino, presenta un número importante de lexemas centrales, siempre pospuestos a sus equivalentes sureños en pares lexémicos (CerrónPalomino, 1992: 224). Incluso hay casos donde Jurado Palomino utiliza el ablativo quechua I -pita en vez del sureño - manta (e.g., ff. 3, 5v, 8, 62v). Estos casos parecen ser lapsus o interferencias, explicables por el hecho de que Jurado Palomino había sido párroco de Cabana y Guandoval (Conchucos) por treinta años cuando se publicó la Declaracion copiosa.

La repentina aparición de varios textos con elementos centrales en un período tan breve pudo estar relacionada con las campañas de extirpación de idolatrías, ya que todos fueron impresos o terminados poco antes de la campaña de 1649 (28). La extirpación suponía, y revelaba, falencias en la formación cristiana de la población indígena de la arquidiócesis que pudieron atribuirse a una incomprensión de la lengua general.

(27) El prólogo del sermonario de Molina fue publicado por Carlos Romero (1928) antes de que el original fuera parcialmente destruido en el incendio de la Biblioteca Nacional.

(28) Sin embargo, hay que señalar que los autores que más utilizan elementos centrales (Molina, Jurado Palomino y Castromonte) no hacen referencia alguna a la extirpación. 
También es posible que haya ocurrido una demanda de textos - en especial sermones para ser utilizados en el transcurso mismo de las visitas. Por esos años se hizo prácticamente de rigor en la arquidiócesis de Lima que los textos pastorales utilizaran por lo menos uno que otro lexema central (29). Por otra parte, dada la profundidad de las diferencias entre el quechua I y la lengua general, no era factible escribir en un quechua netamente central ya que quien se propusiera hacerlo estaría partiendo de cero. Sobre todo, se vería en la necesidad de re-elaborar gran parte del léxico y las expresiones teológico-pastorales definidos por los traductores del III Concilio, con resultados que inevitablemente serían cuestionados. Los textos de la época son el producto de dos exigencias contradictorias: debían hablar a los indios chinchaysuyos, pero sin apartarse de la lengua general.

\section{EL QUECHUA DEL APTAYCACHANA}

El Aptaycachana es con creces el más “central” de los textos quechuas coloniales, pero presenta una mezcla confusa de formas sureñas y centrales en la que predominan ampliamente las sureñas. Los casos donde Castromonte utiliza morfemas gramaticales del quechua I parecen lapsus, ya que ocurren de forma excepcional. Por ejemplo, sólo hay dos casos del sufijo - $\hat{c} /-q /$ para marcar la transición de primera a segunda persona (-yqui en la lengua general), y uno del subordinador verbal - $r$ /-r/ (-spa en la lengua general). Según esta lectura, Castromonte habría pretendido escribir en lengua general con algunos lexemas centrales, más o menos como lo hacía Diego de Molina, y los casos de morfemas gramaticales centrales serían interferencias de su quechua nativo. Aunque no he podido identificar muchas de las formas ajenas a la lengua general que utiliza Castromonte, hay evidencia fonológica, morfológica y léxica de que los elementos quechua I del Aptaycachana provienen de un habla cercana al actual Alto Huallaga, la cual habría aprendido en su infancia.

Por otra parte, es probable que el lenguaje heterogéneo del Aptaycachana sea representativo de la práctica catequística y litúrgica en la sierra central, donde los textos en lengua general se habrían modificado en bocas chinchaysuyas. El objetivo de Castromonte pudo haber sido ejemplificar cómo se usaba la lengua general en la sierra central, de manera que las interferencias del quechua I no son necesariamente errores que quedaron sin corregir. Por ejemplo, parece significativo que el alargamiento vocálico y el sufijo - $y$ como marcas de la primera persona actora ocurran varias veces, pero sólo en las respuestas que debían dar los feligreses en los oficios. Es muy plausible que en esta clase de intercambios- ya sea en el ejercico catequístico, en los oficios sacramentales, o en el confesionario- el sacerdote tendiera a utilizar más las formas sureñas debido a su dependencia de los textos impresos, y que el feligrés respondiera en

(29) El chinchaysuyismo no era, sin embargo, una postura universal en la época. El clérigo cuzqueño Juan Roxo Mexía, catedrático de quechua en San Marcos, publicó en 1648 una gramática donde condenó a quienes sostenían que el quechua cuzqueño no era inteligible en la arquidiócesis de Lima (Torero, 1995: 19). Torero habla de "una pugna, por momentos áspera, entre los propiciadores de un quechua cuzqueño pretendidamente heredado del uso cortesano del Imperio Inca, y los defensores del empleo de un habla más cercana a la entendida por la feligresía en cada región" (Torero, 1995: 18). 
su quechua nativo. Por otra parte, tambien hay casos donde el uso de una forma central parece cumplir una función estratégica — es decir, ocurre donde es más necesaria para la comprensión de un texto por hablantes del quechua central-.

\section{1. Fonología y ortografía}

Aparte del tratamiento de la oclusiva posvelar (/q/), discutida más abajo, el Aptaycachana presenta algunas características fonológicas y ortográficas que la distinguen de la tradición del III Concilio. La tendencia a omitir la tilde en palabras escritas con $\{\tilde{\mathrm{n}}\}$ en la lengua general podría reflejar una despalatalización de la / $\tilde{\mathrm{n}} /$, fenómeno común en el quechua I (Cerrón-Palomino, 1987: 157) (30). El Aptaycachana presenta casos del cambio/s/ $/ \mathrm{h} /$ a comienzo de palabra, también frecuente en las hablas quechua I (Cerrón-Palomino, 1987: 173-175), en las palabras huni “alto” (f. 3v), hutuy "gota" (f. 11), y hama- "respirar" (f. 12). Castromonte usa $\{\mathrm{s}\}$ y $\{c ̧\}$ de forma asistemática, a pesar de que en la tradición del III Concilio estas grafías se utilizaban para representar una oposición fonológica. En éste como en otros casos de uso inconsistente de $\{\mathrm{s}\}$ y $\{c ̧\}$, es difícil determinar si esta inconsistencia se debe a la desaparición de la oposición en el habla del autor (lo que es improbable en el caso de Castromonte), o a una dificultad ortográfica. Hay también un par de anomalías que son difíciles de explicar como interferencias centrales: el hecho de que el pluralizador de segunda persona -chic se escriba -chiq en varias ocasiones, y el uso de las formas ytque (</irqi/, "niño") y millati- (</milla-ri-/, "comenzar a despreciar"), donde aparentemente se ha producido un cambio $/ \mathrm{r} />/ \mathrm{t} /$.

\section{1. 1. Uso del acento circunflejo para /q/}

Uno de los aspectos más destacables del Aptaycachana es el uso del acento circunflejo sobre $\{\mathrm{c}, \mathrm{q}[\mathrm{u}]\}$ para representar la oclusiva posvelar /q/ como en ñoca "yo" o ayquey "huir" (31). La necesidad de utilizar una grafía para distinguir la oclusiva posvelar /q/ de la velar/k/ fue largamente debatida por los quechuistas coloniales. Los traductores del III Concilio Limense optaron por no representar la oposición directamente, escribiendo ambos fonemas con $\{\mathrm{c}, \mathrm{q}[\mathrm{u}]\}$. Esta se convirtió en la práctica ortográfica más difundida, pero a mediados del siglo XVII Avila, Avendaño y Jurado Palomino, siguiendo el ejemplo del lingüista jesuita Diego de González Holguin, utilizaron las letras dobladas $\{\mathrm{cc}, \mathrm{qq}[\mathrm{u}]\}$ para representar/q/, recurso poco práctico dado que estos autores también utilizaban letras dobladas para las oclusivas laringalizadas características del cuzqueño.

Aparte de Castromonte, los únicos quechuistas que utilizaron una grafía especial para /q/ fueron Alonso de Huerta y fray Diego de Molina. En su gramática de 1616, Huerta consistentemente utiliza la "virgula" $\left\{{ }^{-}\right\}$y a veces el acento $\left\{{ }^{\prime}\right\}$ sobre $\{\mathrm{c}, \mathrm{q}[\mathrm{u}]\}$

(30) Por ejemplo: callpaçapanam (f. 3v), ricuaspançhicnam (f. 5v), huanuylla (f. 5), huanuy (f. 5v), manaymi (f. 9v).

(31) A falta de la fuente correspondiente, represento la $\{q\}$ con acento circunflejo con una q. La negrita también se utiliza con algunas otras letras para representar la presencia de un acento circunflejo. 
para representar/q/. Por 1649 Molina lamentaba el hecho de que no se usara un "nuevo caracter... con $\mathrm{q}[$ ue $]$ acabaramos de asegurarnos, y persuadirnos, $\mathrm{q}[$ ue $]$ ay estaba el gutural", pero concluye que no era práctico cambiar la ortografía establecida (Molina, 1649: f. 11v y Romero, 1928: 76). Más adelante, sin embargo, Molina propone un sistema mixto donde /q/ se escribe $\{\mathrm{cc}, \mathrm{qq}[\mathrm{u}]\}$ a inicio de sílaba y $\{\hat{\mathrm{c}}\}$ a fin de sílaba, como en ccapaĉ /qapaq/ (f. 14), llaquipayaĉ /llakipayaq/ (f. 15v), y ñoccaicupaĉ / ñuqaykupaq/ (f. 15v) (32).

El sistema utilizado por Castromonte es más sencillo y práctico: usa, o pretende usar, el acento circunflejo en todos los casos de /q/, de modo que lo aplica tanto a $\{\mathrm{q}[\mathrm{u}]\}$ en la sílaba/qi/ $\{$ que $\}$, como a $\{\mathrm{c}\}$ en/qa/ $\{\hat{c} a\}, / q u /\{\hat{c} o\}, / a q /\{a \hat{c}\}, / i q /\{e \hat{c}\}, y / u q /\{$ oĉ $\}$. Parece que al redactar el Aptaycachana Castromonte no estaba completamente acostumbrado a su uso, ya que hay un alto porcentaje de casos de /q/ donde omite el acento circunflejo sobre la $\{\mathrm{c}\}$ o $\{\mathrm{q}[\mathrm{u}]\}$. Además, Castromonte consistentemente escribe llacta /llaqta/ y caylla /qaylla/ sin acento circunflejo (33), lo que indica que no estaba consciente de que las $\{c\}$ s de estos lexemas eran posvelares.

\section{1. 2. Lapsus $\{g\}-\{\hat{c}\}$}

En varias ocasiones Castromonte escribe $\{\mathrm{g}\}$ donde debía escribir $\{\hat{\mathbf{c}}, \mathbf{q}[\mathrm{u}]\}$ (34); $\{\hat{c}, \mathbf{q}[\mathrm{u}]\}$ donde debía escribir $\{\mathrm{g}\}$ (en palabras castellanas) (35); e incluso escribe $\{\mathbf{g}\}$ (con acento circunflejo) donde debía escribir $\{\mathrm{g}\}$ o $\{\hat{\mathrm{c}}, \mathbf{q}[\mathrm{u}]\}$ (36). Estos lapsus indican que en el habla de Castromonte la /q/ se había sonorizado. La sonorización de /q/en [g] en algunos ambientes es justamente una característica del quechua Alto Huallaga en la actualidad (Weber, 1996: 586), y la evidencia del Aptaycachana muestra que este cambio ya se había producido a mediados del siglo XVII. El que Castromonte escriba "comulçar" y "purĉatorio" o "purgatorio" sólo puede explicarse si él se había habituado a reemplazar $\{\mathrm{g}\}$ con $\{\hat{\mathrm{c}}, \mathbf{q}[\mathrm{u}]\}$. Éste es un ejemplo elocuente del peso de la lengua general, que obligaba a Castromonte a corregir su quechua nativo incluso en aquellos rasgos que lo acercaban más al castellano. En muchos morfemas del quechua huanuqueño la posvelar /q/ se había convertido en un sonido cercano al que en el castellano se representa con $\{\mathrm{g}\}$. La utilización de $\{\mathrm{g}\}$ habría solucionado el problema de la diferenciación ortográfica entre /k/ y /q/, de no ser que violaba las normas ortográficas establecidas por el III Concilio Limense.

(32) Es difícil determinar con seguridad cuál era el sistema propuesto por Molina. Sus comentarios sobre el tema son bastantes oscuros, y la ortografía no queda plenamente ejemplificada ya que no la utiliza en sus sermones, donde escribe $\{\mathrm{c}, \mathrm{q}[\mathrm{u}]\}$ tanto para $/ \mathrm{q} /$ como para $/ \mathrm{k} /$.

(33) Escribe llaĉta sólo en uno de catorce casos (f. 14).

(34) Gespinanpaĉmi por Quespinanpaĉmi (f. 9v), comasgan por comasĉan (f. 11).

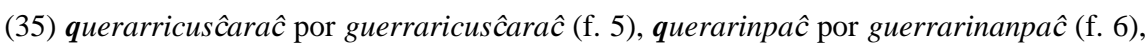

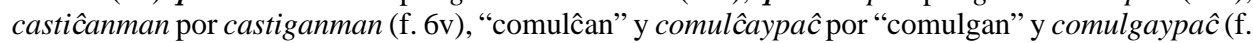
8), Purĉatoriopi por Purgatoriopi (f. 8v), comulĉaĉpa por comulgaĉpa (f. 16).

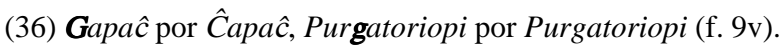




\section{2. Morfología verbal}

\section{2. 1. Alargamiento vocálico o -y para la primera persona actora}

Torero ha notado que el Aptaycachana presenta casos tanto del alargamiento de la última vocal de la raíz verbal como del uso de - $y$ para marcar la primera persona actora. Mientras que la primera forma es emblemática del quechua I, la segunda sólo se da en el quechua de Pacaraos, un dialecto IIA (Torero, 1995: 17). Como ya se señaló, estas formas aparecen sólo en las respuestas de los feligreses, donde son más frecuentes que el -ni de la lengua general y de la mayoría de las hablas de la rama II. En el oficio bautismal encontramos millatimi /millatïmi/ ("renuncio") repetido tres veces (f. 2v), junto a munami /munämi/ ("quiero", f. 3). En las protestaciones previas al viático aparecen las respuestas perdonaymi /perdonaymi/ ("perdono", f. 9) y Manaymi / manaymi/ ("pido", f. 9v). En el desposorio, el novio responde munami /munämi/ y la novia munaymi /munaymi/ (“quiero", f. 13v). Dado que el alargamiento vocálico como marca de la primera persona actora parece haber derivado de la forma - $y$ (CerrónPalomino, 1987: 140), es posible que ambas formas se hayan usado de forma intercambiable en algunas variedades del quechua central.

\section{2. 2. Pluralizador de segunda y tercera persona llapa}

Castromonte consistentemente utiliza llapa como pluralizador de segunda y tercera persona, aunque lo separa del verbo (que en el caso de la segunda persona ya lleva el pluralizador sureño - chic) como si fuera una palabra independiente. Torero, al notar esta característica del quechua del Aptaycachana, señala que un sufijo/-llapa/ se utiliza como pluralizador en las hablas quechua IIB de Ferreñafe y Cajamarca, pero también "en algunas hablas del dialecto QI de Huánuco-Huallaga" (Torero, 1995: 17), lo que explicaría su uso en el Aptaycachana. Independientemente de si éste era o no el pluralizador del habla nativa de Castromonte, llapa es usado en el Aptaycachana como un recurso suplementario para dar a entender la pluralidad de la segunda o tercera persona a hablantes del quechua I. El sistema de pluralización de la lengua general (/-chik/ para la segunda persona y /-ku/ para la tercera, pospuestos al sufijo de persona) es completamente distinto al de las hablas centrales, que ocupan un solo pluralizador para la segunda y tercera persona (/-yä-/ o /-päku-/, según los dialectos) que se antepone al sufijo de persona.

En la mayoría de los casos de segunda persona plural, llapa se añade a-chic, como en:

cayta çhasquispam ari Diospa graçianta çhasquinquiçhic llapa (f. 4)

/kayta chaskispam arí Diospa gracianta chaskinkichik llapa/

"al recibir esto ustedes recibirán la gracia de Dios"

O, en el caso del imperativo:

huçhayquicunacta visçhuyçhic llapa (f. 7)

/huchaykikunakta wischuychik llapa/

"boten sus pecados" 
Hay un caso donde sólo se utiliza llapa para pluralizar la segunda persona:

Huarmi cactaĉa yçhoĉ ricrayquipitâ̂ siriçhi llapa (f. 2v)

/warmi kaqtaqa ichuq rikraykipitaq sirichiy llapa/

"recuesten a los [bebés] que son mujeres en su brazo izquierdo"

En varios casos se omite llapa, pero generalmente la pluralidad de la segunda persona se expresa dos veces, de forma redundante. Se trata de un recurso para hacer inequívoca la pluralidad para un público que no reconocía el pluralizador /-chik/ sin modificar la morfología sureña de las palabras.

Llapa también se utiliza para el plural de tercera persona, aunque sin la intromisión del pluralizador sureño (-cu /-ku/), como en el caso siguiente:

çhay sichpapura tucuytam yaçhaĉcuna cognaçion espiritual ñin llapa (f. 6)

/chay sichpapura tukuytam yachaqkuna "cognación espiritual” ñin llapa/

"los sabios llaman "cognación espiritual" a este emparentamiento"

La ausencia del pluralizador - $c u$ probablemente se deba a que este se prestaba a confusión con el sufijo interrogativo, que es/-ku/y no/-chu/en muchas hablas centrales.

\section{2. 3. Otros morfemas verbales del quechua I}

En adelante enumero los casos donde Castromonte utiliza:

1) - $r$ como el subordinador verbal sin cambio de actor (-spa en los demás casos);

2) - $\hat{c}$ /-q/ para la transición de primera a segunda persona (-yqui);

3) -ma para la primera persona objeto (-hua);

4) -rĉayqui para la segunda persona del pasado (-rĉanqui):

1)

ytque hinallaraĉmi callpaynaĉ canchiq, manaraĉ confirmaçion sacramentocta çhasquirca (f. 3v)

/itqi hinallaraqmi kallpaynaq kanchik manaraq confirmacion sacramentokta chaskirqa/

"somos débiles como niños cuando aún no hemos recibido el sacramento de la confirmación"

\section{2)}

quiquin sacramentocta çhasquinayquiçhicta villaptiĉ.raĉmi, ançha santo, ançha yupaychana casĉanta soncoyquichic vnançhanĉa (f. 5v)

/kikin sacramentokta chaskinaykichikta willaptiqraqmi ancha santo, ancha yupaychana kasqanta sunquykichik unanchanqa/

"cuando yo les avise cómo han de recibir el sacramento, ustedes entenderán que es muy santo y muy estimable" 
Santo Angelniquihuan tinquiçhahuay, gloriayquiman çhayamuspa huyñay

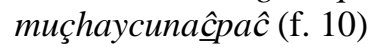

/santo ángelniykiwan tinkichaway, gloriaykiman chayamuspa wiñay muchaykunaqpaq/

"úneme con tu santo ángel, para que llegando a tu gloria te adore para siempre" [En estos casos, la forma sureña de la transición de primera a segunda persona (-yqui) habría sido ambigua con la segunda persona (villaptiyquiraĉmi "cuando tú avises", muçhaycunayquipaĉ "para que tú adores"), de manera que la forma central parece haberse utilizado deliberadamente para resolver la ambigüedad.]

\section{3)}

ayca huçhaçapatapas cuyapayamanĉataĉmi Diosniĉa (f10)

/hayka huchasapatapas kuyapayamanqataqmi Diosniyqa/

"mi Dios me compadecerá por pecador que sea"

Dios comasgan yuyaynihuan (f11)

/Dios qumasqan yuyayniywan/

"con mi entendimiento que me dio Dios"

4)

atinacuyta çuĉariçhinacuyta ĉallarirêayquiçhiq llapa (f. 4)

/atinakuyta, suqarichinakuyta qallarirqaykichik llapa/

"ustedes empezaron a competir y a luchar"

llapan runa quespinanpaĉmi çruspi huañurĉayqui (f. 9)

/llapan runa qispinanpaqmi cruzpi wañurqayki/

"tú moriste en la cruz para que todas las personas se salven"

llapa runa Gespinanpaĉmi cruzpi huañurĉayq. (f. 9v)

/llapa runa qispinanpaqmi cruzpi wañurqayki/

"tú moriste en la cruz para que todas las personas se salven"

ĉammi quespiçhihuarĉayqui, Cruspi huañuspa (f. 12)

/qammi qispichiwarqayki cruzpi wañuspa/

"tú me salvaste al morir en la cruz"

\section{3. Morfología nominal}

Es curioso que se den muy pocas formas centrales en la morfología nominal del Aptaycachana. No he podido identificar sufijos de casos centrales, como el locativo /-chaw/ (/-pi/ en lengua general) o el ablativo /-pita/ (/-manta/), que se mencionan e incluso utilizan en otros textos de la época. 
Hay un caso del uso del alargamiento vocálico en vez de -y para la primera persona posesora:

churillayta casaraçhicunapaĉ ymallactapas cuyallahuay (f. 4v)

/churillayta casarachikunäpaq imallaktapas kuyallaway/

"dame algo, por favor, para casar a mi hija"

Hay también dos casos de un sufijo nominalizador -nni identificable con un sufijo /-ni/ que David Weber, en su descripción del quechua Alto Huallaga, llama el "participio negativo". Este sufijo indica que "el evento indicado por el verbo al que -:ni va afijado no ha ocurrido" (Weber, 1996: 382):

çhay graçiata çhasquicuspaĉa ari, mançhannillam acuyhuan tincunquiçhic. penĉannillam çhristianom cani ñinquiçhic (f. 7v)

/Chay graciata chaskikuspaqa arí, manchanillam akuywan tinkunkichik, pinqanillam “cristianom kani” ñinkichik./

“después de recibir esta gracia, ustedes se enfrentarán al malvado [demonio] sin temor, y se declararán cristianos sin vergüenza"

El mismo contenido se transmite en la lengua general con la construcción /mana [raíz verbal]-sqa/. Ya que las gramáticas de Parker para el quechua Ancash-Huailas (Parker, 1976) y Cerrón-Palomino para el Huanca (Cerrón-Palomino, 1976) no registran este sufijo, éste podría ser un caso de uso de un morfema gramatical característico del quechua Alto Huallaga.

\section{4. Léxico}

Castromonte utiliza varios de los chinchaysuyismos corrientes en los textos de la época, como allauĉa "derecha" y ichoĉ "izquierda" (f. 2), ćaya- "llamar" (ff. 11v, 12 y 13), çhuscu "cuatro" (f. 14v), y huayta "flor" (ff. 4v y 5). También aparecen otros de uso menos común, como chara- "tomar con la mano" (ff. 6, 9, 12v), hacu "ropa" (f. 7), mircapa "fiambre" (f. 16), y yarpa- "recordar" (f. 10). Como era de esperarse, el léxico chinchaysuyo de Castromonte es más cercano a los actuales dialectos Ancash-Huailas y (sobre todo) Alto Huallaga que al Junín-Huanca, como se ve en el uso de chacha "anciano/anciana" (ff. 3v y 6v) (Parker \& Chávez, 1976: 44; Weber et al., 1998: 134), hacu "ropa" (f. 7) (Parker \& Chávez, 1976: 61; Weber et al., 1998: 266) (37), y huallca "poco" (f. 11) (Parker \& Chávez, 1976: 186; Weber et al., 1998: 580). Los diccionarios modernos del quechua Alto Huallaga y Anchash-Huailas también registran la distinción que establece Castromonte entre aru- y vria- (ff. 15 y 15v), en cuanto /aru-/ es trabajo

(37) Aunque ambos le dan el sentido de "manta". $C f$. Torres Rubio, Figueredo et al., 1754: f. 216v para la acepción "todo tipo de vestido". 
en general, y /urya-/ se refiere específicamente al trabajo agrícola (Weber et al., 1998: 69, 569; Parker \& Chávez, 1976: 37, 182).

Es difícil determinar según qué criterio se eligen los términos que se dan en sus variantes centrales. Por ejemplo, Castromonte usa la forma sureña llacta para "pueblo", a pesar de que marca era uno de los chinchaysuyismos más corrientes en el quechua pastoral de la época (38). Algunos lexemas centrales como huallca y yarpa- sólo aparecen de forma excepcional, prefiriéndose sus equivalentes sureños pissi y yuya-, sin que haya un patrón claro en la variación. La variación ollĉco/çari ("varón"), sin embargo, es sistemática: ĉari, la forma sureña, se utiliza durante la plática de la confirmación en contex tos netamente retóricos, pero oll $̂$ co es utilizado para determinar el sexo de un bebé antes del bautismo, ya que en este caso se necesitaba una respuesta certera de personas que no reconocerían la palabra ĉari.

El uso de cheĉanmi ñi- para "creer" parece ser una respuesta a las diferencias léxicas entre el quechua central y el sureño. El término canónico, utilizado casi universalmente en la literatura pastoral, era $i \tilde{n} i$-, un compuesto que literalmente significa "decir 'sî́" (/'i' ñi-/) a base de un afirmativo /i/ propio de la zona cuzqueña (Torres Rubio, Figueredo et al., 1754: f. 54v). El término iñi- habría carecido de sentido en la sierra central, donde el afirmativo era aumi /awmi/ (Torres Rubio, Figueredo et al., 1754: f. 216v). Si bien cheĉanmi ñi- /"chiqanmi' ñi-/ (“decir 'es verdad"”) no es un chinchaysuyismo, su uso parece reflejar una sensibilidad al léxico central.

Finalmente, el Aptaycachana manifiesta algunas idiosincrasias léxicas que no son fácilmente identificables como chinchaysuyismos, sobre todo el uso ocasional de pissi como negador en vez de mana, como en:

ymactapas pissi casaracunanpaĉ yaçhaĉcunaĉa, huillacamuyçhic llapa (f. 13) /imaktapas pisi casarakunanpaq yachaqkunaqa, willakamuychik llapa/

los que sepan algo que impida el matrimonio, avisen de ello

\section{CRITERIOS DE LA EDICIÓN}

Esta edición del Aptaycachana sigue las normas utilizadas por Gerald Taylor en sus ediciones castellanas del manuscrito de Huarochirí (1999[1987]), con la importante excepción de que no he intentado una versión "normalizada", o transcripción al alfabeto fonológico con puntuación moderna, de los textos quechuas. Esto se debe a tres motivos principales. El primero es que cualquier normalización resultaría un tanto arbitraria, dado que los textos quechuas del Aptaycachana son dialectalmente heterogéneos y no pueden reducirse a un sistema fonológico único. En segundo lugar, una de las funciones principales de la normalización ha sido la de servir como una etapa intermedia entre el original y la traducción, justificando la interpretación de los pasajes de difícil comprensión que siempre abundan en los textos quechuas de autoría indígena. Este criterio no se aplica al Aptaycachana por tratarse de un texto pastoral redactado por un español, que

(38) Marca aparece una sola vez, yuxtapuesto a llacta (f. 13v). 
por lo tanto presenta pocos problemas de lectura. Finalmente, el hecho de que el Aptaycachana es una colección de varios textos quechuas (algunos de ellos muy breves) separados por textos castellanos dificultaba la inserción de versiones normalizadas de una forma que permitiera tanto el contraste de las versiones como su lectura continua.

He optado por presentar dos versiones paralelas: una versión paleográfica ("versión A"), y una versión completa en las páginas opuestas con los textos quechuas traducidos al castellano ("versión B"). En la versión A, las notas a pie de página señalan cambios, correcciones o errores en el original (39). Aunque no mantengo la división en renglones del manuscrito, he intentado reproducir su formato — por ejemplo, en la división en párrafos y en el uso de letras de mayor tamaño para los encabezadosutilizado la siguiente simbología en la transcripción:

- Una cursiva indica una lectura paleográfica incierta.

- La barra oblicua (/) indica el fin de un renglón.

-Un número de folio entre dos barras oblicuas indica un cambio de folio o de cara (por ejemplo, "/f. 2v/" indica el paso del recto al verso del segundo folio).

-Los corchetes $<>$ se utilizan al transcribir porciones de texto que se insertaron entre renglones o en el margen.

- Los corchetes \{\} se utilizan al transcribir porciones de texto tachadas.

- Una letra en negrita indica que en el original la letra correspondiente lleva un acento circunflejo. La negrita se utiliza princilpamente para la $\{\mathrm{q}\}$ con acento circunflejo, por no disponer de la fuente, a diferencia de lo que ocurre en el caso de la $\{\hat{c}\}$.

En las notas a pie de página:

= significa "corresponde a", de manera que la palabra anotada debe leerse como aparece en la nota.

sindica que la palabra anotada resulta de la corrección de una forma original, la cual se pone en la nota a continuación del símbolo.

La versión B mantiene el formato del original para facilitar el contraste con la versión A. Los textos que están en castellano en el original aparecen en letra cursiva para distinguirlos de las traducciones, y modernizados en su puntuación y ortografía para facilitar su lectura. En las traducciones no distingo aquellas palabras que corresponden a préstamos del castellano como se ha hecho en otras ediciones de textos quechuas, ya que estos préstamos son demasiado abundantes. Los enunciados latinos y castellanos citados al interior de enunciados quechuas van subrayados, como lo hace Castromonte ocasionalmente en el original. Una letra cursiva en la traducción indica una lectura insegura del texto quechua. Los corchetes [] indican palabras que he añadido a los textos castellanos para facilitar la comprensión. Las notas a pie de página indican problemas de traducción, o dan informaciones filológicas o contextuales.

(39) No indico los casos donde se ha omitido el acento circunflejo de una $\{\hat{\mathbf{c}}, \mathbf{q}[\mathbf{u}]\}$, o la tilde de una $\{\tilde{n}\}$, ya que son demasiado frecuentes. 


\section{Agradecimientos}

Esta edición fue realizada como parte de una investigación más amplia sobre el quechua pastoral financiada por el Departamento de Educación de los Estados Unidos (Doctoral Dissertation Research Abroad Program) y por la National Science Foundation. Agradezco a Laura Gutiérrez y Melecio Tineo, cuya labor de catalogación en el Archivo Arzobispal de Lima me permitió ubicar documentación relativa a Juan de Castromonte, y a Rodolfo Cerrón-Palomino por sus comentarios a un borrador del estudio preliminar. 
Aptaycaçhana/ .O./ Manual en que se contiene todo lo q. los curas an de deçir/ y enseñar a los yndios en su lengua quando les administran/ los santos sacramentos de la ygle=/sia./ Sacado fielmente del Ritual Romano de la santidad/de Paulo Quinto, y traducido en la len=/gua general Çhinçhay suyo, del/ Peru por el B. ${ }^{\mathrm{r}}$ Juan de castro=/monte cura ynterim del Be/neficio de Guanca=/bamba /f. 1v blanco//f. 2/

\section{Notable/ Para Bautizar en casos de neçessidad/}

Cosa es muy llana q. para haçer verdadero sacramento ba=/sta q. el que quiere administrarle, sabiendo bien las palabras/de la forma, tenga yntençion de Baptizar al q. tiene presente/ sea hombre, o muger, y asi eçhandole el agua a la criatu=/ra en la cabesa, si puede ser, o en la mano, o pie (sino esta/ fuera del vientre de la madre, y ay Peligro) diga la forma/ ego te Baptizo in nomine Patris, et Filii et spiritus sancti. Amen/

Si la neçessidad diere lugar dira el q. a de Bauti=/zar, ollĉoçhu ychá huarmiçhu? Responderan los sircunstantes Oll=/ĉom. vl. Huarmim. Luego dira el que Baptiza. Ymam sutin canĉa?/ Respondera el Padrino, o la Madrina, Juan, vl. Maria, y en/ diçiendole el Nombre q. la criatura a de tener dira el q. la/ Baptiza la forma. N. ego te Baptizo. etc. ut supra./

Estas palabras de la forma del Bautismo (q. para/ los casos de neçessidad se an de enseñar a los Yndios mas capa=/çes) diçen asi en la lengua general quiçhua çhinçhaysuyu./ N. Noĉam Baptizayqui, Yayap, Çhurip, Spiritu Santop sutimpi. Amen./

Si se duda si viue la criatura dira debajo de condiçion/

Si viuis. ego te Baptizo. etc. $\%$

Causaptiquiça ñocam Baptizayqui, Yayap, Churip. etc. ${ }^{a} /$

Si es algun monstruo q. no tiene forma humana dira si tu/ es homo. ego te Baptizo./

Runa captiquiĉa Ñoĉam Baptizayqui, Yayap etc ${ }^{a}$./

Quando el niño o niña que se Bautizo sin la/ solemnidad de la yglesia, se llebo a ella, y suplio lo q. faltaba, des=/pues de todo dira el saçerdote al Padrino, o Madrina = Cay $\mathrm{Hu}=/$ ambracta onĉoptin, Bautismo yacucta çhuraĉnimmi sacramento=/cta rurarĉam, chay caĉtaĉmi cay Ytquehuan Yayan Mamanhuampas/ animampi ayllulla tucurĉan, camĉa ari manam aylluçhu tucun=/qui cunan, yçhaĉa cuyanayquim cay Huambracta: christiano cau=/saytapas, yaçhaçhinayquitaĉmi, ripullay Dioshuan: Paytaĉ yanapa=/ ssunq. açhca Huambracta marĉacunayquiçhiqpac. Amen. /f. 2v/

\section{Notable./ Para Bautizar solemnemente/}

Si los q. se an de Bautizar son munchos, varones, y Mugeres, dira/ el saçerdote a los Padrinos en comun. = Marĉacusĉayquiçhicta/ ollco (1) caĉtaĉa allauĉa ricrayquipi siriçhiçhiq. Huarmi cactaĉa/ yçhoĉ ricrayquipitaĉ siriçhi llapa./

Luego preguntara el sacerdote por los Padrinos diçiendo/

(1) = ollêo 
Aptaycachana, o manual en que se contiene todo lo que los curas han de decir y enseñar a los indios en su lengua cuando les administran los santos sacramentos de la Iglesia. Sacado fielmente del Ritual Romano de la santidad de Pablo V, y traducido en la lengua general chinchaysuyo del Perú por el bachiller Juan de Castromonte, cura interino del beneficio de Huancabamba.

\section{Notable para bautizar en casos de necesidad.}

Cosa es muy llana que para hacer verdadero sacramento basta que el que quiere administrarle, sabiendo bien las palabras de la forma, tenga intención de bautizar al que tiene presente, sea hombre o mujer, y así, echándole el agua a la criatura en la cabeza, si puede ser, o en la mano, o pie (si no está fuera del vientre de la madre, y hay peligro) diga la forma "Ego te baptizo in nomine Patris et Filii et Spiritus Sancti. Amen".

Si la necesidad diere lugar, dirá el que ha de bautizar: ¿Es hombre o mujer? Responderán los circunstantes: Es hombre o Es mujer. Luego dirá el que bautiza: ¿Cuál será su nombre? Responderá el padrino o la madrina: Juan o María, y en diciéndole el nombre que la criatura ha de tener, dirá el que la bautiza la forma "N. ego te Baptizo" etc., ut supra.

Estas palabras de la forma del bautismo (que para los casos de necesidad se han de enseñar a los indios más capaces) dicen así en la lengua general quechua chinchaysuyu: N., yo te bautizo en el nombre del Padre, del Hijo, y del Espíritu Santo. Amén.

Si se duda si vive la criatura, dirá debajo de condición "Si vivis ego te baptizo..." etc.: Si vives, yo te bautizo en el nombre del Padre, del Hijo... etc.

Si es algún monstruo que no tiene forma humana dirá "Si tu es homo ego te baptizo...": Si eres un ser humano, yo te bautizo en el nombre del Padre... etc.

Cuando el niño o niña que se bautizó sin la solemnidad de la iglesia, se llevó a ella, y suplió lo que faltaba, después de todo dirá el sacerdote al padrino o madrina: La persona que le puso el agua del bautismo a este niño cuando enfermó hizo el sacramento. Esta persona se hizo pariente espiritual del niño (1) y de sus padres. Tú no te conviertes en pariente espiritual, pero debes amar a este niño y enseñarle la vida cristiana. Ve con Dios, y que Él te ayude para ser padrino/madrina de muchos niños. Amén.

\section{Notable para bautizar solemnemente.}

Si los que se han de bautizar son muchos, varones y mujeres, dirá el sacerdote a los padrinos en común: Si el niño que llevan es hombre, recuéstenlo en su brazo derecho. Si es mujer, recuéstenlo en su brazo izquierdo.

Luego preguntará el sacerdote por los padrinos diciendo:

(1) ytque, probablemente derivado de /irqi/, aunque se ha registrado la forma /iti/ ("el bebé que mama”) para el quechua Alto Huallaga (Weber et. al. 1998: 263). 
Saçer. Pim cay Ytqueta marĉacunĉa? Responde el Padrino Ñoĉam/

Saçer. Ymam sutin canĉa? Responde Juan o Maria./

Saçer. Ymatam Diospa Yglesianmanta mañanqui?/

Padri. Feetam./

Saçer. Feeĉa imatam ĉosunqui?/

Padri. Viñay causaytam./

Saçer. Viñay causayman çhayayta munaspaĉa ari Diospa camachicus=/ĉanta huaçayçhanqui (2). Apu Diosniquicta tucuy sonĉoyquihuan/ hinantin animayquihuan, llapan yuyayniquihuan cuyanqui./ Runa masiquictari quiquita (3) hinatac mayhuanqui./ Dira luego lo q. se sigue en el ritual, y quando aya de entrar/ en la yglesia dira al Padrino, o madrina marĉamuy, y po=/niendo la estola sobre la cabesa del niño, o niña diga/

N. Yaycuy Diospa huasinman, huiñay causaypi Jesuçhistohuan (4)/çhaniiqui cananpaĉ. Luego a los Padrinos. Yñi<nic >ta ñiçhic, y en acabando de deçir el cre=/do dira, Yayaycuctatac ñi, vl. niçhic si fuerint Plures./

\section{Abrenuntias Satanas? etc./}

Saçer. - N. Millatinquiçhu supay satanasta?/

Padr. - Millatimi./

Saçer. - Tucuy rurasĉantaĉa? Resp. millatimi./

Saçer. - Tucuy apuscaçhaynintahuançhu Resp. millatimi/

Despues de auer vngido con el santo oleo de los cathecumenos di=/ra el saçerdote respondiendole el Padrino./

Saçer. - Çheĉammi ninquiçhu llapa atipac Dios Yaya hanaĉ paçhap cay/ pachap ruraquen cascanta?/

Padr. - Çheĉammi niñim (5)./

Saçer. Çheĉanmi ñinquiçhu apunçhiq Jesuçhristo paypa çapay çhurin/f. 3/ Runatucusĉanta, cruspi huañusĉantapas./

Padr. - Çheĉanmi ñinim./

Saçer. - Çheĉanmi ñinquiçhu Espiritu Santocta, Santa Yglesia Catholicacta, San=/ tocunap hucllaçhacuyninta, huçhacunap pampaçhayninta, aychap/ causaripuyninta, viñay causaytahuampas, çheĉanmi ñinquitacçhu./

Padr. - Çheĉanmi ñinim./

Sacer. - Munanquiçhu Bautizasĉa cayta?/

Padr. - Munami./
(2) = huaĉayçhanqui
(3) = quiquiqui $[\mathrm{c}] \mathrm{ta}$
(4) = Jesuçhristohuan
$(5)=$ ñinim 
Sacerdote: ¿Quién cargará a este niño? Responde el padrino: Yo.

Sacerdote: ¿Cuál será su nombre? Responde: Juan o María.

Sacerdote: ¿Qué pides de la iglesia de Dios?

Padrino: Fe.

Sacerdote: ¿Qué te dará la fe?

Padrino: Vida eterna.

Sacerdote: Si quieres llegar a la vida eterna, cumple los mandamientos de Dios. Ama a tu señor Dios con todo tu corazón, con toda tu alma y con toda tu mente. Quiere a tus prójimos como a ti mismo (2).

Dirá luego lo que se sigue en el ritual, y cuando haya de entrar en la iglesia dirá al padrino, o madrina: Tráelo. Y poniendo la estola sobre la cabeza del niño o niña diga: N., entra a la casa de Dios, para que tu recompensa sea con Jesucristo en la vida eterna (3).

Luego a los padrinos: Digan el Credo, y en acabando de decir el Credo dirá, Di el Padre Nuestro vel Digan, si fuerint plures.

\section{Abrenuntias satanas? etc. (4)}

Sacerdote: ¿Renuncias (5) al demonio Satanás?

Padrino: Renuncio.

Sacerdote: ¿Y a todas sus obras? Responda: Renuncio.

Sacerdote: ¿Y a toda su soberbia? Responda: Renuncio.

Después de haber ungido con el santo óleo de los catecúmenos dirá el sacerdote, respondiéndole el padrino:

Sacerdote: ¿Crees en Dios Padre todopoderoso, creador del cielo y la tierra?

Padrino: Sí, creo.

Sacerdote: ¿Crees en la encarnación de Jesucristo nuestro señor su único hijo, y en su muerte en la cruz?

Padrino: Sí, creo.

Sacerdote: ¿Crees en el Espíritu Santo, en la Santa Iglesia católica, en la comunión de los santos, en el perdón de los pecados, en la resurrección de la carne y en la vida eterna?

Padrino: Sí, creo.

Sacerdote: ¿Quieres ser bautizado?

Padrino: Sí, quiero.

(2) Esta admonición no es traducida ni por Oré ni por Bocanegra. "Si igitur vis ad vitam ingredi, serua mandata: Diliges Dominum Deum tuum ex toto corde tuo, et ex tota anima tua, et ex tota mente tua, et proximum tuum sicut te ipsum" (Pablo V, 1649: 14).

(3) Esta invitación no es traducida en los manuales de Oré y Bocanegra. "Ingredere in templum Dei, ut habeas partem cum Christo in vitam aeternam. Amen" (Pablo V, 1649: 14).

(4) La parte del oficio bautismal que sigue es traducida por Bocanegra sólo en su sección para el bautismo de adultos.

(5) El término que Castromonte emplea para abrenuntias es millati-. Juan Pérez Bocanegra también usa la raíz milla-, que podría traducirse mejor como "abominar" (Pérez Bocanegra, 1631: 53-54). 
El Padrino tendra al niño, o niña sobre la Pila, y si ay Ma=/drina le tenga de los Pies, y el sacerdote Bautize como ordena/ el ritual $=\mathrm{Y}$ auiendole dado el capillo, y la candela dira/ Saçer. - Dioshuan riçhiq/

Padr. - Amen./

Saçer. Vyarihuayçhiqçhuricuna cay marĉacusĉayquihuan, o marĉacus=/ĉayquiçhichuan, Paypa yayanhuan, Mamanhuantacmi animayqui=/pi ançha $\{$ yata $\}$ ayllulla tucurĉonqui

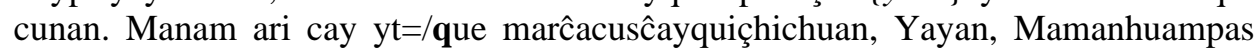
casaracu=/nayqui yaçhacunçhu. Çhaymanta cay Baptizachicusĉayquitam çhuriquita hina cuyanayqui: çristiano causaytapas yaçhaçhinay=/quitacmi. hinaptiquiça Diosmi yupayçhasunqui. Ripullay Di=/oshuan, Paytaĉ yanapasunqui açhca huamracta marĉacunay=/quiçhicpac. Amen. = Fin de lo q. toca a la administraçion/ del santo Bautismo./

\section{Para la confirmaçion/}

Porq. la administraçion deste sacramento pertenese al obispo/ el cura podra haçerles la platica siguiente a los q. se/ vinieren a confirmar, y si el tiempo no diere lugar a tanto/ podra sacar della lo q. fuere n.ario para la ynstrucçion/ de sus feligreses./

Santa yglesia mamançhicpa sacramenton/ Confirmaçion sutiyocta çhasquiĉmi cay yglesiapi tanta canqui=/f.3v/çhiq çhuricuna, señor Arçobispo Apunchicpa cayllampi./

Cay sacramentocta çhasquiĉcunaĉa, may/ çhica ari ĉapâ̂ Diosninchicta muçhaycunayquiçhic (6),/ çhica mayhuacuc sonĉonhuan cay sacramentocta çhasqui=/ cuçhun ñispa Apunçhic señor Arçobispocta cay llactayqui=/çhicman pusamusĉanraycu: chayta sonçoyquiçhic (7) alli çhas=/quinanpac, cay confirmaçion sacramentoctari ancha yupay=/çhanayquiçhicmi hina soncoypi Diospa graçianhuan ruras=/ĉa cananpac vyarihuayçhiq cunan./

Cay sacramentocta ari confirmaçion ñin=/çhiq, taquiariçhicuê, sinçhiyaçhicuc sacramento ñinançhicta (8)/ Ña Bautizasĉa runaĉa confirmaçionta çhasquispa, sancto chris=/mahuan (Apunchiq S. ${ }^{r}$ Arçobispo) vrcumpi llusispa suc an=/çha yupay, ançha santo simicta rimaptillanpunim ari muçuĉ/callpata chasquin. Animampas callpaçapanam tucun/auĉancunacta atiparĉunanpac, Çhayraycu (Çhuricuna) sin=/çhiyacuna Sacramento ñinçhiq, confirmaçion sacramento/ ñispa./

(6) $\leq$ muçhaycunançhic

(7) $=$ soncoyquiçhic

(8) nota marginal: "Explicacion de lo q. es el sacramento" 
El padrino tendrá al niño o niña sobre la pila, y si hay madrina le tenga de los pies, y el sacerdote bautice como ordena el ritual. Y habiéndole dado el capillo y la candela dirá:

Sacerdote: Vayan con Dios.

Padrino: Amén.

Sacerdote: Escúchenme hijos: ustedes se han hecho parientes espirituales con el niño que han cargado y con sus padres. No podrán casarse con este niño ni con sus padres. Además, deben amar a sus ahijados como a sus propios hijos, y enseñarles la vida cristiana. Si así lo hacen, Dios los estimará. Vayan con Dios, y que Él los ayude a apadrinar muchos niños. Amén. Fin de lo que toca a la administración del santo bautismo.

\section{Para la confirmación.}

Porque la administración de este sacramento pertenece al obispo, el cura podrá hacerles la plática siguiente a los que se vinieren a confirmar, y si el tiempo no diere lugar a tanto, podrá sacar de ella lo que fuere necesario para la instrucción de sus feligreses.

Hijos míos, ustedes están reunidos en esta iglesia en presencia de nuestro señor el arzobispo para recibir el sacramento de nuestra madre la Santa Iglesia llamado "confirmación".

Ustedes que recibirán este sacramento verdaderamente deben agradecer a Dios por su compasión al haber traído a nuestro señor el arzobispo a su pueblo para que les administre este sacramento. Para que lo reciban bien, deben estimar mucho este sacramento de la confirmación, y para que con la gracia de Dios esto se logre en sus corazones, escúchenme ahora.

A este sacramento le llamamos "confirmación”, pero deberíamos llamarlo el sacramento que consolida y fortalece (6). La persona ya bautizada recibe nuevas fuerzas en el instante cuando nuestro señor el arzobispo, ungiéndole la frente con el santo crisma, dice unas palabras muy estimables y muy santas. Su alma se vuelve fuerte para poder vencer a sus enemigos. Por eso, hijos míos, cuando hablamos del sacramento de la confirmación estamos hablando del sacramento que fortalece.

(6) Nota marginal: "Explicación de lo que es el sacramento" 
Cay ñisĉayta alli yuyaycuccunaĉa ari, ña/ Baptizasĉa caspaĉa, confirmaçionta çhasquinanpac callpaçha=/cunĉapunim (9). Baptizasĉalla runaĉa ayca çhaçha caspapas/ Ytque hinallaracmi cay carĉoy paçhapi purin, pissi callpa hi=/nallaracmi animanĉa. Allirac çhasquihuayçhiq: Baptis=/mo Sacramentocta çhasquicuspam muçuĉ runa ricarinçhiq,/ Çhay Bautismopin Jesuçhristoçhuriyacuanchiqpaypa glori=/antaeredenançhicpaĉ, çhaypas Ytque hinallaracmi callpaynaĉ/ cançhiq, manaraĉ confirmaçion sacramentocta çhasquirĉa, çhas=/quihuançhu sonçoyqui? allichu huc llullu ytque hatun/ callpaçapa çari runahuan tincunman? camaçhus, ç<h>ayta ati=/panman? pissim. Pitac çhayca Auĉançhiqcuna? S. Pablo<c >ta/ tapuycussun. Pim Aucaycu santo Apostol? Principes/ tenebraris tutapayaĉ yanauyaçhcaĉpa apuncunam ñimmi/ ari, callpaçapa supaycunam Auĉançhic, mayçhay (10) çari, huni /f. 4/ Gigantem çheĉnequençhiq. Chayĉa supaycuna runayoĉçhu? Sa=/ yayniyoĉchu? Gigante runa çari sayaĉ ñinaypac? Ançha ya=/çhaĉmi, maymaypam yallirĉoanchiq, amauta cayninpi, pissim/ayca yaçhac runapas paymanĉa pactanmançhu: ñinaytam hatun/ sayacmi Auĉançhic ñiquiçhic ari. alliçhu chayĉa pissi callpa/vmutulla runa mançhay carihuan auĉanacunman? manam/ churicuna vmutullan cançhiq ñoĉançhicĉa, payĉa sonĉon yallim/ Vyaypas Santa Yglesiap Dotornin san Augustinta scitote vos/ cum callido, antiquo, et veternoso inimico suscepisse certamen (11)/ yaçhayçhiq çhuricuna (ñimmi Santo Dotor) Baptismocta çhas=/quisĉayquiçhic $\mathrm{pu}<\mathrm{n}>\mathrm{chaumi}$ amauta, auquintâ̂ millpuyllacta/ yuyaçhcaĉ auĉahuanmi, atinacuyta çuĉariçhinacuyta ĉalla=/rirĉayquiçhiq llapa, Atô̂ Atoĉ sonĉohuanmi, huyñay çhecni=/ cuĉhuanmi, auĉanacunayqui canĉa, ymahinam rupay onĉoy=/manta hapisĉacuna, calenturan sonĉonta rauraçhiptin ya=/cullacta yuyaçhcan, mama ĉçhactapas millpuyman ñiçhcan,/ chay quiquillantacmi auĉayquiçhicpas (gloriaman quespi=/nayquicta çhi<qui>cuspa) soncon rauraptin yacucta hinalla vpuy=/man ñissunquichic. Ñinantam ari ñihuançhiq yaçhac son=/ĉo San August. çupaycunam ari auĉançhiq churicuna, pay/ cunam ama quespinmançhu ñihuançhiq, ama çhay huy=/ñay cusicuyman chayanmançhu ñispam, huçhaman çha=/yachihuançhic Ytqueĉta (12) hina cay paçhapi cussicuy ricçhaĉ/llahuan llullaçhispa, tucuy mita hamutayninhuammi, y/maymana huateĉayninhuantaĉmi ari, millay callpanhuan hina/ auçaycuançhic (13). caycunamanta quespinançhicpacmi ari ançha/ yupaylla cay santo sacramento confirmaçion sutiyocta/ çhasquinançhin (14) yaçhacun./

Chaymi ari Baptismopi Jesuçhristo çhuri=/yacusĉan runa llullu Ytque hinallarac caspa, cay confirmaçion/ Sacramentocta S. ${ }^{r}$ Arcobispop maquinmanta chasquispam/ Spiritu Santop graçianhuan sinçhiyachisĉa, callpançhacus=/ĉataĉmi ari cay anyanacuy paçhapi casĉancama auĉa supayta /f. 4v/ atipanĉa, çhaypaĉmi Yayançhiq, Apunchiĉpas (15) S. ${ }^{r}$ Arçob. cay/ confirmaçion ñisca sacramentocta chasquichequequiçhic/ hamun./
(9) Nota marginal: "la neçessidad que ay de reçeuirle"
(10) = mançhay
(11) Nota marginal: "D. Aug. in Serm. ad cas. libro 4 cap 1"
(12) = Ytquecta
(13) = auĉaycuançhic
(14) = çhasquinançhic
(15) $=$ Apunchicpas 
Los que consideran bien lo que he dicho y ya están bautizados para poder recibir la confirmación ciertamente se fortalecerán (7). La persona que sólo está bautizada, aunque sea ya mayor (8), todavía anda como un niño en este mundo del destierro, y su alma tiene pocas fuerzas. Escúchenme bien. Al recibir el sacramento del bautismo nos convertimos en personas nuevas. En el bautismo Jesucristo nos hace sus hijos para heredar su gloria. Sin embargo, estamos débiles como niños si aún no hemos recibido el sacramento de la confirmación. ¿Me entienden? ¿Estaría bien que un tierno niño se enfrente a un hombre grande y fuerte? ¿Lo podría vencer? De ninguna manera. ¿Quiénes son, entonces, nuestros enemigos? Preguntémosle a San Pablo. ¿Quiénes son nuestros enemigos, Santo Apóstol? El dice que son los Principes tenebraris, los señores de las tinieblas (9). Nuestros enemigos son poderosos demonios, temibles hombres, altos gigantes. ¿Entonces los demonios tienen cuerpo (10), tienen estatura, para que yo diga que son grandes como gigantes? Más bien, son muy sabios y en todas partes (11) nos vencen. Ninguna persona, por sabia que fuera, les puede igualar en su astucia. Les digo algo importante al decirles que nuestros enemigos son de gran estatura. Entonces, ¿está bien que una persona débil (12) pelee con un hombre temible? No, hijos míos. Nosotros somos débiles, y ellos valientes. Escuchen a San Agustín, el Doctor de la Santa Iglesia: Scitote vos cum callido, antiguo, et veternoso inimico suscepisse certamen (13). Dice el santo doctor: "Sepan, hijos míos, que el día que ustedes recibieron el bautismo, comenzaron a guerrear, a luchar, con un enemigo astuto y aguerrido, que sólo piensa en engullir. Deben enfrentarse a un enemigo cruel que los odia eternamente. Así como los afiebrados, cuando la calentura les hace arder el corazón, sólo piensan en beber agua, y quieren tragarse hasta el océano entero, de la misma manera su enemigo (por envidiar su ascenso a la gloria) con su corazón ardiendo les quiere tragar como si fueran agua". El sabio San Agustín nos dice algo muy importante. Nuestros enemigos son los demonios, hijos míos, ellos nos hacen pecar porque no quieren que nos salvemos ni que lleguemos a la gloria eterna. Ellos constantemente nos hacen la guerra con sus trazas, con todos sus acechos y con su fuerza abominable, engañándonos como a niños con los deleites vanos de este mundo. Para salvarnos de todo esto es muy necesario recibir este sacramento de la confirmación.

Así es que los que se han hecho hijos de Jesucristo por el bautismo pero aún son como niños tiernos, después de recibir este sacramento de la confirmación de manos del señor arzobispo vencerán a los demonios mientras estén en este mundo de enfrentamiento, fortalecidos con la gracia del Espíritu Santo. Es por esto que nuestro padre y señor el arzobispo ha venido para administrarles este sacramento llamado confirmación.

(7) Nota marginal: "La necesidad que hay de recibirle"

(8) chacha - cf. el diccionario Ancash-Huailas de Parker \& Chávez: “Tsatsa... Persona de edad avanzada" (1976: 44).

(9) tutapayaĉ yanauyachcaĉpa apuncunam

(10) runayoççhu

(11) maymaypam

(12) pissi callpa vmutulla runa - no he podido identificar el término /umutulla/.

(13) Nota marginal: "D. Aug. in Serm. ad cas. libro 4 cap 1" 
Pitac çhica allin cocuytaca cuyahuarĉan=/çhic? (16) çhica yupay hampitaca Pictac (17) camacaycaçhipuarĉan=/çhiq? cay sacrametocta çoaĉninçhicta recsispami asninĉa (18)/ yupayçhanquiçhic (19), mapas vyaycuayçhic./

Çuc huacçhalla runas ymatapas ĉossunqui=/çhicman, çhaninnaĉllam ari chayĉa canman: ymatataĉ/ huc huacçha cocunman? huaytallataçh, frutallataçh ari,/ yman captintac? huc caualleros, huc alli caĉsi, haçien=/dayoc poĉô runas ymactapas cossunquiçhicman, çhayĉa/yupayracmi canman: çhaniyoĉtaracmi çhasquinquiçhicman/ llapa. Yçhaĉa Apu yncas, ĉapaĉ Reyninçhic castilla=/pi ĉấsi ymatapas ĉossunquiçhicman çhayĉa çhaymi/yupaymi, chaniyoĉmi canman. Ĉ́cusĉanĉa Apu casĉanta/yuyaricuspam ari ĉapaĉcunaĉa ymactapas ĉcun llapa./

Ñaupam huc ançha ĉapaĉ Rey Alexan=/dro sutiyoĉ carĉan, çhaytam huc huacçhallaĉa. Yaya/ churillayta casaraçhicunapaĉ ymallactapas cuyallahuay Do=/tenme pissipuan ñiptinmi Alexandroĉa, huc llactatam/ coyqui, çhayhuan churiiqui causacuçhun, chay llacta dotem=/paĉ cachun ñircan = çhayna çhay runaĉa Yaya ñoĉa/ churiiqui yanĉa runallam cani, ymanassacmi çhay llacta/ çhica çhaniyocta? çapaccunapa çhasquinanmi çhayĉa ñiptin=/mi Alexandoĉa Huaccha hinam ĉamĉa pissi pissi llacta=/ta mañacunqui ñoĉaça ari ĉapấ casĉayta yuyaspam $\hat{c}$ am=/pa camayquita yallicta coyqui nircam. Humutançhu (20) son=/ĉoyquichiq ñiscayta? Chayĉa yuyayçhic cunan, Pi runam, ycha/ Pi cavallerom, maycam Reymi cay confirmaçion sacra=/mentocta coarĉançhiq ñoĉançhiq huacçha huillullucta?/ Pactaynac apum ari, quiquin Diosmi ari, runallaçhus ĉoa=/çhuan pana pipas canman huacçha masinçhic caspa yanĉa /f. 5/ huayta hina chaquiĉllata cocunman, fruta hina tucuĉllam/ canman = caballerollas coâçhuan, santocunaçhus, Angelcu=/naçhuscay ĉô̂ninçhic canman, çhayĉaançhayupaychaypac/captimpas, manam Diospa cocuyninhuanĉa pactanmançhu/ çhayça pim cay sacramentocta coarĉançhic? Jesuchristom. Dios/ runa tucusĉa Rex gloriae gloriap Apummi. Rex Regis, capaĉ/ yncacunap Yncanmi = Ma çhayĉa sinçhiyacuna ñiscayta, çuc/ allpa tucuc runa, çuc runamasinçhic Alexandrollapas Ynca/ casçanta yuyaricuspam may çhica çhaniyoĉ llactaĉta (21) huaçha (22) $\mathrm{ru}=/$ naman cocuptin. Mana rimay capaĉ yallincama Apu Diosĉa/ çhica cuyaquençhic Jesusĉa, yanĉallataçhus ĉoaçhuan? pissi pi=/ssi chaniyoĉllaçhus huacçha runanta cosĉan canman? mana/ yuyay çhaniyoĉmi (çhuricuna) cay confirmaçion sacramentocĉa (23),/ cayta çhasquispam ari Diospa graçianta çhasquinquiçhic llapa/ Auĉayqui çupayta atipanayquiçhicpac. Chaypaĉmi Apunçhic/ Jesuçhristo cay sacramentocta camaçhirçan, ñacarisĉampa/ chaninta, yahuarninpa callpantasacramentoncunapi çhu=/raspa, animançhiccunaponcoynimpahampimpachamutaspa/

(16) Nota marginal: "El Auctor del sacramento"

(17) $=$ Pitấ

(18) ¿= asuanĉa?

(19) $\leq$ yupayçhayquiçhic

(20) = hamutançhu

(21) = llactacta

(22) = huacçha

(23) $=$ sacramentoĉa 
¿Quién nos hizo este regalo tan bueno (14)? ¿Quién nos hizo preparar esta medicina tan valiosa? Cuando conozcan al que nos da este sacramento lo estimarán aún más. Escúchenme.

Si una persona pobre les regalara algo, no tendría ningún valor. ¿Qué podría regalar una persona pobre? Seguramente una flor, una fruta o lo que tuviera. Si un caballero, una persona próspera con hacienda les regalara algo, sería estimable, recibirían algo de valor. Pero si un rey (15), como nuestro gran rey que está en Castilla, les regalara algo, eso sí que sería estimable y valioso. Los grandes, considerando su condición de señores, son capaces de regalar cualquier cosa.

En la antigüedad, hubo un rey muy grande llamado Alejandro. Un hombre pobre le dijo: "Señor, por favor regálame algo para casar a mi hija, ya que me falta para su dote". Entonces Alejandro le respondió "Te daré un pueblo, que tu hija se case con esto, que el pueblo sea su dote". Cuando el hombre le dijo: "Señor, yo, tu hijo, soy una persona sin importancia, ¿qué haré con este pueblo tan valioso? Éste es un regalo para los grandes", Alejandro respondió: “Tú, como pobre, pides poco (16), pero yo, considerando mi grandeza, te doy más de lo que te corresponde". ¿Entienden lo que he dicho? Entonces piensen ahora: ¿Qué persona, o qué caballero, cuál rey nos dio este sacramento de la confirmación a nosotros, pobres huérfanos? Fue un señor sin igual, fue Dios mismo. Si una persona común nos regalara algo, sea quien sea, por ser un pobre como nosotros su regalo se secaría como una flor, se podriría como una fruta. Si el regalo fuera de un caballero, o de los santos o de los ángeles, entonces por muy estimable que fuera, no podría compararse con el regalo de Dios. Entonces, ¿quién nos dio este sacramento? Fue

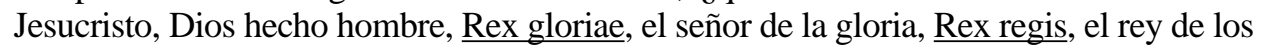
grandes reyes. Pues bien, si Alejandro, un ser que se hace polvo, una mera persona como nosotros, le dio un pueblo muy valioso a una persona pobre por considerar su condición de rey, ¿entonces el señor Dios, que es indescriptiblemente más grande, y Jesús, que nos ama tanto, nos daría en vano este elemento fortalecedor? ¿Su regalo a sus pobres podría ser de poco valor? Este sacramento de la confirmación, hijos míos, es valioso sin medida. Al recibirlo recibirán la gracia de Dios para vencer a todos sus enemigos demonios. Para esto nuestro señor Jesucristo lo instituyó, poniendo el valor de su sufrimiento y la fuerza de su sangre en sus sacramentos, diseñándolos como medicina para la enfermedad de nuestras almas.

(14) Nota marginal: "El autor del sacramento"

(15) Apu ynca

(16) El original parece decir pissi pissi llactata "un pueblo de poca monta", pero es más probable que la intención de Castoromonte haya sido escribir pissi pissillacta. 
çhaymantari cay confirmaçion çhasquiĉpa animan, muçuĉ callpacta/ çhasquiptintaĉmi Jesuçhristo yayançhic Apostolincunacta/ ña Baptizasĉacama captimpas sedete in civitate vsque quo/ induamini virtute ex alto. Nircan (24) Teĉssi muyupi runacunacta/ yaçhaçhê̂ riptiquiçhicĉa ari auĉayqui çupaymi çhecnissunqui=/çhic huanuylla, ymaymanatapas hamutaspamauĉaycussunqui=/çhic ĉamcunacta, çhay auĉata atipanayquiçhicpac ari sedete in/ ciuitate Jerusalen llactapiraĉ tiayçhic amaraĉ lloĉsinquiçhicçhu/çhaypi espiritu santotarac çhasquinquiçhic llapa, paypa callpan=/huan sinçhiyacusĉa, çhay confirmaçion

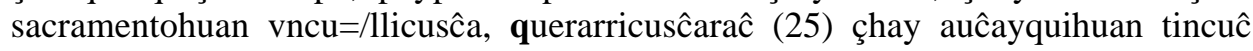
lloĉsinquichic, ñircan=/mi ari Jesus Apunçhic Apostolnincunacta confirmacion sacra=/ mentocta çasquiccunaĉa (churicuna) Espiritu Santoctam chasquin/ animampi paypa callpanhuan graçianhuanriçupayta atipaycu=/nanpac. Manaçhu hatun cocuyta $\hat{c o a r c ̂ a n c ̧ h i c ~}$ Dios Apu cay Sacra=/mentocta coaspançhic çhuricuna? /f. 5v/

Yalli quiquin sacramentocta çhasquinayquiçhicta/ villaptiĉraĉmi, ançha santo, ançha yupayçhana casĉantaĉa sonçoy=/quichic vnançhanĉa (26), vyaycuyçhic cay confirmaçion sacramen=/totaĉa churicuna, Arçobispo, obispocunallam çhasquichin chri=/ stianocunaman manam ari çucĉa. Obispocuna, Arçobispocuna/ Apostolcunap rantin SantaYglesiapi tian llapa, chayraycu/ Paycunaĉa saçerdotecunap Apun niña (27), chayĉa yuyayçhicpas/ çhica collanan Apucunalla çhristianocunacta confirma=/çhinan captinĉa, Arçobispocunallap cay sacramento cocunan/yaçhacuptinĉa ançha hatunnin, ançha santom, ançha $\mathrm{yu}=/$ payçhaypaĉmi cay confirmaçion ñisĉa sacramento. Chay=/mantari confirmacuccunaĉa sonĉoyquiçhicpi vnançhayçhic/ Apunçhic señor Arçobispom vrcuyquiçhicpi Santa crus=/pa vnançhanta ruranĉa santo chrismahuan llusispa (28)/ Santa cruspa vnançhanhuammi vnançhayqui, alli cana/çhrismahuantacmi confirmayqui, Yayap, Çhurip, Espiru (29) san=/top sutimpi. amen. Ñi simicta rimaspa (30) yma ñinantataĉ/ ñinĉa çhayta? Yuyaricuyçhic yaçhanayquiçhicpaĉ. Sanctacrus=/mi ariçhristianocuna Jesuçhristop çhurinpa vnanchan=/çhic, cay vnançhactam, yuyaptiquiçhicĉa Santo Bautismopi/ çhasquirĉançhic llapa, cay cruspi huañuc Jesuchristop chu=/rinmi cani, cruzpi hiçhanĉan yahuarninhuammi huçhay=/ta mayllapuan, cay Santo Bautismopi yayay Jesuçhristo/ cay crusmi vnançhayĉa, ñinançhicta ari santa crusta chas=/quirĉançhic llapa, hinaspatacmi millaticunim çupay sata=/nasta, mananam paypa runançhu cani: tucuy ymantahuam=/ pas huisçhurinim, ñirĉançhictaĉmi, chay paçhamantam/ ari çupaytaĉa auĉançhicpaĉ reĉsirĉançhic, paypas çheĉnita/ ñaupaycuarĉançhic, Bautizacusĉançhicmantatacmi, ña Diospa/çhurin caĉta, ña gloriapi llactayocta ricuaspançhicnam Auĉa/huanuy çhiquicuspa tucuy callpanhuan, Auĉaycuyta ĉalla=/rihuarĉançhic, çhayta atipanançhiqpaĉ, ayca huateĉasĉapas (31)/ ymaymana yntusĉapas, mana llacllarinançhicpaĉtaĉmi, ari

(24) Nota marginal: "Luc. 24"

(25) = guerraricusĉarấ

(26) Nota marginal: "El ministro"

(27) $=$ ñina

(28) Nota marginal: "Materia"

(29) $=$ Espiritu

(30) Nota marginal: "Forma"

(31) Primera $\{s\}$ escrita sobre una $\{c\}$. 
Y es así, ya que el alma del que recibe la confirmación recibe nuevas fuerzas, que nuestro señor Jesucristo les dijo a sus Apóstoles, aunque ya estaban todos bautizados: Sedete in civitate, usque quo induamini virtute ex alto (17). Jesús nuestro señor les dijo a sus apóstoles: "Cuando ustedes vayan a enseñar a las personas de todo el mundo, su enemigo el demonio les odiará intensamente, y les hará la guerra de cualquier forma que pueda. Para vencer a su enemigo sedete in civitate, quédense en la ciudad de Jerusalén, no salgan todavía. Allí recibirán al Espíritu Santo, y saldrán a enfrentarse con su enemigo fortalecidos con su poder y armados para la guerra con este sacramento de la confirmación." Los que reciben el sacramento de la confirmación, hijos míos, reciben al Espíritu Santo en sus almas para vencer al demonio con su fuerza y su gracia. ¿No fue un gran regalo el que nos dio el señor Dios al darnos este sacramento, hijos míos?

Cuando les explique cómo han de recibir este sacramento, entenderán aún mejor cuán estimable y santo es (18). Escuchen: sólo el arzobispo y los obispos administran este sacramento a los cristianos, hijos míos, y ningún otro. Los obispos y arzobispos están en la santa iglesia como representantes de los apóstoles, por eso se deben considerar como los señores de los sacerdotes. Entonces, piensen cuán grande, santo y estimable es este sacramento de la confirmación si sólo los señores excelsos pueden confirmar a los cristianos, si sólo los arzobispos puede administrar este sacramento. Los que se van a confirmar, sepan que nuestro señor el arzobispo va a hacer la señal de la santa cruz en sus frentes ungiéndolos con el santo crisma (19), y diciendo: "Te señalo con la señal de la santa cruz y te confirmo con el crisma de la salud, en el nombre del Padre, del Hijo y del Espíritu Santo" (20). ¿Con qué sentido dirá esto? Piensen, para que lo sepan. La santa cruz es la señal de nosotros los cristianos, los hijos de Jesucristo. En el santo bautismo recibimos esta señal, recibimos la santa cruz como si dijéramos "Soy el hijo de Jesucristo que murió en esta cruz, El lava mis pecados con la sangre que derrama en esta cruz. Por este bautismo, padre mío Jesucristo, mi señal es esta cruz." Dijimos "Renuncio a Satanás el diablo, ya no soy su persona, y deshecho todo lo que es de él". Desde ese momento reconocimos al diablo por nuestro enemigo, y él empezó a odiarnos. Desde que nos bautizamos y vio que éramos hijos de Dios y ciudadanos de la gloria, comenzó a hacernos la guerra con toda su fuerza, envidiándonos mortalmente. Para vencerlo y para que no desfallezcamos por mucho que nos tiente y nos aceche,

(17) Nota marginal: "Luc. 24"

(18) Nota marginal: "el ministro"

(19) Nota marginal: "materia"

(20) Nota marginal: "forma". Castromonte traduce al quechua la forma que el obispo diría en latín: "Signote signo Crucis, et confirmote chrismate salutis. In nomine Patris, et Filii, et Spiritus Sancti. Amen" (Peña Montenegro, 1678: 447). 
Diospa /f. 6/ rantin S.r Arçobispocuna çhristianocunacta santa cruspa/ vnançhanhuan huallpariçhin, santa cruzta querarin=/paĉ (32) çhasquiçhin confirmaspa./

Cruzpa vnançhanmi ari auĉançhicpa man=/çhanan armançhic, cay armacta çaquepuarĉançhic yaçhaq (33)/Diosninçhic Jesuçhristo, çhayta çhasquiçhisuspayquiña S. ${ }^{r}$ Arço=/bispopas cruzhuanmi vnançhayqui Jesuçhristop soldadonta/ hina çinçhi auĉacamayoĉta hina ñissunquiçhic llapa confir $=/$ maçhispa $=\mathrm{Pi}$ callpata cosĉatac çhayĉa çupayhuan tincun=/man pissi callpa runa? Pay hinaçhus amauta yachaĉpas canq.=/çhicman? Vyayçhic S. ${ }^{r}$ Arçobispop ñisĉanta (34). Atipanquim auĉata/ Yayap çhurip Espiritu Santop sutimpi ñisunquim ari, quimça/ sayac caspa huc Diosllap sutimpim, paypa callpanhuammi/ llapa atipaĉ Diospa graçianhuanmi auĉayquicunacta atipanqui/çhic llapa, çhay graçia çhasquisĉayquip vnançhanmi cay $S a n=/$ to çhrisma, ñinantam ari santo çhrismahuan vrcuyqui=/çhicta llusisunquiçhicpac, manaçhus yuyaĉ runapacêa sonĉo=/yoĉcunapacĉa mançhay santo ñina cay confirmaçion sacramento?/ çhaymantari vyayquiçhicpim, ĉaĉllayquiçhicpim llampu maqui=/lla ynçhaycussunquiçhic llapa cusi ĉassilla causacuy ñispa. Jesu=/çhristop soldadon ñinaĉa manam maĉanacuyhuançhu, manam/ çheĉninacuyhuanchu, viñay cussilla causana gloriaman çhayan=/ĉa; paçiençiallahuanracmi, auĉanta atipanĉa, yma ñisĉapas, ayca/ quesaçhasĉapas <muchu>cuspam (35), muçhuspam, alli christiano ninaĉa/ canĉa ñinantam S. ${ }^{\mathrm{r}}$ Arçobispoĉa inçhaycuspa cusi çasilla cau=/sacuy nisunquiçhic llapa./

Chaypaĉtaĉmi confirmaçhicuêniquipac/ huc runacta yayaçhacunquiçhic, huarmictapas mamaçhacunqui=/çhic llapa (36), paymi ari confirmacuptiquiçhic çharaycussunqui/ S. ${ }^{r}$ obispop cayllampi. Çhay runa confirmaçhisuĉniquihuanĉa/ ari animayquiçhi<c>pim ancha sichpapura tucunquiçhic llapa, pi=/ssim pay marĉacoqueyquihuanca casaracunayquipas yaçhacunmançhu/ çhay sichpapura tucuytam yaçhaĉcuna cognaçion espiritual ñin llapa /f. 6v/ yçhaĉa Santa Yglesiap Dotornincuna ñisĉan hinapas, confirma=/cuĉta marĉacuê runas manarac confirmasĉaçhu canman, ma/ nam confirmaçhicusĉanhuan sichpapuraçhu tucunman, $y=/$ mapaĉtaĉ ña çhaçha runaĉa çhay Padrinoctaraĉ pusahuay ñisaĉ?/ ñiptiquiçhicĉa, Ricuyçhic churicuna manachu mayĉmpas/ huc auĉanhuan, huc ñinacuĉmasinhuan tincusaĉ ñispaĉa/ allin auĉanacuy yaçhaĉtarac, alli pucllay yaçhaĉtarac tapuy=/cunman? ymahinam tincusaĉ, ymanaspam

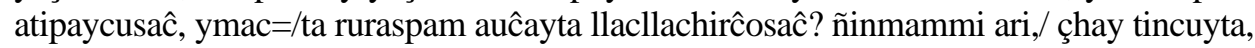
çhay auĉanacuyta yaçhaçhequenpacmi huc/ huamincaĉta (37) mascanman. Çhayhinam ari confirmaçionta/ chasquiĉcunapas Jesuchristop auĉacaman Diospa <soldadon tucuspa huc/ yaçhaĉta, huc padrinocta mascanĉa> (38) cheĉñequen/ çupayhuan, auĉanacuyta yaçhaçhinanpaĉ, alli christiano/ causayta villaĉñinpac. Chaypacmi pussaycusunquiçhic $\mathrm{Pa}=/$ drinoyquicuna $\mathrm{S} .^{\mathrm{r}}$ Arçobispop ñauquinman, ñoĉa cay churita/ yaçhaçhisac, ñocam sonĉolliçhisac, Diospa camaçhicusĉanta/ manalli auĉa mana llullaçhinanpaĉ, ñic hinam ari confirma=/çhicuêniquicuna Apunçhicpa cayllanman pusaycusunqui/çhic llapa./

(32) = guerrarinanpâ

(33) = yaçhac

(34) Nota marginal: "seremonias con q. se da el sacramento"

(35) $\leq$ sufricuspam

(36) Nota marginal: "del Padrino"

(37) = huaminçacta

(38) Este inserto aparece en el margen izquierdo, y el lugar de inserción está marcado con una \{\#\}. 
el señor arzobispo al confirmar nos arma con la señal de la santa cruz, nos hace recibir la santa cruz para hacer la guerra.

La señal de la cruz es un arma temida por nuestro enemigo. Nuestro sabio Dios Jesucristo nos dejó esta arma, y cuando el señor arzobispo les hace recibirla al administrar la confirmación les dice: "Te señalo con la cruz, como a soldado de Jesucristo, como a un fuerte guerrero". ¿Entonces, quién da fuerza para que una débil persona se enfrente al demonio? ¿Podrían ustedes ser astutos y sabios como él? Escuchen lo que les dice el señor arzobispo (21): "Vencerás al enemigo en el nombre del Padre, del Hijo, y del Espíritu Santo". Al ungirles en la frente con el santo crisma les dice que ustedes vencerán a sus enemigos en el nombre del Dios trino y uno, con su fuerza, con la gracia de Dios todopoderoso, y que el santo crisma es la señal de esta gracia que ustedes reciben. ¿No les parece que este sacramento de la confirmación debe ser considerado tremendamente santo por cualquier persona con cordura y corazón? Después, les dará una leve bofetada en la mejilla y les dirá “vive con alegría y paz”. Al hacer esto, el arzobispo les da a entender que el soldado de Jesucristo no alcanza la gloria eterna con peleas y con odio, que el buen cristiano vence a su enemigo sólo con paciencia, padeciendo cualquier insulto o maltrato.

Para esto ustedes deben elegir a un hombre o una mujer como padrino o madrina de confirmación (22). Cuando se confirmen, ellos les tendrán de la mano en presencia del señor obispo. Ustedes se convertirán en parientes espirituales de sus padrinos de confirmación, y no podrán casarse con ellos. Los sabios llaman "cognación espiritual" a este emparentamiento. Sin embargo, como dicen los doctores de la santa iglesia, si el padrino de confirmación no está confirmado, no se convertirá en un pariente del que se confirma. Ustedes dirán que ya son muy mayores como para buscar un padrino que les guíe. Miren, hijos: si una persona se prepara para enfrentarse a un enemigo, ¿no consultaría a alguien experimentado en la guerra? ¿No le preguntaría cómo debe enfrentarse a su enemigo, cómo vencerlo, cómo hacerle perder el coraje? Sin duda que lo haría - buscaría a un soldado experimentado para que sea su maestro en las cosas de la guerra. De la misma manera los que han de recibir la confirmación, para convertirse en guerreros de Jesucristo, en soldados de Dios, deben buscar un padrino que les enseñe a luchar con el demonio y les avise cómo vivir como buenos cristianos. Por eso sus padrinos les llevarán ante el señor arzobispo, como quienes les han de enseñar y animar para que el malvado enemigo no les engañe y desvíe de la voluntad de Dios.

(21) Nota marginal: "ceremonias con que se da el sacramento"

(22) Nota marginal: "del padrino" 
Chaymanta yaçhaytấ çhuricuna (39) <confirmaçion> sacra=/mentocta çhasquiptillayquictaĉmi (40) ĉapaĉ Dios churanĉa animay=/quiçhicpi, Bautismocta çhasquiptiquiçhic çhurasĉan hina/ vnançhacta, chaytam ari character ñinçhic, chay characterĉa/ çhay vnançhaĉa mana cutiĉmi, mana pampaçhacaĉmi, huiñay=/paĉ mana piçhacaĉ vnançham, Çhayraycu cay confirmacuy/ sacramentoĉa huc mitalla çhasquicuna, Bautismo hinatacmi/ ari, cay confirmaçionpas mana yscaypana, ña Bautizasĉa runaĉa,/ na confirmasĉa caĉpas, ñatac Bautizacuspaĉa, yapay confirma=/cuspapas, millay ati hucha saçrilegio sutiyocta ruranman,/ çhica hatun sacramentocta pucllacuê hina, mana yupayçhaĉ/ hinatac, yapaĉllasĉanraycu, yalli çhay hinaycachactaĉa Dios=/ninçhic millay huçhaçhaspam castiĉanman (41), cay tucuy ñiscayta/ sonĉoyquiçhicpi çhasquicuspaĉa ari (churicuna) allin vnançhas=/f. 7/paĉĉa (42), mâ cunan yuyayçhic, manachu ancha yupayçhaypaĉ/ manaçhu ançha mançhay hatun cay confirmaçion sacramento,/ cunan çhasquisac ñiscayquiçhic? (43) ançhapunim ari, santoca=/mam. ymampas çheĉampi Diospa ĉocusĉanmi cayĉa, ançhan=/nintacmi Diosta yupayçhanayquiçhic, cay sacramentocta/ çhasquinayquiçhicpac, cunancama causaçhisusĉayquiraycu,/ S. ${ }^{\text {r }}$ Arco. Apunçhicta cay llactayquiçhicman çhayaçhimus=/ canraycuhuampas/

Yçhaĉa confirmacuspa espiritu santocta/ animayquiçhicpi çhasquinayquiçhicpacmi camaricunayquiçhic/ canĉa, ymahinatac chaypâ̂ camaricunquiçhicman? (44) hamu=/tayçhicrac ñiscayta, huc hatun Apu huasiquiçhicpi paçhacuĉ (45)/ hamunan captinĉa, ymananquiçhicmanmi? piçhanquiçhicman/ çhaççhunquiçhicman allintam ari huasiquicta, quiquiquiçhicpas/ allinnin hacuyqui caĉtam hacullicunquiçhicman, chayĉa Espi=/ritu Santo animayquiçhicpi corpaçhacuê hamunanpac, piçhay=/çhic ari animayquiçhicta, huçhayquicunacta visçhuyçhic/llapa, çhica ĉapac Diosta piñachisĉayquiçhictallaquispa,/ huaĉaspa, huanasaĉ cunanmantaĉa ñispa, çhaymi huasiquicta/ pichasĉayqui, chaççhuscayqui canĉa, çhaymi camaricunayqui=/çhic canĉa (churicuna) yalli sasicuspas, confesacuspas confir=/macuĉ hamunquiçhicman, çhayracmi sumaĉ yupaypas cama=/ricusĉayquiçhic canman (hijos) pissi sasicuĉcuna, pissi confe=/sacuĉcunari ñisĉay hinallapas, huçhallicuspa Diosta piñachisĉay=/quimanta, tucuy sonĉlla llaquispa, huanasac, toĉasaĉñispari Apu/Diosta perdonahuay niçhic. acto de contriçionta rurayçhic, chay=/ĉa cay sacramentocta çhasquispapunillam graçiacta çhasquin=/ quiçhic llapa, chayllam Espiritu Santo animayquiman chayaspa/ sinçhiyaçhinĉa callpa conĉa.

(39) Nota marginal: "Del character q. en el sacram ${ }^{\text {to }}$ se reçiue"

(40) $=$ çhasquiptillayquichictaĉmi

(41) = castiganman

(42) = vnançhaspaĉa

(43) Nota marginal: "Dignidad del sacram ${ }^{\text {to" }}$

(44) Nota marginal: "la disposicion que se requiere para reçeuir la graçia en este sacram ${ }^{\text {to }}$ "

(45) $=$ corpachacuê 
Sepan también, hijos míos (23), que en el instante que reciben el sacramento de la confirmación, Dios impondrá en sus almas una señal como aquella que recibieron en el bautismo. Esta señal se llama carácter, y este carácter o señal no se quita, no se borra, permanece para siempre. Por lo tanto, este sacramento de la confirmación sólo se recibe una vez. Al igual que el bautismo, este sacramento no se debe repetir. Los bautizados y confirmados que se vuelven a bautizar o a confirmar cometen un pecado muy abominable llamado "sacrilegio", al haber repetido un sacramento tan grande como si se burlaran de él. A los que así se comportan, Dios los culpa y los castiga terriblemente. Hijos míos, si ustedes entienden todo lo que les he dicho, y lo consideran cuidadosamente, ¿no les parece que este sacramento de la confirmación, que ahora quieren recibir, es muy estimable y muy impresionante? (24) Verdaderamente es así, es muy santo. Éste es verdaderamente un regalo de Dios, y ustedes deben venerar mucho a Dios por haberles dado vida hasta ahora para que reciban este sacramento, y por haber traído a nuestro señor el arzobispo a su pueblo.

Ustedes deben prepararse para recibir el Espíritu Santo en sus almas al confirmarse. ¿Cómo pueden prepararse para esto? (25) Piensen en lo siguiente. Si un gran señor viniese a hospedarse en sus casas, ¿qué harían? Barrerían y regarían bien sus casas, y se pondrían su mejor ropa (26). Entonces, para que el Espíritu Santo venga a hospedarse en sus almas, deben limpiarlas y botar sus pecados, apenándose de haber enojado tanto a Dios, llorando, y determinando enmendarse desde ahora. Hijos míos, es así como ustedes deben barrer y regar sus casas, y prepararse. Si ustedes vienen a confirmarse en ayuno y después de haberse confesado, entonces su preparación será hermosa y válida. Los que no han ayunado ni confesado, pidan perdón al señor Dios y hagan un acto de contrición, apenándose de todo corazón por haber enojado a Dios con sus pecados y determinando enmendarse. De esta manera recibirán la gracia en el momento en que reciben este sacramento, y el Espíritu Santo al llegar a sus almas les fortalecerá al instante.

(23) Nota marginal: "del carácter que en el sacramento se recibe"

(24) Nota marginal: "dignidad del sacramento"

(25) Nota marginal: "la disposición que se requiere para recibir la gracia en este sacramento"

(26) /haku/ es "manta" en el quechua Alto Huallaga y Ancash-Huailas actuales (Weber et. al., 1998: 266; Parker \& Chávez, 1976: 61), pero en la edición de 1754 del Arte y vocabulario de Torres Rubio aparece como "todo tipo de vestido" (Torres Rubio, Figueredo et al., 1754: 216v). 
Manam yçhaĉa mana Bautizasĉa/ caĉcunaĉa ayca confirmaçionta chasquispapas, Espiritu Santocta/çhasquinmançhu (46), Bautismoracmi ari ñaupacta chasquinançhicĉa/ huayquin sacramentocunap puncunmi ari, Bautismo sacramentoĉa/ (churicuna) mana Bautizasĉa runaĉa, ayca confirmacuptimpas /f. 7v/ ayca çucnin çucnin Santa Yglesiap sacramentoncunacta çhas=/quiptimpas, manam yupaychu canman, manam Diospa graçi=/anta chasquinmançhu, Bautismopiraĉmi çhristianop animan=/pi çhay vnançha character ñisĉacta çhasquinçhic, çhay vnan=/çham (47) ari cay confirmaçionta çhasquiptinçhic miraricun/ çapac Dios Bautismopi çhuriyacusĉanta cay confirma=/ çiompi soldadonpac, auĉa camampac vnançhaptin animan=/çhiqpi confirmaçion character ñisĉacta çhuraptin. Çhay=/raycum ari confirmaçionĉa Baptismo hinataĉmi çuc cu=/tillam, çapan mitallam çhasquina ñircay<q.chic> llapa./

Chayĉa çuricuna, manarâ̂ cay confirma=/çion sacramentocta çhasquiĉcuna (48): hamuyçhic llapayqui Je=/suçhristo yayançhic Bautismopi çhuriyacusĉancuna, llucllu (49)/ Ytquecuna, hamuyçhic, Apunçhic señor Arçobispop cayllan=/pi conĉoricuspa animayquiçhicta çinchiyaçhicuyçhic confir=/maçionta çhasquispa, Espiritu Santocta animayquiçhicpi corpa=/çhayçhic (50) = Huamrapas, ña ĉanchis huatayocĉa, ña sonĉoyoĉ/cunaĉa (51), çhaçha ĉaĉpas (52), auquispas, çhacuanpas manaraĉ con=/ firmaçionta çhasquiĉcunaĉa, manarac cay sacramentop call=/panhuan callpaçhacuĉcunaĉa hamuyçhic tucuyllayqui, animay=/quiçhicpa auĉan çupayta atipanayquiçhicpaĉ cacnamuyçhic/ llapa çinçhi Huaminca hina, Santocunahuan, Angelcuna/huan tanta Dios $<$ pa $>$ glorianman cussi hayllihuan çhayayta mu=/naĉcunaĉa, purimuychic llapa. Caypim callpançhassunquiçhic/ caypim huallparicunquiçhic Diospa graçianhuan (53), çhay graçia=/ta çhasquicuspaĉa ari, mançhannillam acuyhuan tincunqui=/çhic. penĉannillam çhristianom cani ñinquiçhic, çieloman/ quespicuyta munaĉcunaĉa ari callparicusparaĉmi quespinan/ yaçhacupun, auĉancunacta atipaycuĉcunallapaĉmi hanaĉ pa=/çhapi coçhocuyĉa. Regnum cæloris vim patitur callpançapacu=/nallapacmi çielopi huyñaypaĉ causayĉa canĉa, çupaypa llu=/lla siminta mana yupayçhaccunapacmi Diospa añau glorian=/ĉa, acuy ayçhanta mana cusiçheĉcunallam çhaymanĉa çhayanĉa /f. 8/ tucuy sonĉonhuan Diosta huayllucuĉcunallam huyñay cussi=/cuymanĉa yaycunĉa, çhay tucuypacmi cay sacramento callpacta/ coançhic, ma çhayĉa çhuricuna çhica yupay sacramentoc=/ta çhasquicuyçhic cay paçhapi auĉayquita atiparĉospa Dios=/pa cayllanpi mana tucuê paçha cussicunayquiçhicpaĉ. Amen./

(46) Nota marginal: "Este sacram ${ }^{\text {to }}$ presuppone el Bautismo"

(47) $\leq$ vnanchanam

(48) Nota marginal: "Exhortacion a la confirmacion"

(49) = llullu

(50) Nota marginal: "quienes son los q. se an de confirmar"

(51) $=$ sonoyoĉcunaĉa

(52) $=$ caĉpas

(53) Nota marginal: "effectos del sacram" ${ }^{\text {to" }}$ 
Sin embargo, los que no están bautizados, por muchas veces que se confirmen no recibirán al Espíritu Santo (27). Primero debemos recibir el bautismo, ya que el sacramento del bautismo es la puerta de los otros sacramentos. Por muchas veces que los no bautizados se confirmen, y aunque reciban varios sacramentos de la Santa Iglesia, no sería válido, no recibirían la gracia de Dios. En el bautismo recibimos esa señal llamada carácter que está en el alma del cristiano. Esta señal aumenta cuando recibimos la confirmación, cuando Dios señala como su soldado a quien tomó como su hijo en el bautismo y le impone el carácter de la confirmación. Por esto les digo que la confirmación, al igual que el bautismo, sólo se recibe una vez.

Entonces vengan hijos míos, los que no han recibido el sacramento de la confirmación (28), los que se han hecho hijos de nuestro señor Jesucristo en el bautismo, tiernos niños, vengan, fortalezcan sus almas arrodillándose ante el señor arzobispo, alberguen al Espíritu Santo en sus almas recibiendo la confirmación (29). Vengan todos ustedes, los niños que ya han cumplido siete años (30), los que ya tienen entendimiento, también los ya mayores, ancianos y ancianas que aun no han recibido la confirmación, que aun no se han fortalecido con la fuerza de este sacramento. Para vencer al diablo, el enemigo de sus almas, prepárense como fuertes guerreros. Vengan todos los que quieren llegar triunfantes a la gloria de Dios junto con los santos y los ángeles. Aquí les darán fuerzas, aquí se armaran con la gracia de Dios (31). Cuando hayan recibido esta gracia, se enfrentarán con el malvado sin temor, y se reafirmarán como cristianos sin vergüenza. Los que quieren llegar al cielo sólo lo lograrán fortaleciéndose. La dicha del cielo sólo es para los que vencen a sus enemigos. Regnum cæloris vim patitur. La vida eterna en el cielo sólo es para los fuertes. La hermosa gloria de Dios es para los que no hacen caso a las mentiras del demonio. Sólo llegarán los que no complacen a la malvada carne, sólo los que aman a Dios con todo el corazón entrarán a la dicha eterna. Este sacramento nos da fuerza para todo esto. Entonces, hijos míos, reciban este sacramento tan estimable, para que, venciendo a su enemigo en este mundo, pueden alcanzar la dicha eterna al lado de Dios. Amen.

(27) Nota marginal: "este sacramento presupone el bautismo"

(28) Nota marginal: "exortación a la confirmación"

(29) Nota marginal: "quienes son los que se han de confirmar"

(30) En su Norte claro del perfecto prelado (1653) el deán de la catedral de Trujillo, Pedro de Reina Maldonado, sugirió que los obispos confirmaran a todos los bautizados en sus visitas a los pueblos de indios, sin importar su edad, debido a la infrecuencia de estas visitas, aduciendo que ésta había sido la costumbre de Santo Toribio de Mogrovejo (1653: 186). El obispo de Quito, Alonso de la Peña Montenegro, haría la misma sugerencia en su Itinerario para parochos de indios (1678: 451). Sin embargo, Castromonte recomienda la práctica contraria de sólo confirmar a los mayores de 7 años.

(31) Nota marginal: "efectos del sacramento" 
Para administrar la comunion la Pascua, y/ las fiestas solemnes del Año/ Al tiempo de la communion el saçerdote buelto a los q. an de comulgar dira <asi $>$ |

Comulĉaypaĉ (54) caĉcuna, ñoĉa huçhaçapa nichic, y si es/ vno solo el q. a de comulgar dira en singular, Ñoĉa huçhaçapa ñy./

El acolito dira la confesion juntamente con los q./ an de comulgar, y acabada dira el saçerdote misereatr (55) vestri etc. a/ y boluiendose al Pueblo con el sacramento en las manos sobre/ la patena dira a los q. an de comulgar. ĉatiçhihuay vl. ĉati=/çhihuayçhic si son muchos./

Ĉapaĉ Dios Jesuçhristo manam camayquiçhu/ cani huçhaĉapa vcuyman yaucumunayquipaĉ: simillapas/ yaya huçhayquitam pampaçhayqui ñihuay huacçhayquicta/ animay quespinanpâ../

Esta oracion se a de deçir tres beses como lo manda/ el ritual, y si los que comulçan (56) son yndios o yndias ladinas, mesti=/sas, o zambas, en habito de Yndias. porq. les muebe a mayor/ devoçion su lenguaje dira asi:/

Señor mio Jesuçhristo manam mereciniçhu (57)/ huçhaçapa cuerpoyman yaycamunayquipaĉ: simillapas Dios mio/ huçhayquictam perdonayqui nihuay huacçhayquicta animay/ quespinanpaĉ./ comulgado./

Antes de deçir la communicanda de la Misa dira/ el sacerdote buelto a los que an

Huasiquipi micuyta puçhucasĉayquiçhiccamaĉa/ amarac toĉanquiçhicçhu, yalli millpuyçhicrac tocayniquiçhicta/ ĉapaĉ Jesuchristo animayquip corpanta muçhayçhic; alabado /f. 8v/ sea el santissimo sacramento ñispa, Yndulgençiasta gana=/ cunayquichicpaĉ, Purĉatoriopi (58) ñacaricuêcunacta ama ĉon=/ĉanquiçhicçhu./

\section{Para dar el Beatico a los enfermos/}

Por estar tan reçeuida en este Reyno la costumbre tan loa=/ble de q. el enfermo haga la protestaçion de la fee antes/ de reçeuir el Biatico quando la enfermedad diere lugar a/ ello, y q. el ritual en munchas rubricas encarga obser=/vançia de semejantes costumbres, el saçerdote diçha la/ antifona asperges me etc. ${ }^{a}$ dira al enfermo lo siguiente./

Dios huacayçhasunqui çhuri: yma huçhay/quitapas yuyanquiracçhu, ñatac confessacunayquipac $=$ si dixie $=/$ re $q$. si oygale, y si no se acuerda de $q$. confessarse digale/

Ĉapaĉ Jesuçhristo Dios Apunçhicmi tareĉniq./ hamun payta çhasquiptiqui animayqui quespinanpaĉ munan=/quiçhu çhasquiita?/

Responda. Aumi Padre./

$$
\begin{aligned}
& (54)=\text { Comulgaypâ } \\
& (55)=\text { misereatur } \\
& (56)=\text { comulgan } \\
& (57) \leq \text { mereceniquiçhu } \\
& (58)=\text { Purgatoriopi }
\end{aligned}
$$


Para administrar la comunión [en] la pascua y las fiestas solemnes del año. Al tiempo de la comunión el sacerdote, vuelto a los que han de comulgar, dirá así:

Los que van a comulgar digan la Confesión General. Y si es uno solo el que ha de comulgar, dirá en singular: Di la Confesión General.

El acólito dirá la confesión juntamente con los que han de comulgar, y acabada dirá el sacerdote "Misereatur vestri" etc., y volviéndose al pueblo con el sacramento en las manos sobre la patena dirá a los que han de comulgar: Repite, vel Repitan si son muchos.

Gran Dios Jesucristo, no merezco que entres a mi cuerpo pecador, pero sólo di que perdonas mis pecados, señor, para que mi alma se salve.

Esta oración se ha de decir tres veces como lo manda el ritual, y si los que comulgan son indios o indias ladinas, mestizas, o zambas en hábito de indias, porque les mueve a mayor devoción su lenguaje dirá así:

Señor mío Jesucristo, no merezco que entres a mi cuerpo pecador, pero sólo di que perdonas mis pecados, Dios mío, para que mi alma se salve.

Antes de decir la communicanda de la misa dirá el sacerdote vuelto a los que han comulgado:

No escupan, traguen su saliva hasta que hayan terminado de comer en sus casas. Adoren al huésped de sus almas Jesucristo diciendo alabado sea el santísimo sacramento para que ganen las indulgencias, y no olviden a los que están sufriendo en el purgatorio.

\section{Para dar el viático a los enfermos.}

Por estar tan recibida en este reino la costumbre tan loable de que el enfermo haga la protestación de la fe antes de recibir el viático cuando la enfermedad diere lugar a ello (32), y [ya] que el ritual en muchas rúbricas encarga observancia de semejantes costumbres, el sacerdote, dicha la antífona "Asperges me" etc., dirá al enfermo lo siguiente:

Dios te guarde hijo/a. ¿Recuerdas algún pecado para que te confieses nuevamente? Si dijere que sí, óigale, y si no se acuerda de qué confesarse, dígale:

El gran Jesucristo Dios nuestro señor viene a encontrarse contigo para que al recibirlo tu alma se salve. ¿Quieres recibirlo?

Responda: Sí, Padre.

(32) La costumbre de que el enfermo hiciera la protestación de la fe antes de recibir el viático deriva del hecho de que la Iglesia peruana fue, durante mucho tiempo, reacia a permitir la comunión entre indígenas, de manera que el viático fue el único contexto en que comulgaban de forma más o menos automática. El III Concilio dispuso que los que no estaban in extremis sólo podían comulgar con una licencia especial de su párroco, añadiendo "que no dexen de dar el viatico a los yndios... con tal que vean en ellos la disposición, que se requiere, que es fee, y arrepentimiento de sus pecados..." (Vargas Ugarte, 1951: 331, 330). 
Sacerd $=\{$ Çheĉanmi ñinquichu $\}$ Alli çhasquinayquipaĉmi, churi santa/ yglesia mamançhicpa, yaçhaçhicusĉanta paypa huahuan/ hinalla villacunayqui canĉa, çhayĉa nihuay ari, cheĉanmi/ ñinquiçhu llapa atipaĉ Dios, tucuy yma haycatapas camaĉ/ Yaya, Çhuri, Espiritu Santo quimsa persona caspa huc ça=/pallan Dios casĉanta?/

Respon: Çheĉanmi ñynim (59)/

Sacerd: Cheĉanmi ñinquitaççhu Dios çhuri huiñay Virgen Mariap huic=/sampi Runa tucusĉanta, Cruspi çhacatasĉa huañusĉanta, quim=/samnim punchauta, causaricusĉanta, hanaĉ paçhaman hui=/çharicusĉantapas?/

Respond: Çheĉanmi ninim/

Sacer. Çheĉanmi ñinquitacçhu cay paçha puçhucaptin, ĉapaĉ Jesuçhristo/ hinantin runacunacta taripâ̂ hamunanta, çhaypac tucuyllan/ huañuĉcuna causarimunanta. alli çhristianocunacta hanac=/paçhaman huynaypac cusiçhic pussananta, mana alli runacunacta /f. 9/ Runacunacta huiñaypaĉ ñacaricuê vcupaçhaman çarĉonanta?/

Resp. Çheĉanmi ninim/

Sacer. Çheĉanmi ñinquitacchu Çhristianocuna, ymaymana huçhanman=/tapas huanacuê sonĉonhuan Padre saçerdoteman confessacup=/tinĉa tucuyllanta Dios Apunçhic Pampaçhapusĉanta?/

Resp. Çheĉanmi ñinim./

Sacerd. Çheĉanmi ñinquitacçhu Santa Yglesiap tucuy yaçhaçhicusĉanta/ yñisĉanta çheĉanmi ñisĉantapas?/

Resp. Çheĉanmi ñinim./

Sacer. Cay <c>hristiano causayllapi causaçaĉpas, huañusaĉpas ñinquitaççhu?/ tucuy sonĉoyquihuan?/

Resp. Ninim Padre./

Sacer. Perdonanquitacçhu pipas çheĉneĉniquicta, Piñaçheĉniqui/cunactapas./

Resp. Perdonaymi./

Sacer. Ĉamĉa çheĉnisĉayquicunacta, huasan rimasĉayquicunactapas/ perdonta mañanquitaççhu?/

Resp. Mañanim Padre./

Sacerd. Alli çhristiano hinalla cunan cay cruzta muchaycuy ñispa/ Çhunca muçhasĉayqui Mayhuacuĉ Jesuçhristo, llapan runa ques=/pinanpaĉmi çruspi (60) huañurĉayqui. Amen./ Sacer. Ñô̂a huçhaçapa ñy, y a los que acompañan ĉamcunapas niçhictaĉ./

Diçha la confession general $=$ dira misereatur tui etc. ${ }^{\mathrm{a}}$ y dira tam=/bien indulgentia absolutione etc.. Sacara luego la forma y mos=/trandola al enfermo dira, Ecce Agnus Dei etc. ${ }^{a}$ y luego dira al/ enfermo = Çheĉanmi ninquiçhu cay huçhaçapa maquihuan/ çharasĉay hostia causaĉ Jesuchristo casĉanta?/

Resp. çheĉanmi ñinim./

(59) $=$ ñinim

$(60)=$ cruspi 
Sacerdote: Para recibirlo bien, hijo/a, debes declarar las enseñanzas de nuestra madre la Santa Iglesia como hijo/a de ella. Entonces, dime: ¿crees en Dios todopoderoso, creador de todo, que siendo Padre, Hijo y Espíritu Santo, tres personas, es un sólo Dios? Responda: Sí, creo.

Sacerdote: ¿Crees en la Encarnación de Dios Hijo en el vientre de la siempre virgen María, en su muerte en la cruz, en su resurrección del tercer día, y en su ascensión al cielo?

Responda: Sí, creo.

Sacerdote: ¿Crees que Jesucristo vendrá al fin de los tiempos para juzgar a todas las personas, que todos los muertos resurgirán para eso, que conducirá a los buenos cristianos al cielo para glorificarlos para siempre, y que expulsará los malvados al infierno para que sufran para siempre?

Responda: Sí, creo.

Sacerdote: ¿Crees que nuestro señor Dios perdona todos los pecados cuando los cristianos los confiesan al padre con corazón penitente?

Responda: Sí, creo.

Sacerdote: ¿Crees en todas las enseñanzas y doctrinas de la Santa Iglesia?

Responda: Sí, creo.

Sacerdote: ¿Te determinas con todo tu corazón a vivir y morir como cristiano?

Responda: Sí, me determino.

Sacerdote: ¿Perdonas a los que te han odiado y a los que te han hecho enojar?

Responda: Sí, perdono.

Sacerdote: ¿Pides perdón de quienes has odiado y de quienes has hablado mal?

Responda: Sí, pido.

Sacerdote: Ahora adora esta cruz como buen cristiano, diciendo esta oración: "Te adoro infinitamente (33), amoroso Jesucristo. Tú moriste en la cruz para que todos las personas se salven. Amén".

Sacerdote: Di la Confesión General, y a los que acompañan: Ustedes también díganla. Dicha la Confesión General, dirá "Misereatur tui" etc., y dirá también "Indulgentia absolutione" etc.. Sacará luego la forma y mostrándola al enfermo dirá "Ecce Agnus Dei” etc., y luego dirá al enfermo: ¿Crees que esta hostia que tengo en mis manos pecadoras es Jesucristo viviente?

Responda: Sí, creo.

(33) Çhunca muçhasĉayqui - literalmente "te adoraré diez veces". 
Sacer. Tucuy sonĉolla ĉatiçhihuay ñisĉayta $=$ Ĉapac Dios Jesuçhristo/ manam camayquiçhu cani huçhaçapa vcuyman etc. como esta arriba./

Asllacamaĉa amaraĉ toĉanquipaççhu (61), alabado sea, el santissimo/ sacramento ñinqui aycapas yapaspa açhca yndulgençiasta ga=/nacunayquipaĉ. /f. 9v/

$\mathrm{Si}$ Por alguna causa repentina, o accidente grande no pudiera comul=/gar el enfermo le mostrara la forma consagrada y el enfer $=/$ mo, la adorara Diciendo $=$ Çhunca muçhasĉayqui mayhua=/cuê Jesuçhristo, llapan runa Gespinanpaĉmi (62) cruzpi huañurĉayq./ cuyapallay señor yahuarniquip chanin animayta. Amen./

Sacerd. Santo olio Extrema Vnçion sutiyoĉ sacramento=/racmi queparin çhasquinayqui, çhayhuanmi huañuyniqui pa=/çhapâ̂ gracianhuan Diosninçhic callpaçhassunqui, huchayqui=/pas ashuan piçhasĉam canĉa, yallincama llumpaĉlla Dios=/pa cayllanman çhayanayquipaĉ, causanayqui captinĉa Santo/ oliocta çhasquispataĉmi allianqui, çhay tucuypaĉ mañacunqui=/çhu extrema vnçion ñisca sacramentocta./

Resp. Manaymi Padre./

Sacerd. Noĉa ançhaycuptiquiĉa çhasquiçhisĉayqui = Y buelto a la Ygle=/sia anunçia las Yndulgençias a los q. acompañaron al S.r/ diçiendo./

Santissimo Sacramentopi Jesuchristo Dios Apun=/çhic cay onĉô̂ta tariĉ, visitaĉpas riptin ĉatiĉcunam, huc ru=/na cuyapayay obra de misericordia ñiscaĉta (63) ruramunquiçhic/llapa: $=$ Santo Padre Papacuna Romapi tiac $;$ Gregorio deci=/mo tertio, Paulo quintohuantacmi Paçhac Pun<c>hautacama/ ĉarpupussunquiçhic, huçhayquiçhicmanta $\{\mathrm{mu}\}$ Purĉatoriopi/muçhunayquiçhic caĉta, chaytam Yndulgençia ñinçhic, Yalli/ Paulo quintoĉa Purgatoriopi huçhancunaraycu ñacarinan caĉ/ hinantin çarpusĉa <ca>çhun ñissunquiçhicracmi, çhaymi Yndul=/gençia Plenaria sutiyoc. Rauraĉ candelacta apaĉcunaĉa,/ yma ynsigniacta marĉaĉcunahuampas Dobladota çhay perdoncu=/nacta ganacunquiçhic llapa./

Gapaĉ (64) Yayançhicta tiananpi çhurasĉayca=/ma, huc mita Yayaycucta, muçhaycusĉayqui mariatahuan/ resacuyçhic: huañuy huçhapi causaĉcunacta ĉapaĉ Dios cuya=/paycunanpaĉ = Purgatoriopi nacaricuĉcunactari gloriaman ques=/ piçhinanpaĉ /f. 10/

(61) = toĉanquiraççhu

(62) = quespinanpaĉmi

(63) $=$ ñisçacta

(64) $=\hat{\mathrm{C}}$ apa $\hat{c}$ 
Sacerdote: Repite lo que digo con todo tu corazón: Gran señor Jesucristo no merezco que entres a mi cuerpo pecador etc., como está arriba.

No escupas por un tiempo. Di alabado sea el santísimo sacramento, repitiéndolo varias veces para que ganes muchas indulgencias.

Si por alguna causa repentina, o accidente grande no pudiera comulgar el enfermo, le mostrará la forma consagrada, y el enfermo la adorará diciendo: Te adoro infinitamente, amoroso Jesucristo. Tú moriste en la cruz para que todas las personas se salven. Apiádate, señor, de mi alma que redimiste con tu sangre. Amén.

Sacerdote: Falta que recibas el sacramento del santo olio llamado extrema unción. Con este sacramento nuestro Dios te dará fuerzas en el momento de tu muerte, y serás limpiado de tus pecados para que llegues inmaculado ante la presencia de Dios. Si haz de vivir, te mejorarás al recibir el santo olio. ¿Pides el sacramento llamado extrema unción para todo esto?

Responda: Sí, pido.

Sacerdote: Yo te lo daré cuando se acerque la hora de tu muerte. Y vuelto a la iglesia anuncia las indulgencias a los que acompañaron al Señor (34), diciendo:

Los que siguieron a Jesucristo Dios nuestro señor en el santísimo sacramento cuando fue a visitar a este enfermo han hecho una obra de misericordia. Los santos padres papas de Roma Gregorio XIII y Pablo V les absuelve (35) a cada uno de ustedes de cien días que habían de sufrir en el purgatorio por sus pecados. Esto se llama indulgencia. Más aún, Pablo V les absuelve de todo lo que habían de sufrir en purgatorio. Esto se llama indulgencia plenaria (36). Los que llevaron velas encendidas y los que cargaron alguna insignia ganan estos perdones doblados.

Mientras coloco a nuestro señor en el sagrario (37), digan un Padre Nuestro y un Ave María para que Dios se apiade de los que viven en pecado mortal, y para que lleve a la gloria a los que están sufriendo en el purgatorio.

(34) Las siguientes palabras van dirigidas a los feligreses que habían acompañado al cura mientras llevaba la hostia consagrada de la iglesia a la casa del enfermo, en la administración del viático, y en la devolución de la hostia al sagrario en la iglesia. Las indulgencias que se ganaban con estas acciones se describen en Prado, 1641: f. 138 y en Pérez Bocanegra, 1631: 494, 499.

(35) carpupussunquiçhic - no he podido identificar la raíz /qarpu-/. La acción de absolver generalmente se traducía como pampacha- ("nivelar") o pasca- ("desatar").

(36) Esta indulgencia plenaria requería la compra de la Bula de la Santa Cruzada (Pérez Bocanegra, 1631: 499-500).

(37) tiananpi - "en su asiento" o "en su trono". 


\section{Para administrar la extrema vncion (65)./}

Auiendo el sacerdote Diçho la antifona Asperges me etc. ${ }^{a}$ se/ llegara al enfermo y dira lo siguiente./

Churi cuyapayacuê Dios yanapassunqui. yapay/ confesacunayquipaĉ, yma huçhayquitapas yarpanquiraççhu? Si/ tiene q. confessar confieselo y si no prosiga como esta en el/ ritual, desde el verso adiutorium nostrum etc. y auiendo/ diçho indulgentia etc. dira a los çircunstantes./

Cay onĉôta Santo oliohuan llusiscaycama tu=/cuyllayqui Diosta muçhapuyçhic huçhancunacta pampaçha=/punanpaĉ./

Acabada la vncion y diçhas las preçes y ora=/çiones dira al enfermo $=$ Çhuri ayca huçhaçapatapas cu=/yapaycamanĉataĉmi Diosniĉa ñiĉ soncolla ĉatiçhihuay cunan./

Çhicapi, cunanĉa Dios Apu camasĉayqui hu=/acçhayquita cruspi huañuspa quespiçhisĉayqui $<\mathrm{c}>\mathrm{ta}$, sacramen=/toyquicunahuan vyhuasĉayquicta manyayquiman hamuy ñi=/huay, çhenequey (66) çupayta ĉarcopuay, Santo Angelniquihuan/ tinquiçhahuay, gloriayquiman çhayamuspa huyñay muçhaycunaĉpaĉ. Amen./

Luego dira a los q. asisten al enfermo = Amam/ çaquerinquiçhicçhu cay onĉocta ĉamcuna, Jesus Perdonahuay,/ Virgen Maria muçhapuay. Santo Angelnii yanapahuay ñy ñin=/quiçhic llapa, bendisasĉa yacuan puñunan tumariĉta maĉ=/çhipunquiçhic llapa çupay ayquenanpaĉ. Ançhaycuptin hui=/llaçhihuanqui, pitinayacta yanapaĉ hamunaypaĉ./

Con aduertençia no se puso la Platica breue/ q. manda el Ritual se haga de la virtud, y efficaçia del sacra=/mento de la extrema vnçion, porq. diçe se haga quando el ti=/empo diere lugar, Y nunca llaman al cura los Yndios para/ olear al enfermo sino quando esta ya sin habla, y assi para/ vn caso raro parese que basta lo diçho, remitiendo la explicaçion/ de la virtud deste, y de los demas sacramentos de la Yglesia a los/ sermones ordinarios de entre año. /f. 10v/

\section{Para Vissitar a los enfermos que estuuieren en Peligro de muerte./}

Auiendo hecho el sacerdote lo q. para esta sazon/ ordena el ritual, en todo, o en parte, exhortara al enfer=/mo q. haga las Protestaçiones siguientes, dictandoselas/ con affecto de charidad = El Padre D. Antonio de/ molina en su Ytinerario para la Eternidad Affirma/ q. son reueladas, y otros authores de muy grande authori=/dad las traen por cossa de summa vtilidad para aquel/ tiempo tan apretado. Demas de q. contienen los Puntos/ q. manda el ritual, se aduiertan al enfermo en aque=/lla hora, y assi llegandose el sacerdote al paçiente con amor/ de Padre le dira primero asi./

(65) Nota marginal: "Extrema Vncion"

(66) $=$ çheĉnequey 


\section{Para administrar la extrema unción (38).}

Habiendo el sacerdote dicho la antífona "Asperges me” etc. se llegará al enfermo y dirá lo siguiente:

Hijo/a, Dios misericordioso te ayude. ¿Recuerdas algún pecado para que te confieses nuevamente? Si tiene que confesar, confiéselo, y si no, prosiga como está en el ritual, desde el verso "Adiutorium nostrum" etc., y habiendo dicho "Indulgentia" etc. dirá a los circunstantes:

Mientras unjo con el santo olio a este enfermo todos ustedes rueguen a Dios para que perdone sus pecados.

Acabada la unción, y dichas las preces y oraciones, dirá al enfermo: Hijo/a, repite ahora lo que digo con la certeza de que Dios tendrá misericordia de ti por muy pecador que seas.

Señor Dios, llama a tu lado a tu pobre a quien creaste, a quien salvaste al morir en la cruz, y a quien criaste con tus sacramentos. Expulsa a mi enemigo el diablo, y úneme con tu ángel para que llegando a tu gloria te pueda adorar para siempre. Amén (39).

Luego dirá a los que asisten al enfermo: No abandonen a este enfermo, díganle que le pida a Jesús que le perdone, a la Virgen María que interceda por él, y a su santo ángel de la guarda que le ayude. Salpiquen agua bendita alrededor de su cama para que todos los diablos huyan. Cuando esté por expirar me harán avisar para que yo venga a ayudarlo en la hora de su muerte.

Con advertencia: no se puso la plática breve que manda el ritual se haga de la virtud y eficacia del sacramento de la extrema unción, porque dice se haga cuando el tiempo diere lugar, y nunca llaman al cura los indios para olear al enfermo sino cuando está ya sin habla, y así para un caso raro parece que basta lo dicho, remitiendo la explicación de la virtud de este, y de los demás sacramentos de la iglesia a los sermones ordinarios de entre año (40).

\section{Para visitar a los enfermos que estuvieren en peligro de muerte.}

Habiendo hecho el sacerdote lo que para esta sazón ordena el ritual en todo o en parte, exhortará al enfermo que haga las protestaciones siguientes, dictándoselas con afecto de caridad. El padre don Antonio de Molina en su "Itinerario para la eternidad" afirma que son reveladas, y otros autores de muy grande autoridad las traen por cosa de suma utilidad para aquel tiempo tan apretado, demás de que contienen los puntos que manda el ritual. Se adviertan al enfermo en aquella hora, y así, llegándose el sacerdote al paciente con amor de padre, le dirá primero así:

(38) Nota marginal: "extrema unción"

(39) Esta oración no está en el Rituale romanum ni en los rituales de Oré y Bocanegra.

(40) En otras palabras, el párroco de indios debía explicar la importancia de los sacramentos en los sermones que estaba obligado a predicar cada domingo y día de fiesta del año. Para esto disponía de los sermones sobre los sacramentos del III Concilio Limense, impresos en 1585 y reeditados por Fernando de Avendaño en 1648. 
Dios cuyapayassunqui çhuri. ançha cuyaĉniqui ya=/yayquita hinalla vyarihuay cunan ñisçayta $(67)=$ Diosmi ĉam $=/$ raycu ançhanninta rurarĉan, hanac paçhamanta vraycu=/muspa, ĉamraycu Runa tucuspa, quespinayquipacri, ñacari=/cuspa, ançha yupay yahuarninhuan animayquicta rantispa,/ çhayĉa ari ĉamsi cunan (alli çhristiano hina) çhica cuyac ya=/yacta mana tucuy sonĉolla Yupayçhasĉayquicta llaquicunqui,/ paypas perdonasunqui paçhatacmi ari. Yuyacuy alli pacta/ çupay pantaçhisunquiman, huateĉaspa, manam Diosĉa perdo=/nassunquimançhu ñispa, amam siminta çhasquipunquiçhu/ çhuri, mana atipaymi Diosninçhicpa mayhuacuĉ sonĉonĉa,/ Paypa çhurintacmi ari canqui ĉamĉa, Huanacuĉ sonĉolla per=/donahuay ñihuanman, çhayllam perdonarĉoyman, niçh=/canmi Dios yayayquiĉa çhuri, çhayĉa perdonahuay yaya/ huanacusaĉmi ñicuy. Mamayqui Virgen Maria copacabanata/ yanapahuay ñinqui, Santo Angel huaĉayçhacniquita, sayapa=/yahuay ñinqui. llulla simi çupaysi, yma ñispapas mançhaçhi=/sunqui, Diospa alli caynillanpim suyacuni ñinquim(68). Huçha=/ çapacuna quespinanpaĉ huañusĉanraycum, perdonahuanĉa yayayĉa/ ñinquim, ñiĉ sonĉoyquihuanmi, aycapas cruzta muçhanqui, cunan /f. 11/ ari tucuy sonĉoyquihuan, quiquiqui rimac hinalla ĉatiçhihuay/ rimasĉayta./

\section{Primera Protestaçion./}

Ĉapaĉ Dios, Santa Trinidad, Yaya, çuri, Espiritu Santop sutimpi/ Amen. Tucuyllan hanaĉ Paçhapi caĉpas, cay Paçhapi causaĉ=/cunapas, cay rimasĉaypaĉ testigo cayçhic llapa./

Noĉa. N. Romapi Apuyoĉ, Santa Yglesia Yaçha/çhicusĉanta, çheĉanmi ñisĉanta. Fe chatolicacta (69) çhasquicus=/pa, tucuy sonĉoyhuan çheĉantam ñin ñispa, cauçasaĉpas, hua=/ñuçacpas ñinim. Cayta çheĉan ñispataĉmi, hinantin santocu=/na, çielopi caĉpas (70) huañurĉan llapa: Paycunacta ĉaticusaĉ/ ñinim, çuc çuc rimayta Santa Yglesia atatay ñiscantaĉa/ llullam ñisĉantaĉa, çhay hinallataĉmi Ñoĉapas ñini./

\section{Segunda Protestaçion./}

Çhaymantam, allpa tiulla millaymana huçhay captimpas,/ yayay Jesuçhristop ñacaricusĉanraycum cuyapayacuĉ Diosĉa/ tucuy huçhayta perdonahuanĉam, hanaĉ paçhamantacmi/ pusahuanĉa ñispam taquiaĉ sonĉolla Diospa allin cayninpi/ suyacuni. Jesuçhristop yahuarninĉa ari, huc hutuylla/ caĉpas, tucuyllan runacunap huçhantam mayllaripunman./

(67) Nota marginal: "Para q. confie en la misericordia de Dios."

(68) Nota marginal: "Como resistira a las tentaçiones del enemigo."

(69) = catholicacta

(70) $\leq$ ĉâpas 
Dios tenga misericordia de ti, hijo/a. Escúchame ahora como a tu padre que te quiere. Dios ha hecho muchas cosas por ti (41): bajó del cielo, se hizo persona por ti, sufrió para que te salvaras, y redimió tu alma con su preciosa sangre. Por eso si ahora, como buen cristiano, te apenas de no haber venerado con toda tu alma a un padre tan misericordioso, Él te perdonará. Recuérdalo bien, ten cuidado de que el diablo no te engañe tentándote y diciéndote que Dios no te perdonará. No escuches lo que te dice, el amor de Dios lo vence todo y tú eres su hijo. Tu padre Dios te perdonaría al instante si tú se lo pidieras con corazón penitente, así que tú dile: "Perdóname señor, me enmendaré". Pídele ayuda a tu madre la Virgen de Copacabana, pídele a tu ángel de la guarda que te apoye. Si el diablo te asusta con sus mentiras, ten confianza en la bondad de Dios (42). Confía en que te perdonará, ya que murió para salvar a los pecadores, y pensando en esto adora la cruz. Ahora repite lo que digo con todo tu corazón, como si fueran tus propias palabras.

\section{Primera protestación.}

En el nombre del gran Dios, de la Santa Trinidad, Padre, Hijo y Espíritu Santo, amén. Todos los que están en el cielo y los que viven en esta tierra, sean testigos de lo que digo.

Yo, N., me determino a vivir y morir recibiendo la fe católica y afirmando con todo mi corazón la verdad de las enseñanzas y creencias de la Santa Iglesia cuyo señor está en Roma. Todos los santos y los demás que están en el cielo murieron creyendo esto. Me comprometo a seguir su ejemplo, y rechazo todo las afirmaciones contrarias que la Santa Iglesia rechaza y desmiente.

\section{Segunda protestación.}

Aunque mis pecados sean innumerables y abominables, con corazón firme espero en la bondad de Dios, y confió en que Dios misericordioso perdonará todos mis pecados por el sufrimiento de mi señor Jesucristo y me llevará al cielo. Pues en verdad la sangre de Jesucristo, incluso una sola gota de ella, es capaz de lavar todos los pecados de la humanidad.

(41) Nota marginal: "para que confíe en la misericordia de Dios"

(42) Nota marginal: "cómo resistirá a las tentaciones del enemigo" 


\section{Terçera Protestaçion./}

Çhaymantataĉmi paĉta huallca sonĉo caspa, Diospa tari=/payninta mançhaspapas, çupay llullaycaçhisĉapas, onĉoyni=/huan musparispapas, çheĉanmi Fe catholica yaçhaçhicus=/ĉan ñisĉaymanta. Diospa alli cayninpi suyacusĉaymantapas/ pantacurĉoyman, sonĉoypas çhançhaycaçhanman, yuyay=/huampas, Rimayhuanpas, Rurayhuampas, cunan tucuy son=/ĉcoyhuan, Dios ĉmasgan yuyaynihuan caspataĉmi, çhay tu=/cuytaĉa yanĉam ñini, ama yupayçhu caçhun ñinim, Apu/ Diostapas muçhaycunim, ama çhaymantaĉa yaya huçhaçha=/huanquiçhu ñispa, Yalli cunanmantatacmi, Santa Yglesiap/ çheĉanmi ñisĉanmanpas, suyacusĉanmanpas, hucllaçhacuspa/ Diospa misericordianta cayacuni. /f. 11v/

\section{Quarta Protestaçion/}

Çhaymantataĉmi, ĉapaĉ Diosta, Yma haycatapas yalliĉnin/ cuyayhuan, pay camaçhicusĉan hina, cuyaypaĉ casĉan hina=/taĉ cuyacuyman ñinim, yalli çielopi cấ Angelcunapas/ hinantin Santocunapas, cay paçhapi allin çhristianocu=/napas, Diosta cuyasĉan hina ñoĉapas cuyayman ñinim/ sonĉoypi, payta hinantin cuyasĉanmantapas, cusicunita $\hat{c}=/ \mathrm{mi}$. Yçhaĉa ñoĉa mana tucuy sonĉoyhuan Diosta cuyasĉay=/ta yuyaspam llaquicuni, çhica alli Yaya casĉanta, çhica mu=/nayllapac casĉanta, yuyacuspataĉmi, siminta mana $y u=/$ payçhaspa piñaçhisĉayta puticuni./

\section{Quinta Protestaçion/}

Çhaymantam, Diospa munaynillanman çhasquiçhicuni/ ymay paçhapas, huyñay paçhapas, munasĉallanta ñoĉamanta/ rurananpaĉ, cunanmantataĉmi, chicapi huañuçhun ñinan=/ta, allim yaya ñicuni, Jesuçhristop ñacaricusĉanraycu/huañusĉanraycuhuantaĉ, Virgen Maria Mamanraycu, tu=/cuyllan santocunaraycuhuantaĉ, huçhayta pampaçha=/ puay ñinim Diosta, çheĉan contriçionhuan huañunaypaĉ,/ Yanapahuay yaya ñispam muçhaycuni ĉapaĉta, cay ñiscay=/cunacta ricaçhispataĉmi vllpuy sonĉlla mañacuni, gloriapaĉ ac=/llasĉacunahuan, yupahuay ñoĉa çhuriquicta ñispa mana in=/fiernoman ĉarcoaspaĉa, munasĉayquicama Purĉatoriopi ñaĉa=/riçhun ñihuay, ñinim Diosnita./

\section{Sexta Protestaçion/}

Çhaymantatacmi tucuyllan munaynihuanmi munacuni, hi=/nantin sonĉoyhuantacmi cussicuni (Dios cuyaycusĉa) çhris=/tiano <cas >cayta, hinaspam tucuy yma $<c>$ tapas alli çhristiano hina=/lla yuyasĉaymanta, rimasĉaymanta, rurasĉaymantapas, yallin/ camam cussicuni, yalli manas çhristianoçhu cayman cunanmi/ Baptismota çhasquicuyman, çhayraycum llaquini alli çhristi=/f. 12/ano hina causayta pantacusĉaymanta, cunanmantaĉa huañus=/ĉaycamapas, (Diospa graçianhuan) alli çhristiano hinallam/ cauçasaĉ ñinim tucuy sonĉoyhuan./

A! Santo Angel huaĉaychaĉni çhunca/ muçhasĉayqui, cay tucuyllan (Diospa yanapayninhuan) rimasĉay=/ta, cay testamentoyta, cay quepa munayta, Santa Trinidad/ paĉtaynaĉ Apu Diosman ricaçhipuay yaya, huacçhanta cu=/yasĉanraycu, huiñay muçhasĉa cananpaĉ. Amen./ 


\section{Tercera protestación.}

Aunque sea pusilánime, aunque tema el juicio de Dios, aunque el diablo me engañe y yo delire por mi enfermedad, aunque en mis pensamientos, dichos y hechos me desvíe de mi creencia en las enseñanzas de la fe católica y de mi esperanza en la bondad de Dios y mi corazón desespere (43), ahora con todo mi corazón, estando con mi entendimiento que recibí de Dios, digo que todo esto sea vano y que no valga. Ruego al señor Dios y le pido que no me culpe por esto. Desde este momento, uniéndome a la Santa Iglesia en lo que ella cree y espera, pido su misericordia.

\section{Cuarta protestación.}

Me determino a amar a Dios por sobre todas las cosas, según Él lo ordena, y según Él merece ser amado. Me determino a amar a Dios como los ángeles del cielo y todos los santos y los buenos cristianos en esta tierra lo aman, y me regocijo por el amor que todos le tienen. Me lamento al recordar que no he amado a Dios con todo mi corazón, y recordando que es un padre muy bueno y muy querible, me acongojo por haberle hecho enojar al no valorar su palabra.

\section{Quinta protestación.}

Me entrego a la voluntad de Dios para que haga de mi su voluntad ahora y siempre, y si fuera a determinar que yo muera ahora lo aceptaría de buena gana. Le pido a Dios perdón de mis pecados por la pasión y muerte de Jesucristo, por su madre la Virgen María, y por todos los santos. Ruego al poderoso que me ayude a morir con verdadera contrición, y haciéndole ver mis deseos le pido con corazón humilde que me cuente a mi, su hijo, entre los elegidos para la gloria. Y le pido a mi Dios que no me expulse al infierno, sino ordene que sufra en el purgatorio según su voluntad.

\section{Sexta protestación.}

Deseo con toda mi voluntad y me alegro con todo mi corazón [de] ser un cristiano amado por Dios, y me alegro por todo lo que he pensado, hablado y hecho como buen cristiano, y si no fuera cristiano recibiría el bautismo ahora. Por eso me apeno por haberme desviado de la vida del buen cristiano. Me determino a vivir como buen cristiano, con la gracia de Dios, desde ahora hasta mi muerte.

O mi ángel de la guarda, te adoro infinitamente, muestra todo lo que he dicho con la ayuda de Dios, este mi testamento, este mi último deseo, a la Santa Trinidad, Dios el señor sin igual, para que sea adorado para siempre por su misericordia. Amén.

(43) soncoypas çhançhaycaçhanman - no he podido identificar la raíz /chancha-/. 


\section{Acto de Contriçion Vtilissimo diçho con verdadero Dolor de auer offendido a Dios/}

A Ĉapac Dios, huçhaymi, camta piñaçhisĉaytam llaquini (71)/ manam huçhaymanta ñacarinaytaçhu, Señor. $=$ Adui=/ertasele al enfermo q. diga muçhas veçes = Santissimo/ Sacramento muçhasĉa caçhun/

Para ayudar a los q. estan en el tran=/çito de la muerte./

Jesusta cayay çhuri pissi rimaspapas, sonĉollayquihuanĉa/ aycapas Jesus ny (72), Jesus quespiçhihuay, huacçhay cuyâ̂/ Virgen Maria yanapahuay: santo Angel huaĉayçhaĉni/ Diosta muçhapuay. = Sonĉollayquihuampas çhuri ha=/maspa, hamaspa catiçhihuay ñisĉayta./

Miserere mei Deus etc. ${ }^{a}$

Cuyapahuay Dios Apu: mana rimay cuyapayacuĉ son=/ĉyquihuan. Yaya./

In te Domine speraui etc. ${ }^{\circ}$

Ĉamllapim Jesus ñucñu huamraymanta suyacurĉani:/ çhica allipaĉraĉ Diosnipi suyacurĉani ñicusaĉmi ymay/ paçhacamapas./

In manus tuas Domine etc. ${ }^{2} /$

Ĉampa maquillayquipim, yaya animayta çhasquiçhiiqui $\mathrm{cam}=/$ mi quespiçhihuarĉayqui, Cruspi huañuspa, â mana pantaĉ Dios. /f. 12v/

Deus in adiutorium etc. ${ }^{\mathrm{y}} \%$

Çhicap yanapayasaĉ çhurita nillapuay yaya: Vtcascamuy (73)/ huacçhayquita yanapaycuê./

Esto mihi in Deum etc. ${ }^{2}$

Mayhuacuĉ Jesus, Cuyacuê Yaya: huçhay intuaptin, chê̂/nequey çharahuaptimpas, cam amaçhahuanqui: ĉam Jesus/ ñucnu rimapuanqui./

Deus propitius esto mihi etc. a/

Llampuy sonĉolla ĉahuarihuay Dios ĉapaĉ: Ñốa huçhaçapa/ vyhuayquicta/

Dulcissime Domine etc./

Ñucñulla Jesus Yaya, tucuyllan ñacaricusĉayquip çhaninray=/cu, gloriayquipaĉ acllasĉayquicunahuan yupahuay çhuriquicta/

Domine. Jesuchriste etc. ${ }^{\circ}$

Ĉapaĉ Jesuçhristo yahuarniquihuan rantisceayqui animayta/ hamuy nillay: çhasquipullahuay yaya./

(71) $\leq$ llaquimi

$(72)=\tilde{\text { ni }}$

(73) $i=$ Vtĉasĉa hamuy? 


\section{Acto de contrición utilísimo dicho con verdadero dolor de haber ofendido a Dios.}

O Dios, he pecado. Me apeno por haberte enojado, no por lo que habría de sufrir por mis pecados. Adviértasele al enfermo que diga muchas veces: Adorado sea el santísimo sacramento.

\section{Para ayudar a los que están en el tránsito de la muerte.}

Hijo, llama a Jesús, y si no puedes hablar, llámalo en tu corazón, pídele que te salve, pídele a la misericordiosa Virgen María que te ayude, y a tu ángel de la guarda que ruegue a Dios por ti. Aunque sea en tu corazón, hijo, repite lo que digo pausadamente (44).

\section{Miserere mei, Deus etc.}

Ten misericordia de mi, Señor Dios, con tu misericordia indescriptible.

In te, Domine, speravi etc.

En ti solamente esperé desde que era un niño, mi dulce Jesús, y para siempre afirmaré que mi esperanza en ti fue para un gran bien.

In manus tuas, Domine etc.

En tus manos, señor, entrego mi alma. Tú me salvaste al morir en la cruz, O Dios que no se equivoca.

\section{Deus in adiutorium etc.}

Señor, disponte a ayudarme, ven rápido a ayudar a tu pobre.

\section{Esto mihi in Deum etc.}

Amoroso Jesús, cariñoso padre, cuando esté cercado por mis pecados y ya en manos de mi enemigo, protéjeme. Tú, dulce Jesús, serás mi abogado.

Deus propitius esto mihi etc.

Mírame con misericordia gran Dios, a mi, tu criatura pecadora.

Dulcissime Domine etc.

Dulce Señor Jesús, por el valor de tus sufrimientos, inclúyeme a mi, tu hijo, entre los que elegiste para tu gloria.

Domine Iesuchriste etc.

Gran Jesucristo, llama a mi alma que redimiste con tu sangre y recíbela, padre.

(44) hamaspa, hamaspa - "descansando". Cf. la traducción de Bocanegra de la rúbrica correspondiente del Rituale romanum: "Amonestarle a... que de la manera q[ue] pudiere, por lo menos con el coraçon, ore desta manera, con algunos espacios de tiempo" (Pérez Bocanegra, 1631: 549). 


\section{Maria Mater Pauperus etc./}

Huaçha (74) cuyâ̂ Maria, cuyapayacuê Diospa maman, ama=/çhahuay çheĉnequeymanta, pitiipi Señora hamullay ñihuanq. (75)/

Sancte Angele custos etc./

Diospa Santo Angelnin, huiñay huaĉayçhaĉnii, paĉta au=/ĉay atirĉoanman: cunan sayapayahuay yaya./

Omnes sancti etc. $\%$

Llapantin Angelcuna, hinantin Santocuna gloriapi caĉpas/ ñoĉa huacçhapaĉ muçhapuayçhic, Diosta yanapaytac ni=/çhic, auĉaypa maquinmanta quespinaypaĉ. Amen./

Luego dira a los q. asisten al enfermo, y a los cir=/cumstantes $=$ Tucuyllayquiçhic Diosta muçhapuyçhic, mana/çhu ĉamcunamanta (76) mayĉaniquipis hina caspa $\mathrm{p}<\mathrm{i}>$ llapas ya/napahuanman ñinquiçhicman? çhayta yuyaspa cay oncoĉ hu=/añunayaĉ captim, capaĉ Diosta huçhanta pampaçhapullay/ ñispa muçhapuyçhic llapa./

Acabada la antip $<\mathrm{h}>$ ona asperges me etc. ${ }^{\text {a }}$ dira $/ \mathbf{f . ~ 1 3 / ~ a l ~ e n f e r m o ~ m o n s t r a n d o l e ~}$ vn crucifixo, o dandole a besar la cruz./

Cay cruspi çhacatasĉa huañuc Jesusta ĉayacuy/ çhuri, Jesus cuyapayahuay ñi, yanapasunqui paçham cuyacuĉ/ yayayquiĉa. Jesus Maria ñy, glorianmammi pusacussunqui payta çayaptiquiĉa çhuri./

A los çircumstantes les dira esto q. se sigue an=/tes de deçir las letanias = Çucniqui rinrinpi Jusus (77) Maria/ ñypay, huaquinĉa Diosta muçhapuyçhic, hinantin Santocu=/nactapas, cunan yanapananpaĉ, ñoĉa Diosta muçhapusĉayca=/ma, ĉamcunapas muçhapuyçhictaĉ, Diosta./

Diga luego el saçerdote las letanias pre=/çes, y letanias encomendandole el alma, como esta en el ritu=/al, y al tiempo q. espire ayudele diçiendo Jusus. Jesus. Maria/ y auiendo espirado digale el responso, Subuenite etc. ${ }^{\text {/ }}$

(74) $=$ Huacçha

(75) $\leq$ ñihuay

(76) $\leq$ camcunapas

(77) $=$ Jesus 


\section{Maria mater Pauperus etc.}

Misericordiosa María, compasiva madre de Dios, protéjeme de mi enemigo y llámame en la hora mi muerte.

\section{Sancte Angele custos etc.}

Santo ángel de Dios, que siempre me protege, no permitas que mi enemigo me venza, protégeme ahora.

\section{Omnes sancti etc.}

Todos los ángeles y santos que están en la gloria, rueguen por mi a Dios, pídanle que me ayude para que me salve de las manos de mi enemigo. Amén.

Luego dirá a los que asisten al enfermo, y a los circunstantes: Todos ustedes rueguen por él a Dios. ¿Acaso ninguno de ustedes desearía tener quien les ayude al estar así? Piensen en esto, y cuando este enfermo esté moribundo pídanle a Dios que perdone sus pecados.

Acabada la antífona “Asperges me” etc., dirá al enfermo mostrándole un crucifijo o dándole a besar la cruz: Llama a Jesús que murió crucificado en esta cruz, pídele que tenga compasión de ti, y tu misericordioso padre te ayudará de inmediato. Di "Jesús María”, Él te llevará a su gloria si tú lo llamas.

A los circunstantes les dirá esto que se sigue antes de decir las letanías: Uno de ustedes diga "Jesús María” en su oído, y los demás rueguen a Dios y a todos los santos para que lo ayuden ahora. Mientras yo ruego a Dios, háganlo ustedes también.

Dirá luego el sacerdote las preces y letanías encomendándole el alma, como está en el ritual, y al tiempo que expire ayúdele diciendo "Jesús María”, y habiendo expirado dígale el responso "Subvenite" etc. 


\section{Del sacramento del matrimonio/}

Forma de las amonestaciones, mutatis mutandis/

Vyayçhic llapayqui. Martin Ticlayauri cay/ Huancabamba llactayoĉ Çhaupis (78) ayllu, Pedro/Haçhap churin, Maria Ĉolquipa huahuan Diospa yanapay=/ninhuanmi, Santa Yglesiap camaçhisĉan hina casaracuy=/ta munan Ynes çhoquehuan, cay huarmin quiparaĉra/ marcayoĉ ô llactayoĉ Tambos (79) ayllu, Luis/Pomap çhurin clara çhiuçhip huahuan, pacta caycuna/ hallan, hallanpas mana Baptizascea canman, Bautismopi/ Confirmaçionpipas marĉanacuê canman: huc yahuarllapas/ ançha hicpa purallapas canman, maypipas çuchuan desposas=/ĉa canman, ymactapas pissi casaracunanpaĉ yaçhaĉcunaĉa,/ huillacamuyçhic llapa, chayta pacaĉĉa Diospa taripayninpim/ ançha huçhaçhasĉa canquiçhicman, caymiñaupaĉ, vl. ys=/caynin, vl. quimçannin amonestaçion. /f. 13v/

Esta forma de amonestar mutatis mutandis esta muy/reçeuida en este arçobispado de los Reyes, y se debe obser=/uar por ser en la substançia la misma q. enseña el/ritual, y muy allegado a las rubricas del su vso./Por ser mas breue la forma de amonestar q. pone el ritu=/al podra seruir para la segunda, y terçera bes la qual/ dice Assi./

Vyarihuayçhic llapayqui, Sebastian Riui/ cay vllucmayo llactayoĉ ollĉom collệa Pachac Allauĉa Ayllu/ Pedro Ayrap çhurin, Catalina Anapa huahuan, Diospa yanapayninhuan munan casaracuyta, Pascu<a>la çhequiayhuan/ cay huarmin carhuamayo llactayoĉ, llacsamayo Paçhac çha=/upis ayllu Julian de la cruspa çhurin, Ynes toctop huahuan/ Paĉta mayçayquiçhicpas, yaçhanquiçhicman caycuna ançha hicpa/ pura casĉanta, Baptismopi, Confirmaçionpipas marĉanacuê/ casĉanta, ymamantapas pissi casaracunan yaçhacusĉanta $\mathrm{y}=$ /matapas ari musiaccunaĉa huillacamuyçhic, caymi iscay=/nin vl. quimçannin amonestacion. $=$ En respondiendo/ los sircunstantes allim casaracunĉa./

\section{Desposorio}

Los contrayentes a la puerta de la yglesia como es costum=/bre dira el saçerdote al varon./

Sebastian Riui munanquiçhu cay Pascu=/ala çhequiayta (80) huarmiquipaĉ çhasquita, santa ygle=/sia Mamançhic camaçhisĉan hina? = Responda munami./

Luego le preguntara el Saçerdote a la/ muger Diçiendo = Pascuala çhequiay munanquiçhu cay/ Sebastian riuita cosayquipac çhasquita Santa Yglesia ma=/mançhic camaçhisĉan hina $?=$ Responda munaymi $=\langle$ Sacer.$>$ allau $=/$ ĉa maquipura çharanacuyçhic $=$ Quod Deus coniunxit ho=/mo ne separet. Ego Vos in matrimonium coniungo in nomine etc./

(78) Antes de la palabra "Çhaupis" hay un espacio suficiente para dos palabras.

(79) Antes de la palabra "Tambos" hay un espacio suficiente para dos palabras.

(80) $\leq$ çhequiayhuan 


\section{Del sacramento del matrimonio.}

Forma de las amonestaciones, mutatis mutandis:

Escuchen todos. Martín Ticlayauri de este pueblo de Huancabamba, ayllu Chaupis (45), hijo de Pedro Hacha y María Colqui, quiere casarse con la ayuda de Dios y según lo ordenado por la Santa Iglesia con Inés Choque, del pueblo de Quiparacra, ayllu Tambos, hija de Luis Poma y Clara Chiuchi. Tengan cuidado de que ambos (46) estén bautizados y de que no estén relacionados por padrinazgo de bautismo o confirmación, que no sean parientes cercanos, y que no estén casados con otras personas en algún otro lugar. Quienes sepan algo que impida este matrimonio, avisen de ello. Quienes escondieran esto quedarían gravemente culpados en el juicio de Dios. Esta es la primera/segunda/tercera amonestación.

Estaforma de amonestar, mutatis mutandis, está muy recibida en este arzobispado de Los Reyes, y se debe observar por ser en la sustancia la misma que enseña el ritual, y muy allegado a las rúbricas de su uso. Por ser más breve la forma de amonestar que pone el ritual, podrá servir para la segunda y tercera vez, la cual dice así:

Escúchenme todos. Sebastián Riui de este pueblo de Ullucmayo, pachaca Ollcom Collca, ayllu Allauca, hijo de Pedro Ayra y Catalina Ana, quiere casarse con la ayuda de Dios con Pascuala Chequiay, del pueblo de Carhuamayo, pachaca Llacsamayo, ayllu Chaupis, hija de Julián de la Cruz e Inés Tocto. Si alguno de ustedes supiera que son parientes cercanos o que están relacionados por padrinazgo de bautismo o confirmación, o cualquier cosa que impida su matrimonio, deben avisar de ello. Ésta es la segunda/tercera amonestación. En respondiendo los circunstantes: Está bien que se casen.

\section{Desposorio.}

Los contrayentes a la puerta de la iglesia, como es costumbre, dirá el sacerdote al varón:

Sebastián Riui, ¿quieres recibir a Pascuala Chequiay como tu esposa, según los mandamientos de nuestra madre la Santa Iglesia? Responda: Sí, quiero.

Luego le preguntará el sacerdote a la mujer, diciendo: Pascuala Chequiay, ¿quieres recibir a Sebastián Riui como tu marido, según los mandamientos de nuestra madre la Santa Iglesia? Responda: Sí, quiero. Sacerdote: Tómense de la mano derecha. Quod Deus coniunxit homo ne separet. Ego Vos in matrimonium coniungo in nomine etc.

(45) Aquí, y en el caso de la novia, hay un espacio antes del nombre del ayllu donde al parecer se había de suplir el nombre de la pachaca, como se hace en las dos amonestaciones siguientes.

(46) hallan, hallanpas - vd. Torres Rubio, Figueredo et al., 1754: f. 219v: "Hallan hallanninpas. El uno, y el otro". 
Quando los q. se quisieren casar son ambos viudos,/ o alguno dellos a mayor abundamiento haçer la amonestaçion /f. 14/ asi = Vyayçhic llapayqui Juan Atoĉ cay huancayo llactayoĉ/ Ĉ́llĉa paçhac racuay ayllu Pablo Vinçhuspa churin, Ynes car=/ huap huahuan Maria Ticlap ĉsan cacmi Diospa yanapaynin=/huan caracuyta (81) munan Ana çhiuçhihuan, cay huarmin Pau=/cartambo llaĉtayoĉ tillau Paçhac Pissa ayllu, Pablo huamanpa/ huarmin câc, Paĉta caycuna hallan, hallanpas etc. ut supra./

En el apendix del ritual estan las bendi/çiones de los anillos y arras conformandose conformandose/ con el parrapho Ceteris de Sacramento Matrimonii del diçho/ ritual, y asi por la costumbre tan antigua, y q. los yndios haçen/ munçho caso de las çeremonias. Pondra el saçerdote vn ani=/llo al desposado (como alli se ordena) Diçiendo Yayap, $\mathrm{Chu}=/$ rip Espiritu Santop Sutimpi. Amen = Lo mesmo dira el des=/posado quando le diere el anillo a su esposa, a la qual dira/ dandole las arras = Esposa cay arrastam, anillotahuan/ çhasquiçhiiqui casarasĉançhicpa vnançhanpaĉ. Y ella respon=/da = çhaypaĉmi çhasquini./

Luego el saçerdote dira, y hara lo q. se/ ordena en el diçho apendix = y acabada la Missa y diçho/ ite missa e. vl. Benedicamus etc. ${ }^{\text {a }}$ dira a los velados./

Nam ari çhuricuna Santa Yglesiap Bendi=/çionninta çhasquicunquiçhic llapa cunanĉa yupayçhanacuy=/çhic Diospa tinquiçhisçan hinalla, $\hat{C} a p a \hat{c}$ Diosta muçhaĉ sonĉo/ causaptiquiçhicĉa paypas gloriampim cussiçhisunqui huyñay=/paĉ=/

Aqui los roçia con agua bendita, y luego di=/ce placeat tibi etc. auiendo dado la bendiçion al Pueblo, y di=/çho el evangelio postrero les mandara tomar las manos/a los velados assi = charinacuyçhic allauça maquiquiçhic/huan, y luego dira al Baron lo siguiente./

Çhuri Yanaqeyquipaĉmi cay huarmicta/çhasquiçhiiqui, manam yanayquipaççhu, Jesuçhristo Yayançhic/ Santa yglesianta cuyasĉan hinallataĉ ĉampas cay esposay=/f. 14v/quicta cuyanqui. Dioshuan riçhic paytaĉ ançha Pauĉarchasunqui. Amen./

Fin de lo que toca a la administraçion de los/ saçramentos./

Siguese el modo de eçhar los dias de Ayuno y fiestas q. de=/ben guardar los yndios./

La Dominica in quinquagesima eçhara el cura/ el ayuno sacratissimo de la quaresma desta manera./

Vyarihuayçhic llapayqui, cay semana Mier=/coles paĉarinmantam camaçhihuançhic Santa Yglesia qua=/resmacta sasicuyçhic ñispa. Mana onĉô̂cunaĉa Viernesnin=/cunam Sabado Santohuantaĉ, ayunacunayqui canĉa. hua=/quin punçhauĉa manam Ayunanayquiçhicçhu, ayçhallatam/ yçhaca hinantiqui çaçicunayquiçhic, onĉô̂cunallapaĉmi $\mathrm{Li}=/$ çençiata ĉoni ayçhata micunanpaĉ./

$(81)=$ casaracuyta 
Cuando los que se quisieren casar son ambos viudos, o alguno de ellos, a mayor abundamiento hacer la amonestación así: Escuchen todos. Juan Atoc, de este pueblo de Huancayo, pachaca Collca, ayllu Racuay, hijo de Pablo Vinchus e Inés Carhua, quien fuera esposo de María Ticla, quiere casarse con la ayuda de Dios con Ana Chiuchi, del pueblo de Paucartambo, pachaca Tillau, ayllu Pissa, quien fuera esposa de Pablo Huaman. Tengan cuidado de que ambos... etc. ut supra.

En el apéndice del ritual están las bendiciones de los anillos y arras, conformándose con el párrafo "Ceteris de Sacramento Matrimonii" del dicho ritual. $Y$ así, por la costumbre tan antigua, y [ya] que los indios hacen mucho caso de las ceremonias, pondrá el sacerdote un anillo al desposado (como allí se ordena) diciendo: En el nombre del Padre, del Hijo y del Espíritu Santo, amén. Lo mismo dirá el desposado cuando le diere el anillo a su esposa, a la cual dirá, dándole las arras: Esposa, te doy estas arras y este anillo como señal de nuestro casamiento. Y ella responda: Para eso lo recibo.

Luego el sacerdote dirá y hará lo que se ordena en el dicho apéndice. Y acabada la misa y dicho "Ite missa est" vel "Benedicamus" etc., dirá a los velados:

Hijos míos, ya han recibido la bendición de la Santa Iglesia. Ahora se deben estimar mutuamente ya que los ha unido Dios. Si viven adorando a Dios, Él los hará bienaventurados en su gloria para siempre.

Aquí los rocía con agua bendita y luego dice "Placeat tibi" etc. Habiendo dado la bendición al pueblo y dicho el evangelio postrero les mandará tomar las manos a los velados así: Tómense de la mano derecha. Y luego dirá al varón lo siguiente:

Hijo, te entrego esta mujer como tu compañera, no como tu sirviente. Debes amar a tu esposa de la misma manera que nuestro señor Jesucristo amó a su Santa Iglesia. Vayan con Dios, y que él los bendiga mucho. Amén.

Fin de lo que toca a la administración de los sacramentos.

Síguese el modo de echar los días de ayuno y fiestas que deben guardar los indios.

La Dominica in Quinquagesima echará el cura el ayuno sacratísimo de la cuaresma de esta manera:

Escúchenme todos. Esta semana, a partir de la mañana del miércoles, la Santa Iglesia nos manda guardar la abstinencia (47) de la cuaresma. Los que están sanos deben ayunar los días viernes y el sábado de semana santa. Los otros días no tienen obligación de ayunar, pero todos deben abstenerse de comer carne. Doy licencia para comer carne sólo a los enfermos.

(47) Uso el término "abstinencia” para traducir çaçi- (Castromonte también escribe sasi- y çasi-), mientras que traduzco ayuna- como "ayunar”. Çaçi- era, originalmente, el nombre del ayuno andino, que consistía en abstenerse de sal, ají y relaciones sexuales durante algunos días antes de una acción de culto importante (vd. referencias bibliográficas en Polia Meconi, 1999: 101). Castromonte, al igual que Pablo de Prado, distingue sistemáticamente entre ayuna-, o el ayuno completo, y çaçi-, la abstinencia de comer carne, que era más frecuente ( $c f$. Prado, 1641:f. 151v-152). Los textos del III Concilio Limense no utilizan el termino çaçi-, seguramente por que estaba demasiado ligado al culto de las huacas. Aparece por primera vez con referencia al ayuno cristiano en el manual de Juan Pérez Bocanegra (1631: 677). 


\section{Para echar las quatro tempo=/ras del año./}

Vyarihuayçhic llapa cay semanapim Santa Yglesia Maman=/çhic camaçhihuançhic miercolespi, Viernespi Sabadopitaĉ ça=/sicuyçhic ñispa, caytam quatro temporas ñinçhic, çhuscu mita/ huc huatapi cay çasicuy paçha hamusĉanraycu; paĉta mana=/ onçospa ayçhata micunquiçhicman, huañuy huçhatam ruran=/quiçhicman llapa./

Para eçhar las vigilias y fiestas de/ los Apostoles q. son de guardar para los yndios./

Vyarihuayçhic llapa cay semanapim santa Yglesia Mamanchic/ Viernes punçhaupi çasicuspa Apostolcuna S. Pedro S. Pablop/ fiestampaĉ camaricuyçhic nihuançhic sabadopitaĉmi cay Apostol=/cunap fiestan canĉa, vigiliampi mana onĉspa ayçhata micuĉpas/ punçhaunimpi mana çamacuĉpas huañuy huçhactam ruranqui=/çhicman llapa. /f. 15/

Para eçhar las fiestas de la Çircumçision y Epifania/ que no traen Vigilia, y son de guardar, para/ los Yndios./

Vyarihuayçhic llapa, cay semanapim Santa Yglesia Maman=/çhic Miercoles punçhaupi Jesuçhristo Dios yayançhicta sutiya/çhisĉanta (et in Epiphania. Jesuchristo Yayançhicta quimsa/ Yncacuna Muçhaycusĉanta) cusicuspa çamacunqui nihuan=/çhic, manam, ychaĉa çasicuy ñihuançhicçhu, çhaypi hatun/ vriayta vriaĉcunaĉa huañuy huçhactam ruranquiçhicman/ llapa./

\section{Para eçhar las Pascuas de Resurrecçion y Pen=/tecostes./}

Vyarihuayçhic llapa, hamuc Domingo punçhaupim, Santa/ Yglesia mamançhic Jesuçhristo cauçarisĉanta 1. Espiritu/ Santo hamusĉanta cusicuspa, çamacunqui nihuançhic, Lu=/nes, Martes ĉateĉninhuantaĉmi cussicunançhic Diosta muçhas=/pa, arucunayquiçhic captinĉa sonçoyquimanta (82) Lunes Martespi/ arucunquiçhic llapa liçenciasĉam canquiçhic çhay punçhaucu=/napacĉa./

Para eçhar las Fiestas de la Ascension/ y corpus çhristi./

Vyarihuayçhic llapa cay semanapim santa <Yglesia> Mamançhic/ juebes punçhaupi ascension fiestacta, vl. corpus christi fiestacta/ cussicuspa çamacuy ñihuançhic, chaypi hatun vriayta vriaĉ=/cunaĉa huañuy huçhactam ruranquiçhicman llapa./

\section{Para eçhar la Vigilia y Pascua de Nauidad./}

Vyarihuayçhic llapayqui cay semanapim Santa Yglesia Maman=/chic Martes punçhaupi sasicuspa camaricuyçhic, Jesuçhristo/ Diosninçhic yurisĉan fiestanpaĉ ñihuançhic, pacta mana onçospa /f. 15v/ ayçhata micunquiçhicman llapa, huañuy huçhactam ruran=/quiçhicman, miercolespitacmi huyñay Virgen Mariap huacha=/cusĉanta cusicuspa çamacunançhic, çhaypi hatun vriayta/ vriaccunaĉa huañuy huçhatatacmi ruranquiçhicman llapa./ Juebes, Viernes, Sabadohuantacmi cussicunançhic Diosta muçhas=/pa, arucunayquiçhic captinĉa soncoyquimanta arucunqui/çhic, Liçençiasĉam canquiçhic çhay huaquin punçhaucuna=/pacĉa./

$(82)=$ sonĉoyquimanta 


\section{Para echar las cuatro témporas del año:}

Escúchenme. Esta semana nuestra madre la Santa Iglesia nos manda guardar abstinencia los días miércoles, viernes y sábado. Esto se llama cuatro témporas porque este tiempo de abstinencia viene cuatro veces al año. Tengan cuidado de no comer carne, por que cometerían pecado mortal.

\section{Para echar las vigilias y fiestas de los apóstoles, que son de guardar para los indios:}

Escúchenme. Esta semana nuestra madre la Santa Iglesia nos dice que nos preparemos para la fiesta de los apóstoles San Pedro y San Pablo haciendo abstinencia el día viernes. Esta fiesta de los apóstoles será el sábado - los que comieran carne sin estar enfermos en la vigilia, y los que no guardaran el descanso en el día de la fiesta cometerían pecado mortal.

\section{Para echar las fiestas de la Circuncisión y Epifanía que no traen vigilia, y que son de guardar para los indios:}

Escúchenme. Esta semana nuestra madre la Santa Iglesia nos dice que el día miércoles celebremos el día en que nuestro señor Jesucristo recibió su nombre (et in epiphania el día en que nuestro señor Jesucristo fue adorado por los Tres Reyes). Sin embargo, no nos ordena que guardemos abstinencia. Los que hacen un trabajo agrícola importante (48) cometerían pecado mortal.

\section{Para echar las pascuas de Resurrección y Pentecostés:}

Escúchenme. Nuestra madre la Santa Iglesia nos dice que este domingo celebremos la resurrección de Jesucristo/la venida del Espíritu Santo. También debemos observar los días lunes y martes subsiguientes. Si tienen algún trabajo menor que hacer, pueden trabajar (49) según su voluntad el lunes y el martes. Tienen licencia para esos días.

\section{Para echar las fiestas de la Ascensión y Corpus Christi:}

Escúchenme. Esta semana nuestra madre la Santa Iglesia nos dice que el día jueves celebremos la fiesta de la Ascensión/la fiesta de Corpus Christi. Los que hacen un trabajo agrícola importante cometerían pecado mortal.

\section{Para echar la vigilia y pascua de Navidad:}

Escúchenme. Esta semana nuestra madre la Santa Iglesia nos dice que el día martes guardemos abstinencia en preparación para la fiesta del nacimiento de nuestro Dios Jesucristo. Tengan cuidado de no comer carne a menos que estén enfermos, porque cometerían pecado mortal. El miércoles debemos celebrar el parto de la eternamente virgen María. Los que hacen un trabajo agrícola importante ese día cometerían pecado mortal. Debemos observar también los días jueves, viernes y sábado - si hay algún trabajo menor lo pueden hacer según sus voluntades, tienen licencia para esos días.

(48) hatun vriayta vriaĉcunaĉa - El término vria- se puede traducir como "trabajo agrícola" en oposición a aru- que se aplica un poco más adelante a los trabajos domésticos esenciales que sí se permitían los días de fiesta, y que traduzco como "trabajo menor" (vd. estudio preliminar). La distinción entre las formas de trabajo prohibidas y las que se permitían los días de fiesta se explica en el sermón XXI del sermonario del III Concilio, que trata sobre la forma en que los indios debían guardar las fiestas (Pereña ed., 1985[1584; 1585; 1585]: 607).

(49) Aquí se utiliza aru- para "trabajar". 


\section{Laus Deo Virginiq. Matri/}

Acto de Contriçion en la lengua/ general çhinçhaysuyu/

A Santissima Trinidad quimsa persona caspa huc capa=/llan Dios, Camaĉnii, quespiçhicnii, tucuy sonĉoyhuanmi llaqui=/cuni (huçhata ruraspa) Yuyayhuampas, Rimayhuampas, Ruray=/huampas ĉamta piñaçhisĉayraycu, huçhaymi yaya, huçhaymi,/ ançha hatun huçhaymi, ĉamĉa Dios ĉapaĉ tucuy ymamanta=/pas, yallinnin munaypaĉ, cuyaypaĉ, yupayçhaypaĉtaĉmi canqui,/çhayraycullam huanacuspa huçhaman cutiriitaĉa toĉacusaĉ/ huañuy causay captimpas, ĉampa graçiayquihuan. Ranti=/qui tiac Padre Saçerdoteman tucuy hu/çhayta confessacuspam Penitençia camachihuas=/canta huntaçhicusaĉ çhay çhica llampu/ soncoyquipim suyacuni señor per=/donahuanĉam ñispa cuyapa=/yahuay yaya alli cayniq.=/reççisĉa cananpaĉ, Apuy/Jesuçhristo Cruspi/ huanusçanraycu./ Amen. /f. 16/ 


\section{Laus Deo Virginique matri}

Acto de contrición en la lengua general chinchaysuyu.

O Santísima Trinidad, tres personas pero un solo Dios, mi creador y salvador: me apeno con todo mi corazón de haberte hecho enojar al pecar con mis pensamientos, dichos y hechos. Por mi pecado, señor, por mi pecado, por mi gran pecado. Tú, gran Dios, eres digno de amor y estima por sobre todas las cosas. Por eso solamente con tu gracia me enmendaré y abominaré el pecado, ya sea que viva o muera. Después de confesar todos mis pecados con tu representante el sacerdote cumpliré la penitencia que me ordene. Pongo mi esperanza en tu manso corazón, y estoy seguro de que me perdonarás. Ten misericordia de mi, señor, para que tu bondad sea conocida, por la muerte en la cruz de mi señor Jesucristo. Amén. 


\section{Cantarçillo/}

Chunca muçhasĉayqui

Jesus yayallay

Pacacusĉa capaĉ

Dios huiçhĉarayaĉ

Tanta vino ricçhâ̂ vcullampim cam

Ĉapaĉ Dios tianqui

Manam sucçhu çhay

Angelcunap Apum

Dios runa camaĉ

ĉamtam vllpuycuspa

muçhan sonĉollay

Cuyahuasĉayquita

yuyarillaspam

çhay cusicuyhuanmi

sonĉoy pissican

Naui, maqui, ĉallu

ançhuricullay

tantam vinum ñispa

pacta muspayman

Rinrillaytam cunam

yaçhaçhipuan

Jesuçhristom ñispa

Fee mana pantaĉ
Dios caynintas cruspi

Pacaycurĉan pay

Runallaçhi ñinas

huañucullarĉam

Cay hostiapim cunan

Runa cayninpas

Pacaycusĉatacmi

Tanta ricçhâ̂llam.

Chaypas Dioshuan runa

Virgen huaçhasĉan

cay hostiapim ñinmi

Pihuan animay.

Huçhanmanta llaquiĉ

Santo suahuan

Yuyallahuay yaya

Ñinim ñoĉapas.

Campim hostia santa

Yuyariçhihuan

Jesus huañusĉanta

Yupayçhanaypaĉ.

Micuĉniqui runap

allin comulĉaĉpa (83)

Huyñaypaĉ causaytam

Çhasquin animan.
Cay animallayta

Cuyapaycutaĉ (84)

graçiayquihuan yaya

causacunanpaĉ

Ĉamllam Jesus Ñucñu

huyñay paçhapas

animaypaĉ canqui

Misqui mircapa

Ñô̂a huacçhayquita

Yaya vyhuahuay

Pelicano hina

Yahuarniquihuan.

Noĉa millay ati

Sumaççhanaypaĉ

Yahuarnillayquihuan

Pariapaycuay.

Causaĉ Dioshuan runa

Ostiapi tiaĉ

Ĉampaĉ gloria caçhun

Huyñay Paçhapaĉ

Finis

(83) = comulgaĉpa

(84) = Cuyapaycuytaĉ 


\section{Cantarcillo (50)}

Te adoro infinitamente, Jesús padre mío, poderoso ser escondido, Dios que está encerrado. Tú, gran Dios, estás dentro de lo que tiene apariencia de pan y vino, y esto no es otra cosa. Señor de los ángeles, Dios creador de las personas, mi corazón te adora humillándose ante ti. Al recordar cuánto me has amado mi corazón se desmaya de alegría.

Aléjense de mi, mis ojos, manos y lengua, para que yo no piense que esto es pan y vino. La fe, que no se equivoca, enseña sólo a mis oídos, diciendo que es Jesucristo.

El escondió su divinidad en la cruz, y solo murió en su humanidad (51).

Ahora también su humanidad está escondida en esta hostia. Sólo es pan en apariencia. Así mi alma (52) declara que el Dios y el hombre parido por la Virgen están en esta hostia. Te pido señor que me trates como al santo ladrón que se arrepintió de sus pecados.

La hostia santa me hace pensar en ti para que valore la muerte de Jesús.

El alma de aquel que te come, del que comulga bien, recibe vida eterna.

Apiádate de esta mi alma para que viva con tu gracia.

Tú solamente dulce Jesús eres para siempre el dulce alimento (53) de mi alma.

Padre, aliméntame a mi, tu pobre, con tu sangre como el pelicano.

Lávame (54) con tu sangre para que yo, abominable, me hermosee.

Gloria a ti para siempre, Dios y hombre viviente que estás en la hostia.

\section{Finis}

(50) Las líneas de la traducción corresponden a las estrofas del original.

(51) La tercera línea de esta estrofa (Runallaçhi ñinas) es de difícil interpretación

(52) La cuarta línea de esta estrofa (Pihuan animay) es de difícil interpretación.

(53) O, más puntualmente, "fiambre", comida que se lleva para un viaje (cf. el término latino viaticum). Mircapa/mirkapa/ es un chichaysuyismo, y su equivalente sureño, cocau/quqaw/, también es aplicado a la hostia consagrada. En la plática eucarística del manual de Oré, la eucaristía es llamada animanchicpa tupa cocauñin "el fiambre excelso de nuestras almas" (Oré, 1607: 96).

(54) Pariapaycuay - no he podido identificar la raíz /parya-/. 


\section{Referencias citadas}

ARCHIVO ARZOBISPAL DE LIMA (A.A.L.),

AVENDAÑO, F. de, s.f. (1649) - Sermones de los misterios de nuestra santafe catolica en lengua castellana y la general del Inca..., 129f. y 110f.; Lima: Jorge López de Herrera.

AVILA, F. de, s.f. (1648) - Tratado de los evangelios que nuestra madre la iglesia propone en todo el año..., 565p.; Lima: s.i.

CERRÓN-PALOMINO, R., 1976 - Gramática quechua Junín-Huanca, 283p.; Lima: Ministerio de Educación - Instituto de Estudios Peruanos.

CERRÓN-PALOMINO, R., 1987 - Lingüística quechua, 425p.; Cuzco: Centro de Estudios Regionales Andinos "Bartolomé de Las Casas".

CERRÓN-PALOMINO, R., 1992 - Diversidad y unificación léxica en el mundo andino. In: El quechua en debate. Ideología, normalización y enseñanza (Godenzzi, Juan Carlos ed.): 205-235; Cuzco: Centro de Estudios Regionales Andinos "Bartolomé de Las Casas".

CERRÓN-PALOMINO, R., 1995 - Estudio introductorio. In: Gramática o arte de la lengua general de los indios del Peru por el maestro fray Domingo de Santo Tomás de la orden de Santo Domingo (Cerrón-Palomino, Rodolfo ed.): VII-LXVI; Cusco: Centro de Estudios Regionales Andinos "Bartolomé de Las Casas".

DAVILA MORALES, J. A., 1739 - Practica de la doctrina christiana. Obra utilissima para los curas , y confessores de Yndios, y de rusticos..., 170p.; Lima: Francisco Sobrino.

DUVIOLS, P., 1977 - La destrucción de las religiones andinas (conquista y colonia), 479p.; México: Universidad Nacional Autónoma de México. Traducción de Albor Maluenda.

HUERTA, A. de, 1993[1616] - Arte breve de la lengua quechua (edición facsimilar del Arte de la lengua quechua general de los yndios de este Reyno del Piru... a cargo de Ruth Moya y Eduardo Villacís), 32p. y 81f.; Quito: Proyecto Educación Bilingüe Intercultural y Corporación Editora Nacional.

JURADO PALOMINO, B., 1649 - Declaracion copiosa de la quatro partes mas essenciales, y necessarias de la doctrina christiana..., 136f.; Lima: Jorge López de Herrera.

MANNHEIM, B., 1999 - El arado del tiempo: poética quechua y formación nacional. Revista Andina, Año 17 No 1: 13-64.

MELGAR, E. S. de, 1691 - Arte de la lengua general del ynga llamada Qquechhua, 52f.; Lima: Diego de Lyra.

MOLINA, D. de, 1649 - Sermones de la quaresma en lengua quechua..., 328f., manuscrito B203 de la Biblioteca Nacional del Perú.

ORÉ, L. J. de, 1992[1598] - Symbolo Catholico Indiano (edición facsimilar a cargo de Antonine Tibesar), 462p.; Lima: Australis.

ORÉ, L. J. de, 1607 - Rituale seu manuale peruanum et forma brevis administrandi apud Indos sacrosancta Baptismi, Penitentice, Eucharistice, Matrimonii, \& Extrema vnctionis Sacramenta..., 420p.; Nápoles: Io. Iacobum Carlinum \& Constantinum Vitalem.

PABLO V, 1649 - Rituale romanum Pauli V. Pont. Max. Iussu Editum..., 351p.; Venecia: Cieras.

PARKER, G. J., 1976 - Gramática quechua Ancash-Huailas, 183p.; Lima: Ministerio de Educación - Instituto de Estudios Peruanos.

PARKER, G. J. \& CHÁVEZ, A., 1976 - Diccionario quechua Ancash-Huailas, 311p.; Lima: Ministerio de Educación - Instituto de Estudios Peruanos.

PEÑA MONTENEGRO, A. de la, 1678 - Itinerario para parrochos de indios en que se tratan las materias mas particulares, tocantes a ellos, para su buena Administracion..., 848p.; Lyons: Joan-Ant. Huguetan.

PEREÑA, L., ed., 1985 [1584, 1585, 1585] - Doctrina christiana y catecismo para instruccion de indios. Facsímil del texto trilingüe, [edición facsimilar de Doctrina christiana y catecismo (1584), Confessionario para los curas de indios (1585), y Tercero cathecismo 
y exposicion de la Doctrina Christiana, por Sermones (1585)], 785p.; Madrid: Consejo Superior de Investigaciones Científicas.

PEREZ BOCANEGRA, J., 1631 - Ritual formulario, e institucion de curas, para administrar a los naturales de este Reyno, los santos Sacramentos..., 720 p.; Lima: Jerónimo de Contreras.

POLIA MECONI, M., 1999 - La cosmovisión religiosa andina en los documentos inéditos del Archivo Romano de la Compañía de Jesús (1581-1752), 627p.; Lima: Pontificia Universidad Católica del Perú.

PRADO, P. de, 1641 - Directorio espiritual en la lengua española, y Quichua general de Inga..., 247p.; Lima: Jorge López de Herrera.

PRADO, P. de, 1705 - Selectas de el directorio espiritual en Lengua Española, y Quichua General del Inga... reimpreso y añadido por el P. Gaspar Manuel..., 184f.; Lima: Imprenta Real.

REINA MALDONADO, P. de, 1653 - Norte claro del perfecto prelado en su Pastoral Gobierno. Tomo $1^{o}$..., 398p.; Madrid: Melchor Sánchez.

REDENTORISTAS, 1889[1888] - Resumen de la doctrina cristiana en kichua dialecto del departamento de Ancash, redactado por los RR. PP. redentoristas... Segunda edición corregida y aumentada, 40p.; Lima: Tipografía Católica.

REDENTORISTAS, 1891 - Kichua shímichu Diosnínzicta mañánanpac. Redentorista Teítacúna rurrashca Libro, 150p.; Einsiedeln (Suiza): Benziger \& Co..

REDENTORISTAS, 1900 - Compendio de la doctrina cristiana en qichua dialecto de Junín por los RR. PP. redentoristas... Séptima edición, 252p.; Lima: Librería e Imprenta Gil.

RIVERA SERNA, R., 1965 - Un Ritual Romano en Lengua Chinchaysuya. Boletín de la Biblioteca Nacional del Perú, años 18-19 No 35-36: 3-21.

RIVET, P. \& CRÉQUI-MONTFORT, G. de, 1951 - Bibliographie des langues aymará et kicua. Vol. I (1540-1875), 499p.; Paris: Institut d'Ethnologie.

RIVET, P. \& CRÉQUI-MONTFORT, G. de, 1952 - Bibliographie des langues aymará et kicua. Vol. I (1876-1915), 655p.; Paris: Institut d'Ethnologie.

ROMERO, C. A., 1928 - Un Libro interesante. Revista Histórica, tomo IX entrega I: 51-87.

SANTO TOMAS, D. de, 1951[1560] - Lexicon o vocabulario de la lengua general del Peru (edición facsimilar a cargo de Raúl Porras Barrenechea), 374p.; Lima: Instituto de Historia de la Universidad Nacional Mayor de San Marcos.

SÍNODO DE HUAMANGA DE 1629, 1970 - Constituciones synodales del obispado de Guamanga (Perú) 1629, 116p.; Cuernavaca: Centro Intercultural de Documentación.

SÍNODO DE HUAMANGA DE 1672, 1677 - Constituciones synodales de el obispado de la ciudad de Guamanga..., 158f.; Lima: Jerónimo de Contreras.

SÍNODOS DE LIMA, 1987 - Sínodos de Lima de 1613 y 1636, 457p.; Madrid y Salamanca: Centro de Estudios Históricos del Consejo Superior de Investigaciones Científicas Instituto de Historia de la Teología Española de la Universidad Pontificia de Salamanca.

TAYLOR, G., 1999[1987] - Ritos y tradiciones de Huarochirí. Segunda edición revisada, 502p.; Lima: Instituto Francés de Estudios Andinos - Banco Central de Reserva del Perú Universidad Particular Ricardo Palma.

TORERO, A., 1964 - Los dialectos quechuas. Anales Científicos de la Universidad Agraria 2: 446-478.

TORERO, A., 1995 - Acerca de la lengua chinchaysuyo. In: Del siglo de oro al siglo de las luces. Lenguaje y sociedad en los Andes del siglo XVIII, César Itier compilador, 13-31; Cuzco: Centro de Estudios Regionales Andinos "Bartolomé de Las Casas".

TORRES RUBIO, D. de, 1619 - Arte de la lengua quichua..., 102f.; Lima: Francisco Lasso.

TORRES RUBIO, D. de \& FIGUEREDO J. de, s.f. (1700) - Arte de la lengua quichua, por el P. Diego de Torres Rubio de la Compañía de Iesus..., 114f.; Lima: José de Contreras y Alvarado. 
TORRES RUBIO, D. de \& FIGUEREDO J. de, et al., 1754 - Arte y vocabulario de la lengua quichua general de los Indios de el Perú... 262f.; Lima: Imprenta de la plazuela de San Cristóbal.

VARGAS UGARTE, R., 1951 - Concilios Limenses (1551-1772), Tomo I, 426p.; Lima: s.i.

VARGAS UGARTE, R., 1960 - Historia de la iglesia en el Perú. Tomo III (1640-1699), 487p.; Burgos: Imprenta de Aldecoa.

WEBER, D. J., 1996 - Una gramática del quechua del Huallaga (Huánuco), 641p.; Lima: Ministerio de Educación - Instituto Lingüístico de Verano.Versión castellana de Marlene Ballena Dávila.

WEBER, D. J., CAYCO ZAMBRANO, F., CAYCO VILLAR, T. \& BALLENA DÁVILA, M., 1998 - Rimaycuna. Quechua de Huánuco. Diccionario del quechua del Huallaga con índices castellano e inglés, 799p.; Lima: Instituto Lingüístico de Verano. 